\title{
Normative Methods for Lawyers
}

\section{Citation}

Joseph William Singer, "Normative Methods for Lawyers," 56 UCLA Law Review 899 (2009).

\section{Permanent link}

http://nrs.harvard.edu/urn-3:HUL.InstRepos:8519641

\section{Terms of Use}

This article was downloaded from Harvard University's DASH repository, and is made available under the terms and conditions applicable to Open Access Policy Articles, as set forth at http:// nrs.harvard.edu/urn-3:HUL.InstRepos:dash.current.terms-of-use\#OAP

\section{Share Your Story}

The Harvard community has made this article openly available.

Please share how this access benefits you. Submit a story.

Accessibility 


\title{
Harvard Law School \\ Harvard Law School Public Law Research \\ Paper No. 08-05
}

Normative Methods for Lawyers

\author{
by \\ Joseph Singer \\ Harvard Law School
}

This paper can be downloaded without charge from the Social Science Research Network (SSRN) electronic library at:

HTTP://ssrn.com/abstract=1093338 


\title{
Normative Methods for Lawyers
}

\author{
Joseph William Singer
}

$\$ 1.0$ REASONING ABOUT JUSTICE: FINISHING THE "BECAUSE CLAUSE" 2

$\$ 2.0$ WHY LAWYERS CANNOT ESCAPE NORMATIVE ARGUMENT 13

$\$ 2.1$ How conventional approaches fail to avoid normative engagement 13

$\$ 2.1 .1$ The problem with doctrine 13

$\$ 2.1 .2$ The problem with efficiency 15

$\$ 2.1 .3$ The problem with rights 22

$\$ 2.1 .4$ The problem with democracy 26

$\$ 2.1 .5$ The problem with critique 27

$\$ 2.2$ Living in moral space 28

$\$ 2.2 .1$ The limitations of analytical methods 28

$\$$ 2.2.2 Moral reasoning: "as much clarity as the subject matter allows" 30

\$3.0 LAW AS APPLIED MORAL AND POLITICAL THEORY 37

$\$ 3.1$ What lawyers can learn from moral and political theory 37

$\$ 3.2$ What lawyers can teach moral and political theorists 39

$\$ 3.2 .1$ Law is complex 39

$\$$ 3.2.2 Context matters 43

$\$$ 3.2.3 Narrative matters 45

$\$$ 3.2.4 Practical reason can handle incommensurable values 47

$\$ 3.2 .5$ Justification constrains judgment: the art of talking to the loser 51

$\$ 4.0$ NORMATIVE METHODS FOR LAWYERS 54

$\$ 4.1$ Orientation 55

$\$ 4.1 .1$ Background understandings 55

$\$ 4.1 .2$ Framing the question 59

$\S 4.1 .3$ Narrative 61

$\$ 4.2$ Evaluative assertion 63

$\$$ 4.2.1 The argument from humanity (dignity) 63

$\$$ 4.2.2 Asserting values (ought statements) 68

$\$ 4.2 .3$ Responsibilities in human relationships 72

$\$ 4.3$ Contextualization 74

$\$$ 4.3.1 Situation sense (distinguishing cases and making analogies) 74

$\$ 4.3 .2$ Restrained interpretation of values 76

$\$$ 4.3.3 Social and historical accommodation 78

$\$ 4.4$ Prioritization 79

$\$$ 4.4.1 Balancing interests 80

$\$$ 4.4.2 Contractualism (golden rule or role reversibility) 81

$\$$ 4.4.3 Reflective equilibrium (coherence) 83

$\$ 5.0$ RESPONSIBILITY AND HUMAN JUDGMENT 85 
2/1 I/08 II:32 AM

\section{Normative Methods for Lawyers ${ }^{\alpha}$}

\section{Joseph William Singer ${ }^{\beta}$}

Prime numbers are what is left when you have taken all the patterns away. I think prime numbers are like life. They are very logical but you could never work out the rules, even if you spent all your time thinking about them. ${ }^{x}$

$\sim$ Mark Haddon

[J]ustification of a given end depends not on our ability to identify indubitable first principles that support it but rather on our ability to persuade others to act upon one set of uncertain beliefs rather than another. ${ }^{\varepsilon}$

$\sim$ Eric MacGilvray

[T]o be a full human agent, to be a person or a self in the ordinary meaning, is to exist in a space defined by distinctions of worth. A self is a being for whom certain questions of categoric value have arisen, and received at least partial answers. Perhaps these have been given authoritatively by the culture more than they have been elaborated in the deliberation of the person concerned, but they are his in the sense that they are incorporated into his self-understanding, in some degree and fashion. My claim is that this is not just a contingent fact about human agents, but is essential to what we would understand and recognize as full, normal human agency. ${ }^{\phi}$

$\sim$ Charles Taylor

Government must treat all subject to its dominion with equal concern: everyone's lives matter, and equally. That is non-negotiable. ${ }^{\gamma}$

$\sim$ Ronald Dworkin

${ }^{\alpha}$ (C) 2008 Joseph William Singer

$\beta$ Bussey Professor of Law, Harvard Law School. Thanks and affection go to Martha Minow, Mira Singer, Greg Alexander, John Goldberg, Kent Greenfield, Alec Karakatsanis, Eduardo Peñalver, Jed Purdy, Jim Ryan, Mike Seidman, Laura Underkuffler, Johan van der Walt. x Mark Haddon, The Curious Incident of the Dog In the Night-Time 15 (2004).

${ }^{\varepsilon}$ Eric MacGilvray, Recontructing Public Reason 155 (2004).

ф Charles Taylor, Philosophy and the Human Sciences: Philosophical Papers 2, at 3 (1985).

${ }^{\gamma}$ Ronald Dworkin, Do Values Conflict? A Hedgehog's Approach, 43 ARIZ. L. REv. 251, 259 (2001). 


\section{$\S 1.0$ REASONING ABOUT JUSTICE: FINISHING THE "BECAUSE CLAUSE"}

We live in an age that swings wildly from passionate commitment to studied skepticism. True believers who are certain about right and wrong co-exist with cynics who are equally sure that all claims about morality and justice are "just your opinion." Fierce defenders of the rule of law and human rights contend with hard-nosed realists who view legal reasoning and rights discourse as ideologies whose only purpose is to dress up power relationships to make them seem legitimate, inducing the oppressed to accept their fate and suffer in silence. Rationalists who view justice as based on human reason vie with irrationalists who view justice as a human invention based on essentially nonrational grounds. Deontological theorists who believe moral duties can be derived from a deep understanding of the human condition contend with utilitarians who think the only legitimate way to respect individuals is to maximize satisfaction of human preferences, whatever they happen to be.

The irony is that both believers and cynics see little need to justify their beliefs to others or to engage in acts of persuasion. You either see the light or you don't; morality and justice are either based on reason or on unfettered individual preference. ${ }^{1}$ Whether the truth is a set of universal norms or the absence of any pre-given norms at all, there appears to be no means to bridge gaps of understanding or commitment. ${ }^{2}$ The truth for both sides is a matter of faith.

Then there are the rest of us - the muddled middle. We have intuitions about what is just, moral, good, and right, and we sometimes feel quite strongly about those intuitions. Indeed, those intuitions seem like much more than personal preferences; certain things seem fundamentally right not "just for us" but for everyone. ${ }^{3}$ We can even give reasons for our views and

\footnotetext{
${ }^{1}$ Robert Fogelin, Walking the Tightrope of Reason: The Precarious Life of a Rational ANIMAL 3 (2003) (arguing that we often appear to be forced to choose between absolutism and nihilism as in the idea that "[e]ither absolute moral standards exist or there is no such thing as morality.").

${ }^{2}$ See id. at 11 ("those who defend so-called absolutes and those who adopt various forms of absolute relativism share a commitment to a rationalist ideal. Those who think that the rationalist ideal can be satisfied swing one way; those who think it cannot, swing the opposite way. Under the sway of the rationalist ideal, no middle ground seems possible, and none is tolerated.").

${ }^{3}$ See Elizabeth Anderson, Value in Ethics And Economics 92 (1993) ("Mere likings or tastes are distinguished from other attitudes in that they are largely exempt from processes of justification.").
} 
answer objections from those who promote competing claims. ${ }^{4}$ Yet, if we are thoughtful, we are aware of objections that can be made to our own claims. Moreover, not only are such things essentially contested, but on reflection, we find that our own arguments are often inconsistent. We want freedom of action, but we also want security, and there is no way to achieve security for ourselves and our families without limiting freedom of action. Where do we draw the line? We want freedom of religion but we do not necessarily think this means a church should be able to ring its bells all night if this will keep everyone else from getting some sleep. We want to be able to use our property as we see fit but we recognize that we cannot, in general, use our property in ways that harm others, and the question of how to define what constitutes a "harm" is a perennial cause of disagreement.

In short, there are hard cases where our values conflict, and lawyers know that nonlawyers severely underestimate the number of hard cases we are likely to face. We have trouble drawing lines in hard cases, and we have even more trouble defending our moral beliefs to those who have opposite intuitions or commitments. Disagreement seems to be permanent and inevitable - even among persons of good will who actively seek to reach agreement or to discover the truth of the matter. When asked to defend our views, we can come up with reasons, but we know that our arguments can always be met with the question "Why?" and we are acutely aware that at some point, we have nothing else to say. What is the foundation of assertions of justice, morality, right, and fairness? Why is a claim of justice any more than your personal opinion? Is it possible to reason about justice?

Philosophers want to know the answer to these questions; they want to think clearly and get to the bottom of things. Legal theorists are also eager to find out if judicial pronouncements about the law are anything other than assertions of raw power or partisan advantage. These theorists are not so different from children who annoy their parents by repeatedly asking "why?" again and again until we no longer know what to say. "Why not do that?" we ask, and the reply is: "Because it's wrong." But then, why? "Because people should not be cruel to others." But why? "Because you would not like it if she did that to you." But what if I knew I would not get caught? "You shouldn't do it anyway." But why? "Because it's wrong to hurt other people." But why? "Because..."

We know the feeling of being confronted with the "why?" question and not knowing what to say after "because...," yet feeling we should be able to say something. There is that horrible ellipsis - how do we fill it in? We may

${ }^{4}$ See FogELIN, supra note 1, at 5 ("Debates concerning radical choices are carried on in a way that insulates them from the ordinary, workaday world."). 
find ourselves saying, "that's what I think" or "that's how I feel" or "that's just the way things are" - or even a circular "because it's wrong." Or perhaps we adopt the pragmatic approach and try to turn the tables by asking: "well, don't you agree?" But these answers feel unsatisfying; there seems to be something else we should be able to say, and it seems to be on the tip of our tongues - if we could only figure out what it was. ${ }^{5}$ That is the problem: we have trouble finishing the "because clause"; reasons run out.

As a law professor, I have noticed this problem acutely among my students. They quickly learn to make sophisticated arguments about interpreting precedent and statutes, making analogies and distinguishing cases, debating the judicial role (active or restrained), and discerning the advantages and disadvantages of rigid rules versus flexible standards. They also learn to use cost-benefit analysis, measuring the expected consequences of alternative rules of law in monetary values and adding up the costs and benefits to determine which rules appear to maximize social welfare. But when I ask my students to make or defend arguments based on considerations of rights, fairness, justice, morality, or the fundamental values underlying a free and democratic society, they are mute. They get out the first sentence: "I have a right to use my property as I see fit" or "I have a right to be left alone." But then they go silent; they do not have a second sentence - they do not know how to go on. Their silence is partly caused by their not knowing what to say; they cannot figure out what vocabulary to use or how to make the argument. But the underlying reason for this uncertainty is their fear that such arguments are merely matters of opinion that have no objective basis. They know that others can disagree and they feel they do not have way to defend their arguments or ground them.

They do not feel this away about cost-benefit analysis. Contemporary efficiency analysis is the contemporary way of interpreting and operationalizing the classical consequentialist normative theory of utilitarianism. It is attractive to students (and professors) because it takes individual preferences for granted (thereby promoting individual autonomy), counts each person's interests equally (thereby promoting equal concern and respect for human beings), and then uses math - the most objective procedure imaginable - to figure out how to maximize human welfare. It thus both appears to serve widely shared values (autonomy and equality) and to produce answers to complex questions through a process that is neutral and rational.

5 See Henry S. Richardson, Practical Reasoning about Final Ends 9 (1997) ("Trying to explain why one pursues what one does take to be worth pursuing for its own sake ties the tongues of the most articulate."). 
Most, but not all, students, recognize that there are severe limitations to efficiency analysis. One problem is that many (I would say most) human values cannot be adequately expressed in numerical or monetary terms. Nor do maximizing procedures give us any assurance that individuals will not be sacrificed for the greater good. For these reasons (among others), students need to able to make arguments that can express and defend claims of right and justice. My thesis is that we have no alternative but to make arguments that elaborate fundamental human values and which express our considered commitments to judgments about morality and justice. Students need to know this because practicing lawyers need to know this; judges base their decisions partly on such considerations and the ability to make sophisticated arguments about justice and morality is a basic skill all lawyers need.

They will not find much help in the law reviews. Legal scholarship today has limitations when it comes to normative argument. Most scholarship either uses economic analysis of law, traditional doctrinal analysis that focuses on precedent and eschews sustained normative argument, critical analysis that reveals inconsistencies in the law or the arguments of others but refuses to make normative claims, or social science analysis that understands law from the outside, developing empirical information about how the world works. There is little work that looks at the law from the inside, asking, for example, how a judge should not only decide a case but justify the result to the public. How should the opinion be written? What, exactly, should it say?

The normative work that one finds in the law reviews is often done at such a high level of abstraction (such as interpretations of the work of Rawls and Nozick) that it is not clear how to apply the analysis to particular legal disputes. Or it is so sophisticated, nuanced, and complex that it cannot easily generate the few sentences one can write in a judicial opinion. Although scholars have the luxury of equivocation, the truth is that judges need such sentences; unlike theorists, judges decide cases and they need reasons to justify their choices. ${ }^{6}$ Normative arguments are of crucial importance to the rule of law; they are the way we show respect to the losing party in a real world dispute. Abstract theoretical work is important but it will not help judges and lawyers if they cannot figure out how to use it appropriately in real world situations.

I believe it is a big problem if we are tongue-tied when asked to talk about fairness and justice. Growing up as I did during the civil rights era, I heard arguments of this sort all the time, and I do not view them as merely

\footnotetext{
${ }^{6}$ See RichaRdSON, supra note 5, at 31 ("In being at least potentially expressible in words, a course of deliberation that is rational is one that can be assessed and explained, justified and criticized - publicly, it goes without saying").
} 
expressions of personal preference. They are, in effect, moral demands that can be, and must be, defended. ${ }^{7}$ And there are better and worse ways of doing this. Both law professors and students are in need of advice about how to think about the nature of morality, fairness and justice. ${ }^{8}$ More importantly, they need some vocabulary for talking about normative matters and a set of resources and methodologies for structuring relevant arguments.

One way to move toward this goal is to look to moral and political theory and see what it can offer lawyers. As I will argue below, I believe this is an incredibly useful step to take. We lawyers have borrowed liberally from economic theory; it is time to extend our reach to political and moral theory in an equally sustained way. They provide some structure for thinking about the basic contours of institutions, laws, and practices in a just society - the social, legal, and institutional framework within which economic life goes on and efficiency analysis can legitimately be undertaken. Moreover, emerging schools of thought in both political and moral philosophy have begun to create a middle path based on reviving the notion of practical reason - a conception of reason that turns out to be especially congenial to lawyers. It turns out that those of us in the "muddled middle" may not be so muddled after all; in fact, we may be sophisticated moral reasoners.

For that reason, an alternative, equally fruitful, way to proceed is to look at what lawyers and judges actually do - to discern how we reason about morality and justice. When we do this, we will learn that lawyers have multiple, sophisticated methods for engaging in normative argument. Lawyers are especially good at negotiating contradiction; we live in the world of hard cases where plural values reign and basic principles are inconsistent or in tension. ${ }^{9}$ We have techniques for dealing with such situations that are

7 See Charles Taylor, Sources of THe Self 4 (1989) ("strong evaluation ...involve[s] discriminations of right or wrong, better or worse, higher or lower, which are not rendered valid by our own desires, inclinations, or choices, but rather stand independent of these and offer standards by which they can be judged.").

${ }^{8} \mathrm{I}$ do not mean the word "nature" to suggest that there is a timeless natural law structure to such arguments. As a pragmatist, I see such arguments as grounded in human culture. The nature of normative argument changes (legitimately) over time and is relative, to some extent, to particular societies. This does not mean that we cannot make judgments about the values of other cultures, because I believe we can, at least about fundamental human rights. On students' need to learn how to talk about justice, see Peter L. Davis, Why Not a Justice School? On the Role of Justice in Legal Education and the Construction of a Pedagogy of Justice, 30 HAMLINE L. REV. 3 (2007).

9 See Anderson, Value in Ethics And ECOnOmics, supra note 3, at 218 ("Commonsense ethical thinking is deeply pluralistic, contentious, embedded in social practices conceived in 'think' terms, and expressed through non-consequentialist norms. It lacks the unity, self- 
useful, illuminating, and productive. Moral and political theorists have much to teach lawyers, but lawyers are experts in applied practical reason, and we have much to teach moral and political theorists. ${ }^{10}$ Indeed, I will argue that legal reasoning is, at base, a highly sophisticated form of moral reasoning.

For some, the very concept of "moral reasoning" is an oxymoron. Reason is about things that everyone can and should agree upon, but in a democratic society, morality is precisely the thing that we do not agree upon. Just think about religion, abortion, same-sex marriage. Moreover, the idea of liberty is based on our ability to live our lives as we please; any attempt by government officials to tell us that our way of life is "wrong" is tyrannical. Yet, at the same time, it is obvious that we want to have government of some kind and that one of the functions of that government is to regulate our conduct so that we do not harm others in course of exercising our own liberties. Liberty is not anarchy but freedom within the bounds of the rule of law. We enlarge our liberty by laws that limit our liberty. I am free to walk the street knowing that you are prohibited from harming me. Yet because we live in an age of diverse viewpoints, we find it hard to agree on the kinds of harms that government should prevent. We therefore look for a method of reasoning that can reconcile conflicting interests and worldviews without privileging one over the others. It is an open question whether this is possible.

One path is to seek a neutral, rational decision procedure that both stands above (or outside) all these hard substantive disputes and is also sufficiently powerful to adjudicate them definitively. Such a stance may be substantive in nature (based on utilitarian or deontological reasoning) or it could be procedural in nature (based on notions of democratic governance or separation of powers or the idea of a social contract among "free and equal persons"). ${ }^{11}$ It could try to bridge the substance/procedure divide by reference to the idea that our moral claims fit together in a coherent package,

evidence, universality, and tidiness many philosophers demand of theoretically respectable claims. But the very features of commonsense ethical thinking thought to constitute philosophical vices are indispensable for self-understanding. We need to think of values as plural to make sense of the variety of ways we have of valuing things. We need to contest their meanings to explore and cultivate our evaluative sensibilities. We need to think of valuations as embedded in social practices to make sense of their meaningfulness to others and their susceptibility to criticism and justification in dialogue with others.").

10 For two very different accounts of the nature of practical reason, see ROBERT AUDI, Practical Reasoning and Ethical Decision (2006); Charles Taylor, Philosophy and the Human SCIEnCEs; Philosophical PAPers 2, 91-115 (1985); Edward C. Lyons, Reason's Freedom and the Dialectic of Ordered Liberty, 55 Cleveland ST. L. REV. 157 (2007).

${ }^{11}$ John Rawls, Justice as Fairness: A Restatement $\$ 2$, at 5 (Erin Kelly ed.) (2001). 
thereby mutually supporting each other in a wide circle; alternatively, we could appeal to tradition or our "way of life" or precedent. Whatever approach one adopts, the idea is to start from noncontroversial (or at least widely accepted) premises (whether universally applicable substantive norms, impartial procedures, or established practices) and then reason deductively or analogically from those agreed-upon premises to find answers to controversial questions.

These strategies are attractive, but critical analysis of such approaches reveals that they fail to solve the problem they were created to address. There is a pervasive fantasy that we can escape the need for normative argument, controversial assumptions, and human judgment by adopting the right decision procedure; but this is an illusion. The unavoidable fact is that no matter how hard we try to define impartial decision procedures, we face persistent disagreement both about basic notions of what is good and right and just and about which procedures are suitably impartial. Our substantive premises wind up being contested and controversial, and we find that we cannot define "neutral" procedures without resorting to controversial substantive judgments. Even our understanding of the facts is colored by our preconceptions about justice. Where a libertarian sees a voluntary contract between self-governing individuals, a liberal critic sees an oppressive imposition of grossly unfair terms by a powerful employer on a disempowered migrant farmworker.

The problem recurs when we try to draw implications from the premises we have adopted. We may believe we have described impartial premises or procedures, but then we flounder when we try to derive answers from them. To identify seemingly noncontroversial premises, we have to state them at such a high level of generality that they wind up either being empty or too full of implications. We find that they are sufficiently abstract that we can deduce several alternative, competing solutions from them. No consistent set of premises seems to generate a complete set of answers to normative questions; any complete set of premises will necessarily generate internally contradictory guidance. Life is too complicated to embody in a simple theory, and our moral impulses are too various, too situated, too contingent, and too complex to be derived from any single decision procedure. ${ }^{12}$

\footnotetext{
${ }^{12}$ ISAIAH BERLIN, FOUR ESSAYS ON LIBERTY 1 (1969) ("The simple point which I am concerned to make is that where ultimate values are irreconcilable, clear-cut solutions cannot, in principle, be found. To decide rationally in such situations is to decide in light of general ideals, the overall pattern of life pursued by a man or a group or a society."); see id. at li ("The need to choose, to sacrifice some ultimate values to others, turns out to be a permanent characteristic of the human predicament."). See also FoGELIN, supra note 1, passim.
} 
We face a dilemma: If we make our normative premises sufficiently neutral, then they are too abstract to generate determinate answers, but if we make them sufficiently definite to solve the indeterminacy problem, we wind up sacrificing impartiality or neutrality. Determinacy and neutrality seem to be in tension with each other. We are then left with the same conflict we had before: the true believers cannot justify their non-neutral premises in terms that others can accept and the skeptics conclude that impartial premises and procedures do not exist, or that if they do exist, they are indeterminate. Either way, we are left with the problem we started with; claims of justice and morality cannot be justified in an impartial manner acceptable to persons with different conceptions of the good. After all this, we appear to be no better off than before we tried to identify neutral procedures for normative reasoning. What to do then?

We could give up and join the cynics. From the standpoint of the universe, any view is as good as any other; there are no built-in standards of justice or morality to which we can appeal or which we can "discover" by observation or introspection. Justice and morality are things we invent, and they are nothing more than human creations; normative arguments are therefore inevitably defective if they claim an objective basis outside human choice. ${ }^{13}$ The only alternative left is a "leap of faith." ${ }^{14} \mathrm{I}$ ' $\mathrm{m}$ for poor people and you're for rich people and that's just the way it is. You want environmental protection and I want "small government." Are you with me or against me? On this view, persuasion is simply beside the point. Moral argument is not a matter of proof but of recruitment to a cause; it is based, not on reason, but emotional attachment and irrational faith. ${ }^{15}$ One simply adopts an existentialist stance, asserting what life means to us and inviting others to sign onto our normative projects. There is no way to defend normative claims other than to describe them vividly, to present them as proposals for action, as invitations to participate in a certain form of social life - an invitation one must accept or reject on essentially irrational (or nonrational) grounds. Alternatively, one may believe that persuasion is possible but that it occurs not through reason but sophistic rhetoric. What we need are smart Madison Avenue advertising executives, not arm chair theorists to help us convince others about right and wrong. ${ }^{16}$

\footnotetext{
${ }^{13}$ Pierre Schlag, Normative and Nowhere to Go, 43 STAN. L. REV. 167 (1990).

${ }^{14}$ JONATHAN LARSON, Leap of Faith, from RENT (musical play) (1996).

15 On the importance of emotion in persuading others see DreW Westen, The Political BRAIN (2007).

16 Richard RORTY, CONTINGENCY, IRONY AND SOLIDARITY (1989) ("[Moral] dilemmas [involving conflicting moral obligations] we shall always have with us, but they are never
} 
We could even justify this cynical resolution by comforting ourselves with the idea that we have finally seen the light - there is no moral truth out there for us to latch onto; instead the moral truth lies in us. Protagoras was right when he tried to convince Socrates that "man is the measure of all things" ${ }^{17}$ Nietzsche was right when he characterized conventional morality as an artificial constraint on human freedom. ${ }^{18}$ Viewed in this way, the critical impulse is liberating: it allows us to see existing ideologies as elaborate justifications for existing distributions of power, and seeing the impartial or indeterminate nature of all moral systems frees us from their evil grip, allowing us to become what we wish to be. Human preference becomes the key, and the only question is what we want to desire. We will have some form of justice and morality and its content is in our collective hands - or in the hands of those powerful enough to impose their moral vision on the rest of us.

There is a problem with this resolution of the normative question. Lawyers are perhaps more aware of what is problematic about it than anyone else. The problem is that we want those who exercise power over others (judges and legislators, for example) to defend public policies that affect the people regulated by those policies. We especially want reasons from judges who are supposed to be acting impartially, treating like cases alike, and according each person equal concern and respect. ${ }^{19}$ We do not like the idea of judges who simply say: "I' $m$ in charge and this is how it is going to be." But if we are not in agreement already, what reasons could be good enough? What can be said to the losing party to a lawsuit that is not just a transparent attempt to dupe her into accepting a painful loss? Why accept the result as anything other than the raw exercise of power? The cynic responds that our

goingto be resolved by appeal to some further, higher set of obligations which a philosophical tribunal might discover and apply."). See also RICHARD RORTY, Pragmatism, Relativism, and Irrationalism, in CONSEQUENCES OF PRAGMATISM 160-175 (1982).

${ }^{17}$ Plato, Protagoras (Adam Beresford trans., Penguin ed. 2006). See Robert Fogelin argues that Protagoras's maxim suggests that he adopted a "radical perspectivism." Fogelin, supra note 1 , at 73 . However, it is possible to interpret the Protagoras view as based on sensitivity to the importance of human judgment in moral matters (as opposed to the more formal view espoused by Plato), much as Fogelin argues in his own work.

${ }^{18}$ Friedrich Nietzsche, Beyond Good and Evil: Prelude to a Philosophy of the Future (Walter Kaufmann, trans. 1966)(1886). For a postmodern variant of this, see ZYGMUNT BAUMAN, POSTMODERN ETHICS (1993).

19 Will Kymlicka, Contemporary Political Philosophy 4 (2nd ed. 2002) (noting the focus of almost all modern political philosophies in the fundamental assumption that "government treat its citizens with equal consideration; each citizen is entitle do equal concern and respect."). 
desire for adequate reasons does not mean that they are available.

In the middle (where I find myself) are those who suggest that the problem lies in a cramped and unsuitable conception of reason. ${ }^{20}$ The reasoning methods appropriate to moral argument are not the same as those that are appropriate when doing a math problem. Nor are they the same as those one uses when looking for a cure for cancer. We should not expect algorithmic formulas to solve our problems. ${ }^{21}$ Rather, human judgment is required. How do we make these judgments? Traditionalists (both conservative and liberal) suggest we elaborate the implications of our way of life by reference to tradition, original intent, immanent reason, custom, precedent, evolving principle. Pragmatists, on the other hand, argue that law and morality are human institutions designed to solve human problems. Because these problems are complex and because no pre-given answers are available, they propose experimenting to find out "what works." I am sympathetic to these projects. At the same time, their pretense to transcend normative debate is unconvincing. After all, we will understand our traditions in various ways, judge our customs harshly or kindly, reveal conflicting immanent principles. Nor can we talk about "what works" without some idea of what our problems are, how to understand them, and what it would look like to "solve" them. Normative argument is inescapable.

How can we make normative arguments in a fragmented and skeptical age? How can we justify legal rules that bind everyone when we have fundamental disagreements about the nature of the good, and our methods of reasoning seem to embody, rather than transcend, those disagreements? If all our decision procedures turn out to be either incomplete or contradictory and if all our normative frameworks rest on controversial and contested values, do we have nothing left but existentialist leaps of faith? Is there a way to frame normative arguments that can give them sufficient persuasive force to support the values we hold dear while retaining a sophisticated understanding of the complexities and perplexities of human life in a diverse society composed of individuals with vastly different conceptions of the good? Descending from the airy realm of political and legal theory to the day-

\footnotetext{
${ }^{20}$ See Fogelin, supra note 1, passim; Mark Timmons, Moral Theory: An Introduction (2002); STEPHEN TOULMin, RETURN TO REASON (2001) (all arguing that such an approach is both possible and desirable).

${ }^{21}$ See RiChARDSON, supra note 5, at 32 ("not all rational deliberation from a given starting point need converge on a unique answer about what is to be done as the alternative required by reason"). For a brilliant account of moral reasoning in the face of insolvable dilemmas, see Martha Nussbaum, The Fragility of Goodness: Luck and Ethics in Greek Tragedy and PHILOSOPHY (1986).
} 
to-day job of lawyering, how can competent lawyers make normative arguments when the need arises without engaging in sophistry (understood as fallacious arguments intended to deceive)? ${ }^{22}$ Is normative argument possible?

Today the dominant answer is no. The main alternatives we find in the law review literature are doctrinal analysis, democratic theory, rights, efficiency, and critical theory. Each of these approaches seeks to avoid or contain normative argument and, as I will explain below, each fails. The question is whether there is any alternative. I believe the answer is yes. ${ }^{23}$ And I also believe that legal scholars are much in need of an articulated normative alternative to these approaches - especially to the seductive attractions of unsophisticated versions of cost-benefit analysis. Moreover, part of the impetus for this project is the need to explain to law students how to argue about justice and fairness in a manner that will cause a judge to listen to them and take them seriously. I have long faced the challenge of answering students who want to know how to fill in the "because clause." When I demand that they explain why the plaintiff s interest in sleeping outweighs the neighbor's interest in holding a raucous, all-night party, they want a clue about how to go about answering this question. They deserve an answer from me.

In $\$ 2$, I will explain in more detail why lawyers cannot escape normative argument. I will show how various approaches seek to avoid or set aside sustatined normative engagement and why these efforts fail.

Section 3 will explore what lawyers can learn from (and teach) moral and political theorists. Legal methods are not merely watered down versions of

\footnotetext{
${ }^{22}$ I add the caveat in parentheses because the word "sophistry" has come to mean the concept contained in those parentheses. It is not clear, however, that this is what the actual Sophists intended. Some recent scholars have argued that this view of the Sophists comes from Plato's picture of them - or perhaps even Aristophanes' caricature of them, and that the actual Sophists had a sophisticated (not sophistic) view about the nature of truth and rationality that is superior to the Platonic theory of Forms. See Francis J. MoOtZ III, RHETORICAL KnOWLEdge in Legal Practice and Critical Legal Theory 36-41 (2006). My approach in this article is compatible with this new, approving view of Sophistry which views rhetoric and practical reason as means to justify law and morality in defensible ways.

${ }^{23}$ See Fogelin, supra note 1, at 9 (arguing "that inconsistency does not always render a system useless, that consistency is not always the most important goal of inquiry, and that it might be wholly unreasonable to suppose that human beings will ever be able to attain a view of the world that is both suitably rich and completely consistent."); id. at 42 ("in practice, it is often quite reasonable to employ systems of rules with no guarantee that they are consistent.... Sometimes the best available strategy is to learn to live with inconsistency in, as we might say, a discriminating and civilized manner.").
} 
more sophisticated theories; rather, lawyers have insights gleaned from the practical activity of law making and legal argument that enrich the methods typically used by moral and political philosophers.

In $\$ 4$, I will describe four general families of methods that lawyers employ to frame normative arguments about justice including (1) orientation, (2) evaluative assertion, (3) contextualization, and (4) prioritization. First, we orient ourselves in a moral universe through basic assumptions about human nature, the good society, and social relationships. We also frame the particular issue that confronts us in a way that highlights our underlying moral concerns while using narrative accounts to help us come to understand the meaning of events, disputes, and situations.

Second, we make evaluative assertions that identify human interests, wants, needs, and preferences that count as human values that deserve respect by others or which count as moral demands we make on each other. We do this in a variety of ways, including arguing about what it means to treat human beings with dignity, elaborating the values we hold dear, and analyzing responsibilities associated with defensible human relationships.

Third, when values conflict, we seek to interpret those values, if possible, to be consistent with each other in particular cases through a process of contextualization, which may involve situational framing, restrained interpretation of values, and social and historical accommodation.

Finally, when value conflicts cannot be avoided, we employ various methods of prioritization to determine which of the values should prevail in particular cases. We do this by adopting a suitably impartial procedure to help us think through the practical problem of what to do when values conflict. Three of the most important procedures include balancing interests, contractualism, and reflective equilibrium.

Part 5 concludes with thoughts on responsibility, as well as the necessity for and limitations of human judgment on matters of political morality and the rule of law.

\section{$\$ 2.0$ WHY LAWYERS CANNOT ESCAPE NORMATIVE ARGUMENT}

\section{$\$ 2.1$ How conventional approaches fail to avoid normative engagement}

\section{\$2.1.1 The problem with doctrine}

Beginning law students are often surprised by many things in legal education. The first surprise for many students is that they generally learn the law, not by reading a rule book, but mostly by reading appellate opinions. The second 
surprise is how hard it is to apply the rules they learn to new cases; it turns out that rules do not determine the scope of their own application. The third surprise is how hard it is to apply rules even if their scope is clear. Often the rules themselves are ambiguous; they may contain vague terms or reference ultimate standards, such as good faith or reasonableness, that require judgment if they are to be interpreted and applied. Often one rule may conflict with another and it may not be obvious where to draw the line between them. In addition, a case may involve facts so different from those in which the rule has been applied in the past that prior law appears to give no answer to what to do in this new situation. The gaps, conflicts, and ambiguities in rules are far broader and deeper than most nonlawyers imagine. A final surprise is how much class time teachers spend on seemingly theoretical questions.

Why do we teach law this way? We do so because, as Karl Llewellyn explained, "[w]e have discovered that students who come eager to learn the rules and who do learn them, and who learn nothing more, will take away the shell and not the substance. We have discovered that rules alone, mere forms of words, are worthless." ${ }^{24}$ Because rules do not determine the scope of their own application, they cannot be understood apart from cases; their meaning is clear only in their application. The ubiquity of gaps, conflicts, and ambiguities in the rules in force generates the need for argumentation based on policy and principle, as well as the invocation of analogy and situational context, in order to draw lines in hard cases. Students need to understand, not only the instances (fact situations) to which the rules apply, but the principles and policies underlying them; the applicability of a rule often depends on the context in which it is appropriate, as well as the purposes the rule is intended to serve, and those purposes inevitably include normative considerations. These considerations seem to be necessary ways to address complexity. If this is so, then a judge deciding a common law decision who sought to "apply law" rather than "make it" would have nothing to do. She might as well go home. This does not mean that judges make law in a vacuum, or in an unconstrained manner; it does mean that rules do not interpret themselves and that interpretation is an inevitably normative enterprise.

Positivists seek to avoid this conclusion. Identifying law with commands of the sovereign, they emphasize the distinction between law and morals, drawing our attention to the fact that there is such a thing as an immoral law and that rules of recognition often point to indicators other than morality or

\footnotetext{
${ }^{24}$ Karl Llewellyn, The Bramble Bush 2 (1930)(1960 reprint, 7th printing 1981).
} 
justice to define the rules in force. ${ }^{25}$ One might think that this approach allows lawyers to eschew normative argument. Unfortunately (or maybe fortunately) that is not the case. When we generate the holding of a case describing the rule of law for which it stands - the teacher often confounds the class by changing one fact and asking if the rule applies to that changed context. Answering that question is often difficult. That is so because one changed fact may make it inappropriate to apply a rule that initially seemed to apply to the situation. Extension of the rule to the new case may seem unfair rather than fair, or the values promoted by the rule may clash with competing values.

More fundamentally, although we do separate law and morals, we do not separate them entirely. Legal theorists sometimes ignore this reality. It is a fact about the legal system in the United States that judicial reasoning includes explicit normative considerations. Most opinions include some reasoning based on consideration of rights and social utility; they justify rule choices and interpretation of existing rules based on promoting the general welfare and protecting individual rights. Often, these arguments themselves are based on explicit conceptions of morality, such as self-reliance or altruism. Negligence law, for example, is premised on the notion that individuals have an obligation to act reasonably; moral conceptions are an explicit part of determining what obligations we have have toward each other. Many legal rules are indeterminate without reference to considerations of morality and justice. More importantly, we want and expect the law not only to be regular and predictable but defensible from the standpoint of morality and justice. We expect the law to be fair, or to promote social welfare, or to be consistent with human liberty and dignity. What we need are reasons to interpret precedents one way or the other. Law is justified and shaped, not just by reference to rules, tradition, custom, and precedent, but by reference to normative considerations. Or perhaps a better way to say this is that our legal rules, traditions, customs, institutions, and precedents are themselves partially defined by moral principles, norms, and conceptions of the just society. Normative concerns inevitably shape both social policy and interpretations of precedent. For these reasons, application of doctrine is impossible without normative argument.

\section{S2.1.2 The problem with efficiency}

Utilitarian approaches seek to fill the need for normative argument in law in

${ }^{25}$ John Austin, LeCTURES ON JuRISPRUdenCE (1861-1863); H.L.A. HART, The CONCEPT OF LAW (1961). 
a suitably impartial way. They do this by seeking to maximize social welfare by adopting rules of law that have the best overall consequences for individuals and for society as a whole. This normative approach is both consequentialist and maximizing. Utilitarianism is consequentialist because it judges the justice of legal rules by reference to their consequences. What behavior will follow from these rules? What incentives will they create? What are their costs and benefits? Utilitarianism is maximizing because it judges fairness and justice by converting all consequences to some common metric, adding up the pluses and minuses for each person, treating each person's interests equally in the calculus, and then seeking to promote the rules that, on balance, generate the maximum amount of utility for all persons in society.

Although utilitarianism is clearly a normative theory - and only one theory among several others - its proponents often feel that it is normatively thin in the sense that it bases normative argument on widely shared and noncontroversial values and proceeds through a form of reasoning that is either self-evident or definitionally rational. If the premises of the theory are uncontroversial and the method of applying that theory to decide specific cases is both determinate and widely accepted, then we can either avoid normative disputes or conclude that we have identified a decision procedure for normative argument that solves the problem of promoting justice in a multicultural world.

Why might one believe that utility (or "cost-benefit analysis") was the best answer to the normative problem? Since we care about how law affects people, it arguably makes sense to judge rules based on their consequences. One might believe that a minimum wage promotes human dignity, but if it turns out that imposition of a minimum wage results in firing all the poorest workers, we might well conclude that the law hurts the very people it was intended to protect. It is not much of a protection for human dignity to insist on regulations that harm human dignity; the lawmakers' intent matters less than the effect on the people they are trying to help. In judging those effects, modern day utilitarians tend to look to the preferences of individuals to determine whether consequences of rules are good or bad. By deferring to the views of individuals affected by law, we grant people autonomy to choose their own ends based on their own conceptions of the good and we thereby treat individuals with respect and we avoid paternalism. And by counting each person as one and only one when we aggregate all the good and bad effects of alternative laws to come up with the laws that have the best consequences overall, we treat each person equally. This method then appears to to respect the autonomy of individuals or treat them as, equal, 
free, self-actuating human beings.

Attractive as this approach may seem, utilitarianism faces insuperable difficulties that undermine its claim to be a determinate, noncontroversial normative decision procedure. First, and most obviously, it is premised on the twin notions of autonomy and equality - autonomy because it defers to individuals' conceptions of what is in their own best interest and equality because it attempts to count each person's welfare equally. While these are widely shared values, they are hardly noncontroversial. Many people believe, for example, that morality is based on the word of God and that laws which contradict God's law are inherently unjust. The ultimate goal for such persons is not autonomy but some form of virtue, defined as compliance with divine law. Others may believe that what matters most is not autonomy but social justice and that achieving social justice often requires sacrificing individual freedoms.

Second, even if one believed that autonomy and equality were noncontroversial values, their meaning is contested in ways that utilitarians usually do not recognize. It is not obvious, for example, that the best way to promote autonomy is to satisfy people's preferences, whatever they happen to be. ${ }^{26}$ Most moral theorists (and some economists) argue that we should defer, not to actual preferences, but to idealized preferences - those preferences individuals would have if they possessed perfect information and were choosing in a suitable institutional setting - one that might or might not correspond with our current institutions. ${ }^{27}$ Further, it is possible that preferences would change if circumstances changed. Views about racial equality have changed enormously over the last fifty years. Should a utilitarian judge the net social value of the 1964 Civil Rights Act based on the preferences of persons living in 1964 or what persons in 1964 could or should have predicted their preferences would be in the future or should they focus on the preferences of persons as they are now in 2008 after that law has been in effect for so long? ${ }^{28}$

More fundamentally, it is not an uncontroversial idea that we should

\footnotetext{
${ }^{26}$ KyMLICKA, supra note 19, at 14 (noting the "preference-satisfaction" account of utility which assumes that "increasing people's utility means satisfying their preferences, whatever they are"); Jules L. Coleman, The Grounds of Welfare, 112 YALE L.J. 1511, 1519 (2003) (arguing that "we cannot infer choice from preference"); $i d$. at 1542-1543 (distinguishing between a person's preferences and a person's interests, meaning "what is good for him").

${ }^{27}$ See id. at $15-20$.

${ }^{28}$ See Louis Kaplow \& Steven Shavell, Fairness v. Welfare, 114 HARV. L. REV. 961, 1338 (2001)("a long-run strategy designed to change preferences may make society as a whole, over time, better off...).
} 
satisfy all human preferences, no matter what they are, even if they are carefully considered. Some persons may prefer to be cruel and may even persist in this desire after being given perfect information and a suitable decision making setting. To discount such other-regarding preferences, one either must assume that the preferences of those opposed to cruelty would, as an empirical matter, outweigh the preferences of those who desire to be cruel, ${ }^{29}$ or one has to count certain preferences as beyond the pale - as themselves failing to be consistent with the injunction of respecting the autonomy of other persons. ${ }^{30}$

In addition, it is not at all obvious that the best way to promote equal treatment of persons is to count their utility equally and aggregate all individual preferences and follow whatever policy maximizes social utility. ${ }^{31}$ Suppose, for example, social utility is maximized by sacrificing the interests of a minority - say, by enslaving them. This problem is often dealt with by suggesting that the long run interests of society are improved by treating each person with dignity, but these "predictions" of remote effects are often unsupported or conveniently shaped to accord with a priori intuitions. ${ }^{32}$ More importantly, we need not only a way to reach a normatively attractive ends but a reason (or set of reasons) to justify the path we have chosen. To

\footnotetext{
${ }^{29}$ Mark Timmons calls this the "remote effects" argument. TimmOns, MORAL THEORY, supra note 20 , at $137-138$.

${ }^{30}$ Will Kymlicka argues that utilitarianism is premised on the equality of persons and that it therefore cannot consistently value the preferences of individuals who desire to treat others in a manner that does not demonstrate equal concern and respect. KYMLICKA, , supra note 19, at 26-32, 37-45. For a similar argument, see Timmons, MORAL THEORY, supra note 20, at 144147.

31 See KymLICKA, , supra note 19, at 87 ("The utilitarian idea of giving equal weight to each person's preferences has some initial plausibility as a way of showing equal concern for people's welfare. But, on inspection, utilitarianism often violates our sense of what it is to treat people as equals, especially in its lack of a theory of fair shares."); RICHARDSON, supra note 5, at 155 ("arguing for a conception of rational deliberation of ends that resists the lure of maximization").

${ }^{32}$ See Anderson, VAlue in ETHICS AND ECONOMics, supra note 3, at 68-69 (criticizing the failure of consequentialists to make qualitative distinctions among values and their tendency to avoid embarrassing conclusions suggested by their theory through convenient but dishonest devices like "rule consequentialism, slippery slopes, remote effects, and so forth"). See also id. at 89 ("These considerations [of remote effects, slippery slopes, and strategies of indirection, such as rule consequentialism] may generate the intuitively endorsed results, but they fail to expain our confidence in and insistence upon them. Why should we be so confident that remote effects and indirect strategies pan out the way consequentialists need in these cases, when we are so uncertain about consequences and strategies in other cases?").
} 
argue that slavery is wrong because the preferences of those opposed to it outweigh the preferences of those who favor it is to give an irrelevant reason for abolishing slavery; ${ }^{33}$ indeed, it is a reason that is offensive and which itself causes harm by suggesting that the dignity of some can be subordinated to the power of others if the balance of preferences works out that way. Because utilitarianism is based on treating persons equally, we would better promote this goal by tempering the maximization method with a principle of tolerable fair distribution of the costs and benefits of promoting social welfare. When we do this, normative complexity and normative argument are inevitable.

Third, even if we accept the idea of deferring to preferences and using a social maximizing procedure, we still need to operationalize this approach by assigning numerical values to consequences so that we can perform the aggregating and maximizing functions. How do we do this? We do not have an easy metric by which to measure utility. Some utilitarians, like Jeremy Bentham, focus solely on happiness and unhappiness or pains and pleasures; others, like John Stuart Mill, differentiate among kinds of pleasures, rating some as of more value to human welfare or of higher quality than others. ${ }^{34}$ Whatever metric we choose, we then need to assign values to consequences so that we can aggregate and maximize. But we have no natural method for doing this; it is not as if pleasures and pains come in neat packages of "utils" that have a built-in numerical value. For this reason, law and economics scholars have settled on market measures (dollar amounts) to assign values. But dollar amounts are hardly uncontroversial. We must choose between offer and asking prices (the amount one would be willing to pay for something given one's existing wealth versus the amount one would be willing to accept to give up something to another). We must choose whether to assume the existing distribution of wealth or some hypothetical (and perhaps more just - meaning more equal) distribution of wealth. After all, market values are determined not by willingness to pay but willingness and ability to pay. Thus, in a well-known example, it is clear that one would probably decrease social utility rather than increase it by denying medicine to a poor person who cannot afford it rather than giving it to a rich person who can outbid the poor one but does not really need the medicine. ${ }^{35}$ Economists are well aware of the decreasing marginal utility of money but most law and economics scholars are insufficiently attentive to the ways in which this reality undermines the very measures they use to calculate the effects of alternative legal rules on human welfare.

\footnotetext{
${ }^{33}$ On irrelevant reasons, see RICHARDSON, supra note 5, at 61-62.

${ }^{34}$ Timmons, Moral TheORY, supra note 20, at 103-121.

${ }^{35}$ Ronald Dworkin, Is Wealth a Value? in A MATTER OF PRINCIPLE 237 (1985).
} 
Finally, it is not at all apparent either that all values can be reduced to quantitative measures or that the most rational way to make normative judgments about social issues is to aggregate individual preferences and then engage in a maximizing exercise. ${ }^{36}$ Most human values cannot be adequately expressed in numerical (especially dollar) amounts. Nor is our ultimate goal always to maximize particular values; often our goal is to interpret those values in a suitable way so that they support a just framework for social life. Take the example of same sex marriage. If we go by current preferences, it is apparent that same sex marriage is very controversial in the United States. It is probably the case that more people are opposed to it than are in favor of it. Almost forty states have statutes banning it. Moreover, the intensity of views on both sides seems to be very high. But it is not at all clear that the right way to analyze the question of whether the state should recognize same-sex marriages is to defer to the preferences of individuals, or even to attempt to predict what individuals would want a hundred years from now if circumstances and values were to change. How do we value the interest in refusing to recognize same sex marriages? Is there a market measure for this? ${ }^{37}$ Do we go by intensity of preference? More fundamentally, why is maximizing happiness or satisfying preferences the right way to solve a problem like this, much less the best way? Isn't part of the problem that some people have strong views about how other people should live (asking others either to refrain from same-sex relationships or to tolerate and live with them) and that this is true whether we allow or prohibit same sex marriage? What do we do with these other-regarding preferences? ${ }^{38}$

In the real world, and especially in our legal system, we do not simply defer to individual preferences no matter what they happen to be. Even if we adopt utilitarianism as a normative method, we do not count all preferences; some preferences are simply intolerable, and do not enter into the calculus of

${ }^{36}$ Frank Ackerman \& Lisa Heinzerling, Priceless: On Knowing the Price of Everything and the Value of Nothing (2004); Elizabeth Anderson, Pragmatism, science, and moral inquiry, in IN FACE Of THE FACTS: MORAL INQUIRY IN AMERICAN SCHOLARSHIP 10, 11 (Richard Wightman Fox \& Robert B. Westbrook eds. 1998); RiCHARDSON, supra note 5, at 131 (explaining the difficulty of converting qualitatively distinct values into quantitatively comparable measures); Joseph William Singer, Something Important in Humanity, 37 HaRV. C.R.-C.L. L. REV. 103, 116-119 (2002).

37 See Anderson, VAlue in Ethics AND ECONOMics, supra note 3, at 210 (arguing that the theory of consumer sovereignty "fails to capture the ways people value goods outside of market contexts, which in principle cannot be measured by a cash value. It also fails to be responsive to the ways citizens think their values should be reflected in public policy.").

38 On the special problems posed by other-regarding preferences, see TIMMONS, MORAL THEORY, supra note 20, at 144-147. 
interests engaged in by conscientious judges and legislators. If utility is premised on both autonomy and equality, then perhaps we do not count the interests of racists in determining whether a law prohibiting intentional discrimination in housing is a good law. ${ }^{39}$ Perhaps we judge certain preferences as denial of the rights of others, and thus excluded from the utilitarian calculus. For this reason, various scholars have proposed morally constrained utilitarianism which uses normative argument to weed out certain preferences before the utilitarian calculus begins. ${ }^{40}$

Nor, in the real world, do we make all decisions by numerical, aggregative, and maximizing formulae. ${ }^{41}$ Although we often find ourselves looking at the costs and benefits of alternative courses of action, we do not uniformly act as if the only rational way to perform cost/benefit analysis is to assign numerical values to specific costs and benefits and then add them up to see how the calculus comes out. ${ }^{42}$ Often, we consider the pluses and

${ }^{39} \mathrm{Id}$. at $144-145$.

${ }^{40}$ Id. See also Gerald F. Gaus, Value and Justification: The Foundations of Liberal THEORY \$20, at 329-336 (1990) (discussing “constrained teleology”); Robert Hockett, Minding the Gaps: Fairness, Welfare, and the Constitutive Structure of Distributive Assessment $\begin{array}{llll}\text { (manuscript } & \text { on } & \text { SSRN) }\end{array}$ (http://papers.ssrn.com/sol3/papers.cfm?abstract_id=933129); Eyal Zamir \& Barak Medina, Incorporating Moral Constraints into Economic Analyisis (2006)(manuscript on SSRN) (http://papers.ssrn.com/sol3/papers.cfm?abstract_id=931988). See also AMARTYA SEN, DEVELOPMENT AS FREEDOM 77 (1999) ("To insist that there should be only one homogeneous magnitude that we value is to reduce drastically the range of our evaluative reasoning. It is not, for example, to the credit of classical utilitarianism that it values only pleasure, without taking any direct interest in freedom, rights, creativity or actual living conditions."); AMARTYA SEN, RATIONALITY AND FREEDOM 39 (2002) ("Reason has its use not only in the pursuit of a given set of objectives and values, but also in scrutinizing the objectives and values themselves. Maximizing behavior can sometimes be patently stupid and lacking in reasoned assessment, depending on what is being maximized."). For a similar approach from the opposite direction, i.e., a deontological, rights-based approach that is combined with utilitarian considerations, see T.M. Scanlon, Rights, Goals, and Fairness in THEORIES OF RIGHTS 137 (Jeremy Waldron ed. 1984).

41 See Anderson, Value in Ethics And ECONOMics, supra note 3, at 35 (contrasting consequentialist aggregative and maximizing norms with expressive and distributive norms); Gillian K. Hadfield, Feminism, Fairness, and Welfare: An Invitation to Feminist Law and Economics, 1 ANNU. REV. L. SOC. SCI. 285, 301 (2005)(noting that "there are values that human beings receive from nontradeable goods such as the right to be free of harassment, the entitlement to dignity and equality in social processes, or the care that is embedded in particular nonmarket relationships such as the family").

${ }^{42}$ For a critique of such methods, see ACKERMAN \& HeInZERLING, Priceless, supra note 36; David Driesen, Is Cost-Benefit Analysis Neutral? 77 U. Colo. L. ReV. 335 (2006); Kent 
minuses of different courses of action and then make a considered judgment based on holistic consideration of all the relevant information. Mathematics is far from a noncontroversial way to engage in normative analysis. Indeed, when a question involves interpretation of human values, mathematics is ordinarily an irrational way to think about the matter. And if this is so, then arguments will ensue, not only about the numerical values of different costs and benefits but about the maximizing procedure itself. If we are shaping the legal and institutional framework of a suitable and defensible way of life, we need to make judgments about the contours of that way of life; maximizing a single value (even as innocuous a one as "human welfare") is not necessarily the right way to do this; certainly, it is not the only way. ${ }^{43}$ Normative arguments are therefore inescapable in this form of reasoning.

Cost-benefit analysis, especially its efficiency form, cannot avoid the twin charges that it rests on controversial premises and that derivation of specific legal rules from these premises cannot be accomplished in a mechanical or nondiscretionary manner. Normative choices cannot be avoided in the economic analysis of law. The question then is whether there is any viable alternative to the methodology of economics to engage in normative analysis.

\section{\$2.1.3 The problem with rights}

One obvious alternative to efficiency as a normative framework is the elaboration of human rights and liberties. Arguments based on rights and duties (deontological approaches) are, in one sense, obviously based on normative considerations. By definition, they rest on values, or assertions about good and bad, right and wrong, justice and injustice, freedom and oppression, autonomy and servitude. They distinguish legitimate from illegitimate interests; they judge preferences, rather than merely defer to

Greenfield \& John E. Nilsson. Gradgrind's Education: Using Dickens and Aristotle to Understand (and Replace?) the Business Judgment Rule, 63 Brooklyn Law Review 799 (1997). See also ANDERSON, VALUE IN ETHICS AND ECONOMICS, supra note 3, at 200 ("Cost-benefit analysis is properly committed to the view that people should be able to decide for themselves the values of different risks and to express their values in their choices. But it is mistaken in thinking that people can adequately and autonomously express all their valuations through market relations.").

${ }^{43}$ See Anderson, VAlue In ETHICS AND ECONOMiCs, supra note 3, at 38 ("consequentialists recognize only one frame for justifying actions, whereas expressivists recognize different frames for different contexts... [ [ ] ... Because states of affairs have only a context-dependent extrinsic value, it doesn't make sense to globally maximize the value of states of affairs. This is as incoherent as trying to globally maximize the instrumental value of tools, apart from the contexts which give them any usefulness."). 
them. ${ }^{44}$ Similarly, arguments that start from the idea of liberty (especially libertarian approaches) need to define the scope and meaning of liberty; freedom of action is limited by the harm principle (the duty not to harm others) and some normative framework is needed to define what constitutes a legally cognizable harm. ${ }^{45}$

At the same time, most rights theorists seek to avoid or contain normative argument by trying to step above it in some way through decision procedures which are intended to develop determinate answers to controversial questions by reference to noncontroversial premises or foundational nonmoral facts. Some scholars do this by creating presumptions against regulation (as in libertarian approaches to rights) and some do this by explicit reference to idealized preferences, filtered through a suitable decision making setting like a hypothetical bargain, constitutional convention, or social contract (Rawlsian analysis).

As a practical matter, these efforts are unlikely to be successful. One need only observe the division of the country between Republicans and Democrats, religious groups and secularists, as well as division among academics on moral, legal, and political theory, to conclude that it is unlikely to be the case that we have identified a noncontroversial, determinate method for adjudicating normative disagreement. Rights arguments wind up being either indeterminate or controversial, no matter what form one adopts separation of the right and the good (classical liberalism), derivation from foundational human interests (foundationalism) or the requirements of reason (Kantianism), elaboration of a suitable setting for creating a social contract (contractualism) or mutual entailment of principles in a coherent whole (coherentism), or reflective equilibrium between intuitions about particular cases and governing principles. Again and again, we face the problem of the tension between determinacy and neutrality. Principles and decision procedures that are sufficient robust to actually decide specific cases turn out to be controversial, while noncontroversial premises are too abstract to generate determinate answers to hard cases.

\footnotetext{
${ }^{44}$ See RICHARDSON, supra note 5, at 204 (explaining the importance of criticizing desires rather than merely satisfying them); Charles TaYlor, Human Agency and Language: PHILOSOPHICAL PAPERS 1, 66 (1985) ("It is because this [process of normative evaluation] involves ranking motivations that I speak of it as strong evaluation. It means that we are not taking our de facto desires as the ultimate justifications, but are going beyond that to their worth. We are evaluating not just objects in the light of our desires, but also the desires themselves.").

${ }^{45}$ See Joseph William Singer, How Property Norms Construct the Externalities of Ownership (forthcoming in a book to be edited by Gregory S. Alexander \& Allain Pottage).
} 
It is also unlikely that we can identify theoretically satisfying decision procedures that will avoid the need to make normative arguments or to engage in persuasion. Traditional liberal political theory seeks to avoid normative controvery by identifying a decision procedure that can develop principles of right that can shape and ground the basic political and legal institutions of a free and democratic society in a manner that allows individuals to pursue what John Rawls called their own "comprehensive philosophical moral doctrines" (principles of the good). ${ }^{46}$ Rawls developed the idea of public reason to capture this goal of separating the right and the good. ${ }^{47}$ The idea of public reason is an attractive one. Governments have historically oppressed individuals by coercively and violently imposing a particular religion on them. We value individual liberties which encompass both freedom of conscience and the ability to choose our own ends, to live our own life on our own terms, and to form associations with others of oiur own choosing. We hope to create basic social and governmental institutions that we could accept despite our differing conceptions of the good.

Attractive as the idea of separating the right and the good may be, it faces pervasive and probably insurmountable problems, not only in practice but in theory, as well. Michael Sandel has argued that conceptions of the right cannot be completely divorced from conceptions of the good, if indeed they can be separated at all. ${ }^{48}$ Sandel sometimes goes so far as to argue that our normative arguments must be based squarely on elaborating a conception of the good that could be supported by everyone and that principles of right are simply unavailable if they are not based on a moral conception of the good. ${ }^{49}$

${ }^{46}$ RAWLS, JUSTICE AS FAIRNESS, supra note 11 , at $\$ 6$, at 14 .

${ }^{47}$ John Rawls, Political Liberalism 212-254 (1996). See also Rawls, Justice as Fairness, supra note 11 , at $\$ 3$, at 8 ("a public conception of justice"). For a refreshing approach to the idea of public reason, see Eduardo Peñalver, Is Public Reason Counterproductive? (manuscript on SSRN)(http://ssrn.com/abstract=981010).

48 Michael SANDel, Liberalism ANd the Limits of Justice (1982). On the difficulty (or impossibility) of distinguishing the right and the good, consider Lawrence v. Texas, 539 U.S. 558 (2003), holding that the constitution does not permit the criminalization of private, consensual sexual conduct among adults. No resolution of this case could have been made that did not significantly burden someone's conception of the good, either by interfering with the ability to engage in intimate personal contact or by promoting conduct incompatible with the traditional family or good morals. Of course, justifications can be constructed that focus on constitutional rights, such as the right to privacy, or democratic powers, such as the power to pass legislation promoting the public welfare, but application of those principles of "right" in a case like this has obvious differential effects on particular comprehensive moral systems effects that it is impossible for a decision maker to ignore.

${ }^{49}$ Michael Sandel, Public Philosophy: Essays on Morality in Politics (2005). 
Whether or not this latter point is correct, it does seem to be true that we cannot completely separate the right from the good and that attempts to do so inevitably privilege some conceptions of the good over others and rest on values that have their source and justification in basic moral commitments that emerge from individual conceptions of the good.

Lawyers are more aware of this truth than anyone else. We know, as a matter of fact, that our legal system rests on arguments that directly involve conceptions of the good. Case analysis, opinion writing, and legal argument all involve and require lawyers to make, defend, and criticize arguments based on both rights, morality, and social utility in common law adjudication. It is true that during the Lochner era, many judges and law professors entertained the fantasy that the entire legal system could be reduced to a few basic principles and that the specific rules of the common law could be deduced from those widely accepted premises. ${ }^{50}$ But the legal realists destroyed our confidence in our ability to use deductive logic to play out the necessary logical implications of concepts such as freedom of contract, negligence, and property. Instead, judges balance competing interests and justifying the balances they make, judges make arguments that are partly, if not wholly, based on notions of the good and not just the right. For example, the question of whether a owner should be able to take advantage of the adverse possession doctrine when he knowingly and in bad faith placed his fence two feet onto his neighbor's property is an issue that cannot be resolved without reference to controversial moral considerations. The concept of private property is compatible with various answers to this question. For this reason, lawyers are acutely aware that Rawls was wrong to think that one could just look at basic institutions in setting principles of right. The common law governs many social interactions that go beyond what Rawls thought of as "basic institutions" and moral conflict involving competing conceptions of the good goes all the way down. The details of the legal rules governing social life cannot be defined by deduction or mechanical derivation from the nature of basic institutions or concepts or rules. Our common law system defines those legal rules partly by reference to moral considerations, and it is not clear that our legal system could operate at all if it put these controversial moral arguments off the table.

This does not mean that analysis of rights, liberties, and duties should not be part of the answer to the normative problem. Nor does it mean that we should not be concerned with trying to find approaches to justifying legal rules that could be accepted by people who adhere to very different

${ }^{50}$ Duncan Kennedy, The Rise and Fall of Classical Legal Thought (1975). 
(reasonable) comprehensive moral theories. It does mean that we need to be realistic about our ability to reason about the nature of rights in a manner that avoids, settles, or sets aside debates about morality and justice. We need other methods to elaborate reasons that can justify rule choices and institutional settings for a free and democratic society characterized by widespread disagreements about morality. We are unlikely to find a rigid decision procedure that will be decisive in answering questions about what the law should be; we are also unlikely to develop methods of analysis that eschew all moral considerations. Both our procedures for answering normative questions and the reasons we give to justify the rules we enforce are likely to involve controversial premises and a reasoning process that is far from a mechanical one. We need a form of normative argument that recognizes the complexity and plurality of our values and which allows for forms of moral reasoning and justification that are based on argument, persuasion, and rhetoric and not just logic. ${ }^{51}$

\section{\$2.1.4 The problem with democracy}

Democratic theory defines appropriate institutions and social decision making procedures to ensure that decisions can be defended as chosen by the people or by their legitimately chosen representatives through democratic processes. ${ }^{52}$ On the judicial front, most theories of this type counsel a subordinate role for judges, suggesting they leave most controversial questions of social policy to the legislature. Or these theories suggest following the rules - applying the law, rather than making it. And when the law is unclear, there is a preference for "deregulation," understood to mean increasing the range of freedom of action, even if this free action allows some to harm others. ${ }^{53}$ However, other approaches defend judicial activism, partly on the ground that the law develops in a dialogue between legislatures and courts and that each institutional setting reveals normative truths in a way that is unavailable in the other setting. ${ }^{54}$ For example, legislation is often directed to solving particular social problems and the wording of statutes may fail to deal adequately with particular situations that are not the

\footnotetext{
${ }^{51}$ See Timmons, Moral TheOry, supra note 20, at 267-270.

52 IAN SHAPIRO, DEMOCRATIC JUSTICE (1999).

${ }^{53}$ David Shapiro, Courts, Legislatures and Paternalism, 74 VA. L. REV. 519 (1988).

${ }^{54}$ Joseph William Singer, Catcher in the Rye Jurisprudence, 35 RUTGERS L. REV. 275 (1983); Joseph William Singer, Things that We Would Like to Take for Granted: Minimum Standards for the Legal Framework of a Free and Democratic Society, 2 HARV. L. \& POL'Y REV. (forthcoming, 2007).
} 
exemplary cases in relation to which the legislature framed the statute. Courts confront the facts of particular cases, responding to particular conflicts, and may understand the normative limitations of general legislative principles in ways that were not obvious to legislators acting in a planning capacity. ${ }^{55}$ Thus a court may be understandably reluctant to apply a statute providing that a joint tenant succeeds to the ownership interest of his co-owner when she dies if the reason she died is because her co-owner murdered her. ${ }^{56}$ The legislature may not have been thinking about murder of one owner by another when they drafted the general law and might be happy for the court to conclude that the statute was never intended to apply in such a case. ${ }^{57}$ At the same time, other theorists may believe that the court should apply the statute mechanically and leave it to the legislature to create an exception for murder. Such choices of approach mean that democratic theory can provide guidance for judges only when coupled with a normative framework about both the nature, shape, and contours of democracy and the proper relations among different branches of government.

More to the point, when adjudicating an issue of common law, "deference to the legislature" is hardly a solving formula, given the judge's power and responsibility to interpret precedent and enforce common law rights. The common law simply does not work mechanically; the process of distinguishing cases means that state judges applying common law cannot consistently refuse to find legal rights merely because the legislature has not previously created them. The question is always why the precedents of the common law should be interpreted the way the defendant wishes (giving her freedom of action) rather than as the plaintiff wishes (regulating conduct to provide security). It is not possible to reserve all "policy" questions for the legislature on the pretense that the courts can interpret the common law in a neutral, value-free way.

\section{$\$ 2.1 .5$ The problem with critique}

Finally, normative argument is inescapable even for deconstructionists, critical theorists, and postmodernists who might seek to avoid it entirely. It is easy for the armchair theorist to say that normative argument is inescapably circular, indeterminate, controversial, misleading, and ungrounded, or to argue that complete justice is impossible. We can sit in our offices and seek to

${ }^{55}$ See Carol M. Rose, Crystals and Mud in Property Law, 40 Stan. L. Rev. 577 (1988).

${ }^{56}$ See Lee v. Snell, 25 MAss. Lawyers WeEkly 1210 (Mass. Probate Ct., Feb. 10, 1997 (No. 95E0019-GC1).

${ }^{57}$ Joseph William Singer, An Introduction to Property $\$ 8.2$, At 361-362 (2d ed. 2005). 
explain and tear apart arguments made by law makers without attempting to say what we would have done in their place. But it is not so easy for judges and legislators to refuse to engage in normative argument. A judge who decided a case by flipping a coin or without considering competing considerations carefully would be justly criticized as acting in an oppressive manner. We demand that judges think carefully about their exercises of power. More importantly, we demand that judges give reasons to explain how they have exercised their power. Understanding that all reasons can be criticized, undermined, countered, and dissected does not remove the normative and political demand that such reasons be given. Even if reasons cannot be given that are airtight, we still want power holders to give them. And we especially want judges to give them.

The fact that there are no "killer arguments" that definitively resolve normative conflicts does not mean that all arguments are therefore ideological window dressing. The arguments we give for and against different rules of law are based on considerations we in fact care about. Our inability to prove that we are right does not remove the need to justify ourselves. Nor does our desire to rest our normative claims on secure foundations protect us from the need to justify our actions and our laws even when it turns out that such foundations do not exist. ${ }^{58}$ The inability to generate a noncontroversial, determinate decision procedure for normative conflicts does not obviate the need to engage in normative reasoning or argument. We need methods other than an axiomatic decision procedure to fill in the "because" clause. And perhaps most surprisingly, it turns out that lawyers do have a special skill set and specialized knowledge that can aid both moral and political philosophers in doing exactly this.

\section{\$2.2 Living in moral space}

\section{$\$$ 2.2.1 The limitations of analytical methods}

The legal realists demonstrated the limitations of traditional doctrinal analysis. They showed that general principles could not generate detailed rules in a non-discretionary fashion; nor could the concepts contained in those principles or in the resulting rules be specified without engaging in judgments of both policy and principle. Some realists reacted to these demonstrations by rejecting the utility of legal doctrine altogether; they

${ }^{58}$ On the possibility of doing this, see Mark Timmons, Morality Without Foundations: A Defense of Ethical Contextualism 147 (1999); Arthur Allen Leff, Unspeakable Ethics, Unnatural Law, 1979 DUKE L.J. 1229. 
suggested that rules and doctrinal categories give us no help or guidance indeed, they have negative utility because they hide the real policy considerations underlying the rules. Similarly, some moral theorists today advocate a form of "particularism" which asserts that moral rules have no real role to play in moral reasoning; rather, particular facts and contexts must be considered to determine the right thing to do in any situation. ${ }^{59}$

Law and economics scholars have similarly turned their attention away from legal doctrine and moral principles, instead trying to using cost-benefit analysis, among other approaches, to identify rules that maximize social welfare. Several professors at Harvard Law School have responded to the legal realist critique of doctrine by developing a course called "Analytical Methods for Lawyers" now enshrined in a coursebook of the same name. ${ }^{60}$ In the place of legal doctrine, the text suggests solving legal problems by using basic business and economic concepts and methods of analysis, such as decision theory, game theory, information theory, contracting theory, accounting, finance, statistics, microeconomics, and law and economics. ${ }^{61}$

As I have explained, useful as they may be for certain kinds of questions, there are built-in limitations to these "analytical methods." At their best, they are incomplete as decision procedures for choosing appropriate courses of action; at worst, they are misleading and distorted. They presume that all relevant values can be reduced to monetary values (or at least are measurable in some way). Yet this is clearly not true. Even if the analysis recognizes that not all values can be reduced to dollar values, any values which cannot be so expressed are generally omitted from the analysis. But the result of the analysis is usually enthroned as the "welfare-maximizing" result despite the incompleteness of the analysis. Moreover, the assumption appears to be that justice-based goals, such as distributive fairness, must be achieved by sacrificing social welfare. I have argued, in contrast, that economic analysis cannot itself be applied analytically without making controversial assumptions about fundamental values. With different baseline assumptions, the analysis would come out very differently. And one cannot define a legitimate baseline without considering normative questions involving things like distributive justice. Further, because many important values cannot be

\footnotetext{
59 See Contemporary Debates in Moral Theory 283-322 (James Dreier ed. 2006); Timmons, MORAL THEORY, supra note 20, at 245-266.

${ }^{60}$ Howell E. Jackson, Louis Kaplow, Steven M. Shavell, W. Kip Viscusi \& David Cope, ANALYTICAL METHODS FOR LAWYERS (2003).

${ }^{61}$ While these tools are useful to lawyers, legislators, and policy makers, their utility to judges is less clear. While one might believe that judges should ignore precedent and simply choose efficient results, this is not an attitude fully embraced by any judge.
} 
reduced to numbers, an adequate normative method would include methods of reasoning and justification that are outside the scope of the methods described in Analytical Methods for Lawyers.

Law makers also need to articulate acceptable reasons for a rule choice that can explain to the losing party why the result is fair and just. Cost-benefit analysis suffers from the limitations of all utilitarian reasoning; it fails to respect the separateness of persons because it assumes that the gains of some can fully offset the losses of others. A judge cannot explain a decision this way. From an external perspective, it may seem sensible to say, "We considered your claim but concluded that the social costs of ruling in your favor outweigh the social benefits." The problem is that the losing party will hear this argument to mean: "We decided to sacrifice your interests for the good of the community." This is not an adequate argument; it does not treat individuals with equal concern and respect. We need ways of reasoning and methods of justification that go beyond these methods. These economicallyoriented analytical methods for lawyers need to be supplemented by normative methods for lawyers.

\section{$\$$ 2.2.2 Moral reasoning: "as much clarity as the subject matter allows"}

I have argued that we have many reasons to avoid normative argument. Normative disagreement seems fundamental and permanent and we have no apparent noncontroversial methods for choosing among competing moral views. But I have also argued that normative argument is unavoidable in a legal system in a free and democratic society. Nor should we want to avoid it. Judges need presentable and persuasive ways to argue about justice, fairness, and morality. Lawyers need the ability to do this, as well, not only to give persuasive arguments to judges, but to be able to interpret existing law.

Contrary to the assumptions underlying much current efficiency analysis, not all preferences can or should be indulged and not all preferences can be given equal weight. And when we reject a preference, we should be able to explain why. When we raise some interests to the level of fundamental values, we should be able to justify this. The language of justice grows out of the human impulse to give reasons for our claims, to justify the demands we make on others. ${ }^{62}$ We want to say something other than "I prefer that you

62 Christine M. KorsgaArd, et al., The Sources of Normativity (1996); T.M. SCANLON, WHAT We OWE TO EACH OTHER (1998). See also RAWLS, Justice AS FAIRNESS, supra note 11, at $\$$ 9.2 at 27-28 (noting the public justifications are "addressed to others who disagree with us" and "appeal[ ] to beliefs, grounds, and political values it is reasonable for others also to acknowledge"); id. $\$ 9.2$, at 28 ("For justice as fairness to succeed, it must be acceptable, not 
stop torturing that man" or "I have a taste for treating other people respectfully" or even "the costs of torturing that man outweigh the benefits." We want to say something other than "come play for our team." We feel entitled to make moral demands on each other; we believe some political and legal systems, and some legal practices, are inherently unjust. We want to say - without irony - that "torture is wrong" and "people deserve to be treated with dignity" - and we would like to be able to say why. We especially want to be able to give good reasons for imposing laws on those who may disagree with the values underlying the laws. Is there really anything wrong with this impulse?

I would say not. As Charles Taylor explains, "It is a form of self-delusion to think that we do not speak from a moral orientation that we take to be right. That is a condition of being a functioning self, not a metaphysical view we can put on or off." ${ }^{\prime 3}$ We need to be able to talk more cogently about our moral values, but in order to do so, we may need to give up the artificial constraints on moral reasoning that we had unconsciously imposed on ourselves. ${ }^{64}$ If it is not possible to identify neutral, determinate decision procedures for reasoning about values, then perhaps our idea of what reason entails in the realm of normative argument was misplaced. Perhaps reason can coexist with controversy; perhaps reason manages disagreement without abolishing it. ${ }^{65}$ Perhaps normative arguments are not an enclosed deductive, self-evident system but a form of practical reason, a means of living in the world, rather than a theoretical construct. ${ }^{66}$

only to our own considered convictions, but also to those of others ....").

${ }^{63}$ TAYLOR, SOURCES OF THE SELF, supra note 7. at 99.

${ }^{64}$ Lloyd L. Weinreb, Legal Reason: The Use of Analogy in Legal Argument 92 (2005)("A decision is not a proof; it does not afford certainty, and reasonable persons may disagree. But in law, as in human affairs generally, a proof is not to be had."); Martha Nussbaum, Valuing Values: A Case for Reasoned Commitment, 6 YALE J.L. \& Human. 197, 202 (1994) ("getting rid of transcendent standards does not mean getting rid of good reasons").

${ }^{65}$ FogELIN, supra note 1, at 59-60 ("Reflecting on certain features of a situation can trigger our deontological instincts; reflecting on other features can trigger our consequentialist instincts. Sometimes-perhaps even usually-these instincts support each other. Sometimes, however, they conflict. These, I think, are simply facts about our moral life. The thought that there must be some unifying source for our moral instincts-one that shows their underlying coherencestrikes me as wholly unlikely on its face."); ERIC MACGILVRay, ReCONTRUCTING PUBLIC REASON 155 (2004) (arguing that we should not assume that public reason requires moving from uncontroverial - and possibly empty - premises to controversial - and substantively charged conclusions).

${ }^{66}$ See Toulimin, supra note 20 (arguing to recreate a sense of the reasonable rather than attempting to define what is "rational"). As Charles Taylor argues: 
If so, how do we reason about normative matters? Charles Taylor suggests we can gain traction by "articulating" what he called our "strong evaluations" 67 and our "moral frameworks." 68 "Strong evaluation ... involves a standard, independent of my own tastes and desires, which I ought to acknowledge." ${ }^{69}$ Articulating such strong evaluations helps us better understand our deep, and possibly unconscious, beliefs and assumptions; it also allows us to see their complexity and to criticize and improve them. The complexity that emerges in this process gives us reason to reject the idea that normative reasoning either appeals to "self-evident truths" or is based on mechanical, logic-driven decision procedures.

Long ago Aristotle argued that we cannot expect exactitude in the realm

"If you want to discriminate more finely what it is about human beings that makes them worthy of respect, you have to call to mind what it is to feel the claim of human suffering, or what is repugnant about injustice, or the awe you feel at the fact of human life. No argument can take someone from a neutral stance towards the world, either adopted from the demands of 'science' or fallen into as a consequence of pathology, to insight into moral ontology. But it doesn't follow from this that moral ontology is a pure fiction, as naturalists often assume. Rather we should treat our deepest moral instincts, our ineradicable sense that human life is to be respected, as our mode of access to the world in which ontological claims are discernible and can be rationally argued about and sifted."

TAYLOR, SOURCES OF THE SELF, supra note 7, at 8. Accord, KYMLICKA, supra note 19, at 44 ("The question is which form of equal treatment best captures the deeper ideal of treating persons as equals. That is not a question of logic. It is a moral question, whose answer depends on complex issues about the nature of human beings and their interests and relationships. In deciding which particular form of equal treatment best captures the idea of treating people as equals, we do not want a logician, who is versed in the art of logical deductions. We want someone who has an understanding of what it is about humans that deserves respect and concern, and of what kinds of activites best manifest that respect and concern.").

67 TAYlor, SOURCES OF THE SelF, supra note 7, at 4 ("strong evaluation ...involve[s] discriminations of right or wrong, better or worse, higher or lower, which are not rendered valid by our own desires, inclinations, or choices, but rather stand independent of these and offer standards by which they can be judged."

${ }^{68}$ TAYLOR, SOURCES OF THE SELF, supra note 7, at 4 (discussing the importance of "articulating" and thus "making sense" of the "background picture lying behind ourm oral and spiritual intuitions."); see id. at 3-52 (generally discussing the role and importance of moral frameworks).

69 TAYlor, SOURCES OF THE SElf, supra note 7, at 4. See also TAYlor, Human AgENCY AND LANGUAGE, supra note 44, at 3 (defining a "strong evaluation" as "a background of distinctions between things which are recognized as of categoric or unconditioned or higher importance or worth, and things which lack this or are of lesser value."). 
of moral reasoning; the nature of the subject prevents it. He began his Nichomachean Ethics by noting that "[o]ur discussion will be adequate if it has as much clarity as the subject-matter allows..."70 Perhaps we need to give up, or at least relax, our expectation that normative argument should derive the answers to hard questions from uncontroversial premises, or our expectation that neutral procedures can be wholly divorced from substance, or our expectation that what we need are decision procedures that generate answers in a mechanical or deductive fashion. ${ }^{71}$ Perhaps what we need are structures of normative reasoning that recognize the inevitability both of controversial normative premises and procedures and the need for contextualized human judgment to apply those normative methods to concrete cases. ${ }^{72}$

Yet giving up the idea of an orderly, self-proving moral system raises the possibility of self-delusion and false legitimation. What we seek are legitimate justifications of normative choices; what we fear are attractive arguments that legitimate oppression. We are aware that we can talk ourselves into doing horrible things. How do we engage in justification and avoid oppressive legitimation? If competing moral claims seem relevant in a particular case, and we do not have a noncontroversial method to solve the battle of

${ }^{70}$ ArIstotle, ARISTOTLE's Ethics 5 (John Warrington ed. 1963)(c. 340 в.C.E.).

${ }^{71}$ As Isaiah Berlin argued in a radio address in 1957:

The arts of life-not least of politics - as well as some among the human studies turn out to possess their own special methods and techniques, their own criteria of success and failure... Bad judgment here consists not in failing to apply the methods of natural science, but, on the contrary, in over-applying them... To be rational in any sphere, to apply good judgement in it, is to apply those methods which have turned out to work best in it... [To demand anything else] is mere irrationalism.

Isaiah Berlin, quoted in ToulMIN, supra note 20, at viii.

${ }^{72}$ See Fogelin, supra note 1, at 61-62 ("It is essential to see that an irreconcilable moral conflict can exist without bringing all morality down around it.... Thinking otherwise is almost certainly the result of placing ultrarationalist demands on moral systems. They are either dilemma-free or wholly arbitrary. A leading aim of this work is to break the spell of thinking of that kind."); KYMLICKA, supra note 19, at 44-45 ("What we have in political argument is not a single premises and then competing deductions, but rather a single concept and then competing conceptions or interpretations of it. Each theory of justice is not deduced from the ideal of equality, but rather aspires to it, and each theory can be judged by how well it succeeds in that aspiration."); CHARLES TAYLOR, SOURCES OF THE SELF, supra note 7, at 7 (arguing that modernity has inherited "a deeply wrong model of practical reasoning, one based on an illegitimate extrapolation from reasoning in natural science."). 
competing norms, then we have no choice but to rely on contextualized, carefully considered human judgment. We work within a tradition, developing both high-level and low-level norms of interpretation, argumentation, justification, and defense. But retreat to notions of "craft" or "expertise" or pronouncements by "experts" that certain arguments are not "sound" inevitably appears to the losing side to be mere assertions of power words designed to get the loser to shut up rather than reasons that could be accepted as legitimate if not persuasive. It is so easy to slip into a selfjustifying stance, convincing ourselves that we are in the right when we are actually doing wrong.

This worry is real but the remedy it suggests is misconceived. We should worry about self-delusion and the unfair treatment of others. But the remedy for this worry is not to go back to the failed strategy of seeking to identify noncontroversial premises or pretend that the premises we do adopt generate answers in a mechanical or logical manner. Nor is the remedy to give up on the idea of pursuing justice. Neither of these extreme response solves our problem. The real remedy is to continue to worry. We do this by acknowledging the need for argument, and the need to give reasons addressed to the losing side. We do this by attending to the arguments on both sides, to seeing the case from someone else's point of view. We cannot avoid the problem of talking ourselves into injustice by giving up on the idea of justice. The absence of clear, noncontroversial decision procedures does not make normative argument impossible or pointless or self-deluding. ${ }^{73}$

Reason in the realm of values must attend to the fact that human beings are "self-interpreting creatures" and that we are as much the source as the object of our normative claims. ${ }^{74}$ The skeptics are right that normative argument requires controversial claims even to get off the ground and that any set of reasons is likely to be both incomplete and inconsistent. Yet they are wrong to conclude that this makes such arguments meaningless or inherently obfuscatory. ${ }^{75}$ Normative arguments express what we value but they do more than this. The reasons we give to support moral claims are not just reports of preferences or tastes; rather, they are both "felt obligations"

\footnotetext{
${ }^{73}$ See RAWLS, JUSTICE AS FAIRNESS, supra note 11, at 30 ("Many of our most serious conflicts ar conflicts within ourselves. Those who suppose their judgments are always consistent are unreflective or dogmatic; not uncommonly they are ideologues and zealots."); Timmons, MORAL THEORY, supra note 20, at 96-97, 267-272 (arguing for "limited moral pluralism").

${ }^{74}$ See generally KeIth TOPPER, THE DisORDER OF POLITICAL INQUiRy (2005).

${ }^{75}$ KYMLICKA, supra note 19, at 45 ("To demand that [political argument] achieve logical proof simply misunderstands the nature of the exercise.").
} 
and demands we feel entitled to make of each other. ${ }^{76}$ As moral demands, they possess a different status and character than mere preferences. Moreover, reasons can have weight even if we lack a completely coherent framework that determines their relative strength and applicability. Our lack of such a mechanical decision procedure does not require us to give up the idea of reason altogether. It does require us to frame our arguments in ways that are respectful of differences among persons with regard to conceptions of the good and attentive to the ways in which we are shaping our arguments as much as being shaped by them. We may not have access to Reason with a capital " $R$ " (or what Stephen Toulmin calls "rationality") but we have the capacity to give reasons to justify our claims on each other (what Toulmin calls "reasonableness") 77 - and we have, or should have, the capacity to be moved by reasons given by others.

Lawyers need to know how to do this. Normative argument is not just something that philosophers think about in the privacy of their offices; it is not merely the stuff of academic conferences and papers. Lawyers make normative arguments every day. These arguments are especially important in the context of common law development. For better or worse, it is a fixed part of our legal system to give reasons to support proposed rules of law when the rules in force are uncertain, or contain a gap, conflict, or ambiguity. When we argue about what the law is, we inevitably allude to what it should be; whether one is a supporter of natural law or positivism, it is a feature of our legal system to justify legal rights by appeal to normative considerations.

Moreover, one can do better or worse at this project. The fact that one can often write a brief on both sides of a legal question does not mean that all briefs are equally good. As Francis Mootz notes:

Many first year law students are troubled by what they perceive to be the wide freedom of judges to decide cases on personal whim and then later to supply adequate legal justification for their decision, but it is no surprise to find that these same students have difficulty formulating a coherent argumentative essay for the final exam. It is easy enough to believe that the law is "just rhetoric" when reading a case, but the tremendous challenge of confronting a specific legal dispute and arguing persuasively on behalf of a

\footnotetext{
${ }^{76}$ On "felt obligations," Charles Taylor explains, "For I do not just feel desire to help this man. Indeed, I might feel no such desire in the usual sense of the term. But I feel called upon to help him. And I feel called upon qua rational being, or moral being, or creature made by God in his image, in other words capable of responding to this like God, that is, out of agape."). TAYLOR, Human AgEnCy And LANGUage, supra note 44, at 58.

77 Toulmin, supra note 20, at 15 (contrasting the "reasonable" and the "rational").
} 
client quickly demonstrates to students that a rhetorical exchange can be extremely demanding because it is so decentering. Rhetorical engagement demands an intersubjective relationship if it is to be successful in a close case; crude manipulative tricks simply don't work. ${ }^{78}$

We lawyers have tools to engage in normative argument that structure the process of giving reasons for the demands of justice. We cannot do our jobs without them. Some of them track arguments from other fields, such as moral theory, economics, political philosophy, and literature. Some of them are more specific to law; traditional methods of doctrinal analysis embody both general principles and intuitions, rules and cases, broad concepts and specific applications, rules and counter-rules, claims and defenses. Lawyering methods connected with the elaboration of legal doctrine aid clear thinking about the meaning of rule choices and the precise contours of fundamental moral and political values. Lawyers use general norms, such as fairness and efficiency, but we also look to patterns, exemplary cases, and general rules to help us think through the justifiability of alternative resolutions of a case.

It turns out that lawyers have something important to teach moral philosophers, economists, and political theorists. We are the authors of our claims but we are also their subjects; ${ }^{79}$ justice and deconstruction can coexist if we recognize that normative argument need not be airtight or definitive to make it valuable. The fact that we choose how to live together does not mean that we cannot choose wisely or defend our proposed terms of cooperation in ways that others could be expected to accept. One might call this approach critical normativity. ${ }^{80}$ Justice is a human achievement, not a found object. It requires humility in a world of disagreement about conceptions of the good. But the likely continuation of fundamental disagreement does not obviate the need to make considered judgments and to give reasons we can defend to justify our social and legal arrangements. The Talmud teaches, "it is not up to us to finish the task, but neither may we desist from it." ${ }^{81}$ If T.H. White is right that "there is something important in humanity," 82 then we must attend

\footnotetext{
${ }^{78}$ MootZ, supra note 22, at 132-133.

79 See Anderson, Pragmatism, science, and moral inquiry, supra note 36, at 23 ("The subject matter of humanistic and social scientific inquiry is ourselves. This fact has inescapable practical implications. As Charles Taylor has emphasized, it is part of our nature as selfinterpreting, deliberative beings that we must act on our understandings of who we are.").

80 See RICHARDSON, supra note 5, at 305 (explaining his "theory of critically relative rationality").

${ }^{81}$ Mishnah Pirkei Avot (Ethics of the Fathers) 1:18 (BAbylonian Talmud).

${ }^{82}$ T. H. White, The Book of Merlyn: the Unpublished Conclusion to the OnCE AND
} 
to the human impulse to treat each person with equal concern and respect and this fundamentally requires us to figure out how to give legitimate reasons for the laws that structure our lives.

\section{\$3.0 LAW AS APPLIED MORAL AND POLITICAL THEORY}

\section{\$3.1 What lawyers can learn from moral and political theory}

There is a tendency these days for legal scholars to believe that lawyers have no specialized knowledge. Legal reasoning is thought to be empty unless filled with some external theory like economics, moral theory, political philosophy, or history. We no longer have faith in "legal reasoning" or in custom, tradition, or precedent as ways to resolve legal issues. We look to other fields to fill in the gaps of ours. We look to economic theory or moral theory or political philosophy to provide a structure to normative argument in law. If law involves conflicting arguments, competing norms, divergent and contradictory worldviews, we have no choice but to go outside law to find a firm foundation for rational choice, just adjudication, or wise governing.

There are two fundamental flaws with this view. First, it turns out that those fields similarly look outside themselves to answer the questions they cannot answer. Economists for example, assume that the legal system assigns property rights - an institutional fact that is necessary before markets can even get off the ground. Thus, they look to lawyers to answer questions that provide the basis or foundation for their own arguments, concepts, and procedures. So lawyers cannot simply use economic analysis if that analysis needs lawyers to define the baselines from which the economic analysis should begin. Perhaps we could turn to political and moral theory to give us the baseline needed by the economists.

That brings us to the second flaw in the view that social theory can guide lawyers. Political and moral theory tends to operate at a relatively high level of abstraction. Political theorists consider the basic structure of society and moral theorists consider the kinds of reasons appropriate to interpersonal relations. Lawyers, on the other hand, spend more of our time in the world of what is often thought of as applied moral theory. We hammer out the details of concrete social interactions in the context of specific problems. The moral and political theorists seem to assume either that their analyses can be applied in a straightforward manner to concrete cases or that the details of 
legal rules are technical matters unrelated to fundamental normative dilemmas. But we lawyers know better. The normative controversies dealt with by these theorists at the level of high principle go all the way down; they recur at the application stage - they never go away.

That being said, I do believe, that lawyers do have a great deal to learn from economists, moral theorists, and political philosophers. Among other things, economists teach us (1) to look at the consequences of adopting one rule of law over another; (2) to consider the incentives that alternative rules create for behavior; and (3) to compare the costs and benefits of alternative courses of action, and (4) to think systematically about the interplay of forces in social and economic life, the remote and interconnected effects of different rules and institutions, and the ways in which particular changes effect remote and unexpected changes elsewhere. Today law professors and judges generally recognize these benefits of economic theory in choosing and justifying legal rules. What they do not sufficiently appreciate are the benefits of using the insights of moral and political theory to address the issues that economists set aside.

Moral and political theorists have valuable lessons for lawyers. Moral theorists, for example, teach us (1) the importance of giving legitimate and relevant reasons to others to justify our actions when we affect them; (2) the foundational idea that individual persons are of intrinsic and immeasurable importance, that they are imbued with dignity, and entitled to equal concern and respect; (3) that this means that we judge preferences rather than merely deferring to them; and (4) that we cannot legitimately claim to support a particular rule governing individual conduct if we cannot consistently support that principle in similar situations in the future to similarly situated persons (including ourselves). Political theorists teach us (1) that we should attempt to give reasons for laws and governing structures that could, would, or should be acceptable to everyone regardless of their own particular views of the good; (2) that we cannot identify such reasons without making assumptions about human nature and relationships and foundational norms such as autonomy, dignity, security, and equality; and (3) that the persistence of dispute and debate about political and legal questions does not relieve us of the responsibility to specify what these fundamental values mean in a free and democratic society that tries to treat each person with equal concern and respect.

Here is another way to put this: Economic analysis works from a given baseline - usually the status quo - and then asks whether change in that baseline improves things overall. Moral and political theorists focus on defining an acceptable baseline; rather than taking the status quo for granted, 
they seek to understand the basic framework of a free and democratic society within which cost-benefit analysis can proceed. They also develop ways to talk about values that cannot be reduced to dollar amounts or which cannot be sufficiently respected by attempts to maximize them. These theorists therefore work on the questions that preoccupy lawyers: what are the basic entitlements that individuals should have before they begin bargaining with each other or interacting in the market or social life? What are the minimum standards for contractual relationships within a free and democratic society that accords each person equal concern and respect? Not only the questions but the methods of reasoning used by moral and political theorists are congenial to the work that lawyers and judges engage in. For this reason, moral and political theory provide enormously useful resources for lawyers that cannot be replicated by reducing all rule choices to economic terms.

\section{$\$ 3.2$ What lawyers can teach moral and political theorists}

\subsubsection{Law is complex}

I have argued that lawyers have much to learn from moral and political theorists, but I also believe that the oppposite is true as well. Lawyers do possess specialized knowledge that is of immense value to economic, moral, and political theory. What do lawyers know? For one thing, many moral and political theorists appear to underestimate how hard it is to define the legal structures associated with market and social relations in a free and democratic society. ${ }^{83}$ Nonlawyers (and a few lawyers) sometimes imagine

\footnotetext{
${ }^{83}$ I do not mean to argue that all moral and political theorists misunderstand the complexity of moral choices and legal structures supporting a free and democratic society. Indeed, a number of important theorists have articulated and defended the idea that values are complicated, contextually contingent, plural in nature, and conflicting in application, and that the only reasonable way to handle such complexity is through a form of practical reason rather than a tight deductive or logical system of concepts. This article builds on their work. Examples include Anderson, VAlue in Ethics And ECONOMics, supra note 3; Fogelin, supra note 1; RichARDSON, supra note 5; TAYLOR, SOURCES OF THE SELF, supra note 7; Anderson, Pragmatism, science, and moral inquiry, supra note 36; TIMMONS, MORAL THEORY, supra note 20; Margaret Urban Walker, Moral Understandings (1998); Margaret Urban Walker, Moral Understandings: Alternative "Epistemology" for a Feminist Ethics, 4 HyPATIA 15 (1989). My point is not that no philosophers have recognized the complexity of moral life but that, because lawyers are charged with constructing rules and principles to guide numerous real world situations, we have rich experience in applied moral and political theory that tends to cause us to accept the idea that complexity is inevitable and that abstract theories are unlikely to dissolve complexity.
} 
that only a few basic normative choices need to be made (such as deciding to have and to protect private property, to enforce promises, to prevent both intentional harms and negligent conduct, and to support the institution of marriage) and that once those choices are made, application of those norms to particular conduct follows naturally, logically, inexorably, and even mechanically. Nonlawyers generally think that the law could and should be relatively clear and simple; lawyers are unpopular partly because nonlawyers believe that we know how to twist things to make a simple problem complicated..$^{84}$

Lawyers know, on the other hand, that defining the rules governing social interaction and market relationships is a very, very complicated business. ${ }^{85}$ Lawyers are acutely aware that we cannot identify a small number of clear principles and apply them in a straightforward manner to particular cases. Although this was arguably the aim during the era of classical legal thought at the beginning of the twentieth century, it is now fairly well understood that that effort was a colossal failure. ${ }^{86}$ Seemingly simple concepts like "property" or the "free market" cannot be defined in a few sentences. As the foreign minister of Czechoslovakia, Jiri Dienstbier, commented in 1990, "[i]t was easier to make a revolution than to write 600 to 800 laws to create a market economy." ${ }^{87}$ If anything, he understated the case.

Lawyers are expert at one aspect of analytical philosophy; we know how to ferret out ambiguities in fundamental concepts and principles. To clarify those ambiguities, we divide legal issues into many constituent parts. Rather than merely asking whether the defendant wronged the plaintiff, we divide the question into a number of elements, such as duty, breach, causation, damage. Then in defining each of these elements we further distinguish among kinds of duty, breach, causation, and damage. For example, we identify different duties leading to various torts, such as fraud, assault, battery, libel, negligence, infliction of emotional distress. And then we further define what those torts mean; so the duties imposed by the tort of fraud are themselves defined by a number of distinct elements, such as (a) a representation (b) that was false when made, (c) intended to induce reliance by the plaintiff, (d) which did in fact induce reliance (e) where the reliance was reasonable, and (f) caused the plaintiff harm. We then see difficulties in

\footnotetext{
${ }^{84}$ Even a few scholars are taken in by such impossible dreams of simplicity. See RICHARD EPSTEIN, SIMPLE RULES FOR A COMPLEX WORLD (1995).

${ }^{85}$ See RiCHARDSON, supra note 5, at xi ("discerning the true complexity of value").

${ }^{86}$ Kennedy, The Rise and Fall of Classical Legal Thought, supra note 50..

${ }^{87}$ William Echikson, Euphoria Dies Down in Czechoslovakia, Wall St. J. (Sept. 18, 1990), at A26, 1990 WL-WSJ 56114.
} 
determining the meaning of each of these elements of the claim. Then we add defenses, which have their own difficulties of interpretation and application. We refine the meaning of these analytical elements by reference to other concepts, social contexts, underlying norms, narratives, and social policies. We make finer and finer distinctions until the rule books are thousands of pages long.

We lawyers do all this not because we are perverse and not because we get secret thrills in making simple things complicated. Nor do we do it so that we can turn ourselves into an expert guild where we are the only ones able to interpret this morass and are therefore able to earn a living. We make law complicated because qualitative distinctions matter and they matter at this level of detail. The process of applying rules and doctrines to particular cases reveals the normative complexity involved in determining the meaning of moral principles and public policies. As lawyers, we are confronted with, and highly attuned to, the number and the complexity of choices that must be made to put abstract concepts and ideals into practice in the real world.

The field of ethics tends to distinguish general ethical theory (metaethics) from applied ethics. Those who do applied ethics are often looked on as technicians. The real work is done at the level of principle while the application work is done by the hired hands. The division of labor seems akin to those between architect and builder or physicist and engineer or manager and secretary. Lawyers know better. The process of applying law to concrete cases heightens our awareness of the complexity of our values and the difficulty of determining their scope and weight in particular cases. Our society is one characterized by many disagreements about moral values. Even when we agree on fundamental values, we find that they are multiple and conflicting; they push us different ways when we try to apply them to concrete cases; we want efficiency and equality, freedom of action and security, stability and change, majority rule and constitutional rights, freedom of religion and freedom from the establishment of religion. We cannot make grand choices between private property and communism and then assume that these choices come with a built-in institutional structure. We choose to have private property - and then what? Then we wind up with the twenty-volume treatise on my shelves explaining the complexities of defining what that means - a treatise that itself is a summary of thousands of cases attempting to define the contours of the property system.

Drawing appropriate lines between competing values is complicated, and because the rules in force attempt to protect and vindicate conflicting values, the rules in force reflect careful calibration and sophisticated line drawing. The high level theorists often hope that they can invent a metatheory that will 
reconcile all these competing normative considerations. Sometimes the theorists even convince themselves that they have succeeded in that task. However, most lawyers (and judges) know better. When we apply these metatheories to concrete cases, we find ourselves dissatisfied. We are not persuaded that rights should always be sacrified on the altar of efficiency; nor are we persuaded that abstractly and formalistically defined rights be protected though the heavens fall. ${ }^{88}$ Moreover, the application process shows us the utility of looking at the same moral dilemma from multiple points of view. We like using several approaches; we find them useful, illuminating, attractive, and helpful.

Law is complicated not only because our values are complicated, and not only because the application process reveals the limitations of simplistic metatheories, but because our values legitimately and understandably evolve over time. Lawyers know that we need to accommodate rules to existing social values and conditions. We cannot continue to apply rules that may have worked well in 1792 in 2008 if those rules cannot be defended as consistent with current values and circumstances. Arguments for interpreting law in light of "original intent" of the founders are generally limited to constitutional claims and instances of statutory interpretation. And even then room must be made for evoluation of meaning; after all, many of the Founding Fathers owned slaves. Although adherence to precedent and deference to the legislature to overturn precedent are widely accepted arguments when state courts interpret common law, it is not commonly thought that the law should develop by reference to conditions or values that existed 200 years ago. Indeed, if anything, deference to policies enacted in currently enforceable legislation is a stronger source of interpretive guidance than the common law as it existed a long time ago. Moreover, no one can dispute that the common law has changed drastically since the beginning of the nation. Conduct that would not have been thought harmful to land in the past is now understood to cause harmful pollution which can be regulated by the common law of nuisance or environmental law. Exclusionary conduct that would have been perfectly legal in 1858 is now prohibited by public accommodation laws. Current public policies in favor of abolishing racial discrimination in the market place may affect interpretation of common law rules regarding control of property. ${ }^{89}$

\footnotetext{
${ }^{88}$ See Fogelin, supra note 1, at - (explaining the fallacy of assuming that norms must be absolute); RiCHARDSON, supra note 5, at 70-71 (discussing "logically nonabsolute norms"); id. at 77-79 (explaining the importance of specification).

${ }^{89}$ Joseph William Singer, No Right to Exclude: Public Accommodations and Private Property, 90 NW. U. L. REV. 1283 (1996).
} 
In short, the impetus to refine legal rules by making numerous analytical distinctions and by multiplying the number and complexity of rules is not a smokescreen designed to protect a monopolistic guild. Rather, it is a consequence of lawyers' intimate knowledge of the normative complexities involved in making real our most treasured values. Most fundamentally, it results from our commitment to treat human beings with equal concern and respect - a commitment that does not allow us apply a formula mechanically without careful and considered regard for its impact on individuals in particular cases. It results from our commitment to the idea that like cases be treated alike and our awareness from careful studying of prior attempts to accomplish this goal that determining when one case is like another is a process that requires practical reason, moral judgment, and fine distinctions. The complexity of law expresses our commitment to our most basic values, as we see that particular cases cause us to revise those values or delimit their scope when they conflict with other values, thereby necessitating distinctions, multi-layered doctrines, and calibration of rules to appropriate situations. This raises the importance of context in applying norms to cases, and it is to that issue we now turn.

\section{\$3.2.2 Context matters}

A second insight lawyers can teach philosophers is our acute awareness of the importance of context in determining both the scope and content of legal rules. ${ }^{90}$ For example, consider the idea that ownership of land includes the right to exclude nonowners from the property. The right to exclude seems a natural implication of the idea of ownership if ownership is understood to mean exclusive control of valuable objects in the world. Ownership rights, so understood, protect core values of autonomy, privacy, and security, as well as promoting the general welfare. But does the "right to exclude" mean that restaurants are entitled to exclude customers because of their race? Does it mean that employers are entitled to exclude the city health inspector? Does the right to exclude mean that a citizen of New Orleans was trespassing if she sought to save her life by entering a neighbor's house during Hurricane Katrina? Are landlords entitled to prevent tenants from having overnight guests? Can homeowners near airports prevent planes from flying too low over their properties? Lawyers are experts in thinking up questions like this; we do it because we study cases in which existing rules seem to have

\footnotetext{
90 Steven Toulmin and Elizabeth Anderson have both noted the importance of context for understanding the meaning of human events. See Anderson, Pragmatism, science, and moral inquir, supra note 36, at 17-22; TOULMIN, supra note 20, at 21.
} 
unfortunate consequences and mechanical application of a seemingly applicable rule will seem harsh, unfair, or socially destructive. We are experts in finding the limits of principles by examining the cases to which they apply.

Lawyers know that all you have to do is change one fact and suddenly our intuitions about the right result in the situation can change dramatically. Tenants have a duty to pay rent, but suppose the landlord fails to repair a broken furnace and thus fails to provide heat and hot water to the tenant's apartment as required by both the housing code and the terms of the lease agreement; does the duty to pay rent persist? Towns have the power to pass zoning laws segregating incompatible uses such as industry and housing, but suppose a town passes a law segregating homeowners by race? Employers cannot refuse to hire someone because of their sex, but can they refuse because of their sexual orientation? (Although federal law prohibits sex discrimination, most states allow discrimination based on sexual orientation.) The statute of frauds requires transfers of land to be in writing to be enforceable, but if the grantor fails to sign a deed in 1850 , and this is discovered in 2008 , does that mean title should immediately revert to the heirs of the original grantor, and if they cannot be found, that it should thereby escheat to the state? A joint tenant succeeds to the interest of her coowner when the co-owner dies but what if he murdered her?

The law makes distinctions based on the context in which the rules are to be applied. And because context matters, rules do not determine the scope of their own application. ${ }^{91}$ Lawyers are more experienced than nonlawyers with the practice of studying the detailed and varying contexts in which law applies, we are acutely aware that competing values (such as ending racial discrimination in market transactions or saving human life or creating stability in property rights) may cause lawmakers to create exceptions to basic rules or to narrow the scope of those rules to factual settings where they are appropriate. Moreover, changes in facts, social context, environment, other laws, and relationships among the parties, all may be involved in limiting the application of a rule. Karl Llewellyn was correct when he argued that a case has almost no meaning by itself. ${ }^{92}$ We cannot tell whether the rule in the case is broad or narrow without viewing it in relation to rules that came before and cases that come afterwards.

Lawyers are trained in the art of distinguishing cases, and it is, indeed, an

\footnotetext{
91 See Toulmin, supra note 20, at 27 ("The general concepts in which we articulate our ideas and beliefs have formal implications, and it is the task of theoretical analysis to sort out and elucidate them. But, by itself, such a theoretical analysis does not tell us in what situationshow, where, or when-everyday life and practice exemplify those ideas."

${ }^{92}$ LleWellyn, Bramble Bush, supra note 24, at 48.
} 
art. It cannot be done mechanically; nor can it be done arbitrarily. Only some distinctions make sense and will be persuasive to a conscientious decision maker. ${ }^{93}$ This is another reason why law is complicated; it cannot be reduced to a complete system of formal rules without distortion or sacrifice of core values. Lawyer are not only attentive to appropriate contexts for application of basic norms, but understand that defining those contexts is an activity that cannot be performed mechanically or deductively. Rather, it grows out of our considered judgments about the right result in particular cases and an attempt to justify those results by reference to underlying principles. This form of reasoning may seem irrational to those who identify reason with logical, mechanical, or deductive forms of analysis. But these are not the only analytical methods available to us, as I explain in the next sections.

\section{\$3.2.3 Narrative matters}

Lawyers are better aware than most (but not all philosophers) ${ }^{94}$ that we understand both social context and social values partly by narrative techniques. In deciding how to handle any particular case, lawyers begin by telling the story. Every judicial opinion starts with a recitation of the facts essentially a narrative. Lawyers are trained to describe the relevants facts in a manner that unites the facts and the law so as to highlight which facts matter, what social roles the parties are occupying, the nature of their relationships, and the history of the dispute. How one tells the story may affect how one understands the relative importance of competing considerations, facts and values, as well as the morality, justice, fairness, and ultimate justifiability of alternative courses of action. Lawyers understand that the construction of narrative is part of the way we reason morally. Narrative is part of the way we understand and judge relationships, actions, causes and effects; it is a large part of the way we assign responsibility. ${ }^{95}$

93 See Anderson, Value in Ethics and ECONOMics, supra note 3, at 30 ("No adequate interpretation of a way of valuing something can reduce its motivational component to a desire or preference that some states of affairs occur. They must be brought about in the right ways, by the right agents, in the right context... Whether desiring, aiming at, or achieving a given state of affairs adequately expresses the right attitudes toward people and things depends on the context that determines its expressive meaning.").

94 See Toulmin, supra note 20, at 123 ("In place of abstract universal concepts, practical disciplines focus on particular episodes. Convincing narratives have a kind of weight that mathematical formulas do not.").

95 See Toulmin, supra note 20, at 124 ("Despite all the subtlety and depthy they display in abstract general terms, the conclusions of a book like John Rawls's Theory of Justice provide no 
If this is true - that telling the story is a part of how we reason morally then it cannot be true that we could apply the law simply by identifying principles, deducing specific rules, and applying those rules in a manner that is relatively mechanical. There is no decision procedure for creating an appropriate narrative.

Consider the infamous Kelo decision, in which the Supreme Court found no constitutional bar to a city's taking property in a proposed development area by eminent domain and transfering parcels to private developers who would remake the neighborhood so as to create jobs, increase the value of the land (and hence property taxes needed to pay for schools, fire, and police protection), and promote economic development in a depressed municipality. ${ }^{96}$ Critics attacked the decision by arguing that it made every person's property vulnerable to being taken at any time. They argued (wrongly but fiercely) that this decision would allow any city to take anyone's house and transfer it to someone else who the city thought would use the property better. More importantly, the critics emphasized that this power would be (and was) used to displace lower income families and replace them with either richer families or big businesses. It even would allow (and had in the past allowed) urban renewal, whose effect if not purpose was to displace African Americans and replace them with white people.

The defenders of the decision had a very different narrative. They told a story about a depressed municality suffering from economic stagnation, a declining job base, decreasing property values with resulting reductions in property taxes, leading to inadequate funding for public services which in turn led to poor public schools and the flight of the middle class. Each of these conditions fed the others leading to a downward spiral that was hard to stop. Because property taxes pay for most city services, the municality had few options to improve the situation. The state had the power to help but it was indifferent to the suffering occurring in less wealthy communities like New London. The story was one of a powerful but indifferent state and a relatively powerless municipality. To respond to the indifference of state authorities, the city had no choice but to use the one power it had - the power to shape land use to revitalize the local community by bringing in new business, new jobs and thereby increasing property values and taxes to improve the increasingly inadequate public services. Redevelopment of the city would revitalize the economy, create jobs and improve public services.

effective criteria for settling real-life disputes in actual cases."); Dennis M. Patterson, Law's Pragmatism: Law as Practice \& Narrative, 76 VA. L. REV. 937 (1990) (explaining the centrality of narrative to legal reasoning).

${ }^{96}$ Kelo v. City of New London, 545 U.S. 469 (2005). 
Adequate compensation of the displaced owners would enable them to buy comparable replacement housing in the city, perhaps even in the same neighborhood. Displacement of owners who did not want to move was indeed a bad thing but the city's options were limited. By refusing to sell her land or allow it to be taken by eminent domain, Suzette Kelo was vetoing the only plan likely to alleviate the suffering of others in the city. Limiting the city's eminent domain power would condemn everyone in the city to deteriorating conditions, limited prospects, and stifled opportunities.

Competing narratives are one of the main ways lawyers debate the nature of the problem that has to be solved. It is also a major technique for clarifying the norms underlying social relationships and the contours of institutions. Determining the appropriate story is one of the ways we come to understand the meaning of the dispute, as well as the appropriateness of applying particular rules to particular social contexts. ${ }^{97}$

\section{\$3.2.4 Practical reason can handle incommensurable values}

Lawyers recognize that we have plural, incommensurable values and we generally hold to a form of practical reason to decide hard cases in a pragmatic manner. The stance most of us take toward normative argument rests on several observations. First, we are aware that we have multiple values and that these values often conflict with each other. ${ }^{98}$ Second, after long experience in applying norms of fairness and welfare to human conflicts, most of us find it entirely unlikely that anyone will ever construct a metatheory that reduces all human values to a single metric or master value, such as autonomy, pleasure, or happiness. Practicing lawyers are acutely aware that we cannot, without distortion, flatten all distinctions of worth or quality by representing all normative considerations as instantiations of a single supreme value. ${ }^{99}$ And it is an even greater distortion of our values to try to quantify everything of value. Third, for the most part, lawyers are not

97 See Toulmin, supra note 20, at 133 (individual cases in all their particularity cannot be simply 'deduced from' universal and general principles of a theoretical kind: at best, theories can be required to 'make sense of the ways in which we succeed in dealing with particular cases. Theory (so to speak) is not a foundation on which we can safely construct Practice; rather, it is a way of bringing our external commitments into line with our experience as practitioners.").

${ }^{98}$ On incommensurable values, see RICHARDSON, supra note 5, at 89-118.

${ }^{99}$ On "limited moral pluralism," see Timmons, MORAL TheOrY, supra note 20, 189-208. On the nature of plural goods, TAYLOR, PHILOSOPHY AND THE HUMAN SCIENCES, supra note - at 230247. 
attracted by the fantasy that we can use abstractions to dissolve complexity. ${ }^{100}$ Norms such as liberty are too abstract to decide hard cases. Finally, we consider it unlikely that anyone will ever identify rigid priority rules to adjudicate among plural values. We have seen too many cases where a change in the situation in which a rule is operating causes us to distinguish the case and create an exception to the presumptively applicable rule. At the same time, despite our recognition of the complexity of our moral lives, most lawyers stand with those philosophers who argue that it is possible to make considered, reasoned judgments in the face of plural values. We hold to a form of practical reason or rough-and-tumble pragmatism.

To think clearly about the normative implications of rule choices, we make qualitative distinctions among different kinds of human interests. ${ }^{101}$ To do this, we must characterize the interests at stake in social disputes. ${ }^{102}$ Consider the question of whether landlords should have a duty to mitigate damages when tenants breach lease agreements. Assume a law student living in Cambridge, Massachusetts signed a year long lease lasting from September 1, 2007 to August 31, 2008. In January 2008, the student gets a job offer at a law firm in New York City. The lease prohibits subletting. The tenant asks the landlord for permission to sublet the apartment over the summer or the right to get out of the lease obligations. She wants to move to New York and wishes not to pay two rents during the summer months (the rent at the Cambridge apartment and the rent at her new New York apartment). The landlord refuses, the student takes the job in New York and stops paying rent on the Cambridge apartment, and the landlord waits until the end of the summer to sue the tenant for back rent, even though the landlord could have mitigated damages easily by allowing her to sublet the Cambridge apartment for the summer or by himself finding a replacement tenant for those months. Must she pay the summer rent for the Cambridge apartment to the landlord?

100 See FogEgLin, supra note 1, at 66 ("contradiction and other forms of incoherence can...arise because we, as human beings, lead complex, multisided lives carrying commitments that cannot be resolved into a coherent unity without severe loss.").

101 See Anderson, Value in Ethics And Economics, supra 3, at 66-73 (discussing the difference between qualitative and quantitative methods of evaluation). See id. at 72 ("I claim that it makes sense to value different goods in different ways and that we have little idea of what human life could be if it did not engage in social practices that supported different ways of valuing things."). Accord, Benjamin Zipursky, Pragmatic Conceptualism, 6 LEGAL THEORY 457 (2000) (developing a pragmatic approach to conceptual distinctions).

102 See Anderson, VAlue In EthiCs AND ECONOMiCs, supra note 3, at 70-71 (arguing that "[t]wo goods are incomparable in intrinsic worth if they are not candidates for the same mode of valuation" and that "[a] practice is degrading when it expresses a lower valuation of something than it merits"). 
If the landlord has a duty to mitigate damages, then the answer is no; the landlord could have avoided the damages entirely and so should recover nothing. If the landlord has no duty to mitigate damages, then the answer is yes.

One way to address this question is by reference to efficiency concerns, using the notion of "efficient breach." This analysis assumes that the value of the lease can be reduced to economic terms and that the only question is one of price. The landlord bargained for a certain rent, paid monthly; the tenant promised to pay this rent in exchange for the right to live in the apartment for one year. If the landlord's only interest is in the economic value of the lease, then the duty to mitigate damages (arguably) protects that interest fully, while allowing the tenant to maximize her welfare by moving and promoting the interests of the summer subletter who wanted access to the apartment for the summer. The result is Pareto optimal; the landlord is made whole (economically) while everyone else is better off as well (including the tenant, the subtenant, the new employer, and the new landlord in New York).

Not so fast: the economic argument could be turned around. The landlord bargained for the right to monthly rent payments from this tenant for a year. The contract is an annuity; a right to receive a particular income from a particular person for a particular period of time. The landlord may have interests in getting the money from this particular tenant, not others to whom the tenant might transfer her obligations or others that the landlord could find to replace her. Why might the landlord be interested in locking in this tenant to the contract? First, the landlord may not want the hassle of looking for a new tenant twice a year (in September when new students move to town and in June when those students leave and others move into town for the summer). Second, the landlord may believe he has found a creditworthy tenant and wants to take advantage of her ability to pay rather than facing the vulnerability of dealing with a third party whose credit or track record is not so clear. If we characterize the landlord's interest in this way, we may say that the landlord has a property right in the tenant's promise. The landlord owns the right to get a monthly payment from this tenant - an obligation the tenant voluntarily accepted in a freely-negotiated agreement by signing a lease that contained a "no subletting" clause and which had a one-year term. The tenant is not free to move without the consent of the landlord unless she is able to pay double rents for the summer months.

But this raises a crucial question. Is the landlord's interest in getting the money from this particular tenant a legitimate one? One view is that the interest is legitimate if the landlord has it; on an anti-paternalist theory, we should defer to the landlord's preferences, whatever they are. But a 
competing theory would describe the landlord's preference differently, and do so in a manner that implies a moral judgment. Assume that most tenants cannot afford to pay double rents and that the landlord knows this; if that is the case, the landlord is seeking to control the tenant's behavior by coercing the tenant to stay in Cambridge over the summer and turn down the job in New York. Another way to put this is that the landlord is seeking to tie the tenant to the land. If we characterize the landlord's interest in this way, it appears illegitimate; the landlord is seeking to act like a feudal lord, asserting too much power over his "tenant" and treating her like a vassal rather than a person entitled to control her own life - control that requires mobility rights and the freedom to change jobs.

This example shows several things. First, normative considerations enter into our conceptualization of the interests at stake in legal disputes. We may characterize those interests in different ways. Second, it is not possible to reduce all values to equivalent units without distortion of those normative concerns. Lawyers understand that we have plural values and that it is a distortion of those values to characterize them as embodying a single value like utility, happiness, or even "respect." Third, we can and do make judgments about the legitimacy of individual interests. Another way to say this is that we judge preferences and determine some of them to be out of bounds. How then do we compare competing values if they are incommensurable in the sense that they cannot, without distortion, be reduced to a common metric?

Many philosophers seek theories that dissolve incommensurabilities by appealing to higher order norms or metatheories that provide rational priorities among competing values. Lawyers and judges and law makers, on the other hand, are rarely beguiled by monistic theories. We make utilitarian arguments; we talk about rights, justice, fairness; we are concerned to define the appropriate institutional role for judges in a free and democratic society; we tell the story; we resort to process to solve substantive problems. Moreover, we are skeptical about the ability of rigid priority rules to determine just outcomes in specific cases. In short, we use multiple normative strategies, unashamed that we are unable to find killer arguments that put all normative controversies to bed or that we are borrowing from warring traditions.

Lawyers are realistic; we do not expect debate to end or normative argument to be resolved. We know that it is possible to compare values in the context of particular cases, to consider thoughtfully the appropriate "balance" between the competing values, and to reach a considered judgment without 
applying a formulaic or algorithmic decision procedure. ${ }^{103}$ We are comfortable with an "all-things-considered" approach and do not conclude that this makes decisions irrational or indefensible. We accept this muddled situation because we must. The case must be decided; endless debate is not possible. But we also accept it because we need all the tools at our disposal to help us accomplish this task of deciding and giving reasons for the decision. Lawyers and judges do not have the luxury of ideological purity; the inability of philosophers to come to agreement after thousands of years of normative argument means that lawyers cannot simply pick one normative approach over others and fail to listen to other types of arguments. We use what we have. ${ }^{104}$

Legal judgments are essentially based on practical reason. ${ }^{105}$ As in other uses of practical reason, the process of coming to a conclusion about the right thing to do requires judgment; conclusions are not derived mechanically from a logical decision procedure. Multiple factors are taken into account. No theory that purports to choose applicable principles by deductive reasoning or application of a mechanical decision procedure will ever be adequate for helping judges adjudicate disputes or do their job of making, interpreting, and enforcing law. We can reason about values, and give reasons for our decisions, even though we do not have metatheories that reconcile all conflicting values under a common decision procedure or metric or that fit them to preconceived rigid priority rules. Indeed, lawyers know that judgment based on multiple factors and various suitably impartial but non-mechanical decision procedures is the only rational way to make decisions in the face of multiple values. ${ }^{106}$

\section{$\$$ 3.2.5 Justification constrains judgment: the art of talking to the loser}

Lawyers are aware that the process of justifying decisions publicly can constrain choice even if our reasoning processes require the exercise of considered judgment rather than application of an algorithmic decision procedure. Judicial opinions therefore play a crucial role both in helping judges think through the normative issues at stake in particular cases and in

\footnotetext{
${ }^{103}$ See RiCHARDSON, supra note 5, at 271-308.

104 The notion that moral reasoning is based on plural basic values and that many moral choices are not determined by those basic values is recognized by some moral theorists. See Timmons, MORAL THEORY, supra note 20, at 267-272.

${ }^{105}$ For a description and defense of practical reason, see Anderson, Pragmatism, science, and moral inquiry, supra note 36, at 14-22.

${ }^{106}$ RICHARDSON, supra note 5, at 292-307.
} 
limiting judicial discretion. Cases arise not only when lawyers seek to enforce their clients' rights under existing law, but when lawyers call the attention of judges to gaps, conflicts, and ambiguities in the law. In justifying one interpretation of the law over another, the judges must both acknowledge the ambiguity that gave rise to the need for a judicial decision and explain its resolution in a manner that attempts to show how the decision is consistent with existing rules (precedent) and promotes justice. This may, of course, require the existing rules to be reinterpreted or changed if justice so demands. The end goal of this process is to explain to relevant audiences the reasons that justify the resolution chosen by the judge. From the standopoint of normative support, the main audience for the decision is the losing party. If the moral impulse is based on the felt need to give reasons that others can accept, then the core function of the justificatory judicial opinion is to explain to the loser why the law favors the interests of the other party over her own. The obligation to give such reasons has significant constraining effects on the decision itself.

Judges both defer to existing rules and shape them. In general, we want judges to enforce laws passed by the legislature and, when enforcing common law rules, to treat like cases alike while showing equal concern and respect for all persons. But judges have power to decide the cases before them; what, short of impeachment, constrains their exercise of power? The usual answer is that we want judges to follow the rule of law; they should apply the law rather than make it. But lawyers know that this answer is woefully inadequate. Ambiguous statutes require interpretation. Constitutional rights render some statutory provisions void. Common law evolves with changing social values and conditions, and the process of applying the rules in force involves human judgment. Considered by itself, we cannot know what a precedent means. It must be situated in context, and given its appropriate scope, meaning, and force by reference to considerations of utility, rights, social policy, or other normative considerations. Judges must determine the scope of existing rules by deciding when and how to distinguish cases, create exceptions, or apply competing rules or principles.

Although rules do have significant constraining power on judges, they are well versed in how to escape the clutches of those rules. For that reason, I believe the greatest constraining force on judges is not the abstract injunction to follow the law. The biggest check on the arbitrary or oppressive use of judicial power is the duty to give public reasons for their decisions, justifying their choices by writing judicial opinions. ${ }^{107}$ The giving of reasons does have

107 See RAWLS, Justice AS FAIRnESS, supra note 11, $\$ 9.2$ at 27-28 (noting the public justifications are "addressed to others who disagree with us" and "appeal[ ] to beliefs, grounds, 
a significant constraining effect on what judges do.

Lawyers are also acutely aware that judicial judgments do not take place arbitrarily or in an unconstrained manner. Numerous constraining factors limit the actions that judges feel appropriate in particular cases, including role considerations, conceptions of democracy and fundamental rights, the social and historical context in which disputes arise, as well as the numerous normative arguments that influence how judges rule in particular cases. Judges have the peculiar experience of being responsible for making important choices in a manner that is not mechanically determined by superior authority or existing principles while also feeling hemmed in by various constraining factors that very significantly limit their discretion. ${ }^{108}$ The ultimate truth about the judge's lawmaking role is the need to exercise judgment, not on a blank playing field, but in a field of hedging forces.

I have taught a seminar on the Supreme Court for about fifteen years. The students discuss cases being decided in the current term of the Supreme Court, read the briefs, and vote on what they would do if they were on the Supreme Court. After the initial discussion and vote, one student is assigned to write a proposed majority opinion. Every time I have taught this course, at least one student changes her mind about how to vote once she starts trying to write the opinion. It is sometimes the case that she finds that she cannot rule the way she wanted without overruling too many cases, and her conception of the judical role makes this problematic. More common is the problem of answering counterarguments. I insist that the opinion writer explain the strongest arguments on the other side and answer them. When

and political values it is reasonable for others also to acknowledge"); id. $\$ 9.2$, at 28 ("For justice as fairness to succeed, it must be acceptable, not only to our own considered convictions, but also to those of others...”). See Charles Larmore, The Morals of MODERNITY 8, 12 (1996) (locating moral justification in the human practice of "reflection upon reasons for belief and action" and arguing that "[i]n modern ethics, the expectation of disagreement [on the nature of the good life] has turned attention toward a core morality on which reasonable people... can nonetheless agree."). See also id. at 96 ("Moral knowledge is ... best understood as one species of the reflective knowledge of reasons rather than as a kind of perceptual knowledge."). See also generally KORSGAARD, supra note 62; SCANLON, supra note 62 , at 4 . See also RAWLS, JUSTICE AS FAIRNESS, supra note $11, \S 6.5$, at 17 (arguing that the "principles of justice the parties [in the original position] would agree to ... would specify the terms of cooperation that we regard-here and now-as fair and supported by the best reasons.") (italics added). On the ways in which reason giving constrains judgment, see Nussbaum, Valuing Values, supra note 64, at 209-

${ }^{108}$ Duncan Kennedy, A Critique of Adjudication: fin de siĖcle (1997); Karl Llewellyn, The Common Law Tradition: Deciding Appeals 19-45 (1960) (describing "steadying factors" that constrain judicial discretion"). 
the student cannot come up with a good answer to a counterargument, she often reverses the outcome, trying out what it would be like to rule the other way, justify the result, recite the strongest counterarguments and then answer those counterarguments. My insistence on stating the other side's arguments and responding to them sometimes forces the student to switch sides. And often this happens more than once. I have had years when six of the twelve students reversed themselves after trying - and failing - to write the opinion the way they initially voted.

It is the giving of reasons that could be plausibly made to all affected parties that may be the strongest discipline on judicial decisions. Reasons must be given to lower court judges to explain what they are expected to do; reasons must be given to the general public, to the legal profession, to the press. But most important, respect for human dignity requires above all else that reasons be given to the losing side - reasons the judge believes the loser could or should accept. And those reasons turn out to be based overwhelmingly on normative considerations. Sometimes the judge explains that the losing party's interests are illegitimate, at least in the context of the case at hand; at other times, the judge acknowledges the legitimacy of those interests but explains why, in this kind of case, the other side's interests should prevail over the losing party's interests. This kind of argument is inevitably normatively charged. Lawyers and law students therefore need to know the available frameworks and vocabulary for engaging in normative argument - especially normative argument about considerations of fairness, justice, morality, and the basic values of liberty and equality underlying the contours of a free and democratic society that treats each person with equal concern and respect.

\section{$\$ 4.0$ NORMATIVE METHODS FOR LAWYERS}

What are the normative methods used by lawyers? I will identify the most commonly used normative methods used by lawyers and judges in choosing and justifying laws on the basis of their morality, fairness, justice, or compatibility with the framework of a free and democratic society that treats each person with equal concern and respect. There are four stages to normative argument, involving somewhat different tasks: (1) orientation (adopting basic assumptions about human nature, society, and the good; framing the question presented; telling the story); (2) evaluative assertion (identifying legitimate human interests, needs, and wants that count as human values or moral demands); (3) contextualization (interpreting conflicting values in a manner that renders them consistent by identifying the 
situations to which the values appropriately attach); and (4) prioritization (resolving conflicts among values by suitably impartial decision procedures).

My purpose here is not to give a full account of each of these methods, nor to consider the complexities in using each of them. I hope merely to bring to consciousness the fact that we have such methods, what their contours are, why they count as a form of practical reason (rather than being merely arbitrary) and some examples that show how they work. All these approaches should be familiar to any student who has attended law school. For that reason, some of what appears here may seem obvious and my invocation of these methods appear naïve. However, I have tried to show in the earlier part of this article why articulating these normative methods is important and needed. The prevailing approaches suggest that normative argument about fairness and justice is either pointless or obfuscatory. I seek to show that, on the contrary, normative methods are available, important, helpful, and, indeed, necessary to adjudicating cases fairly and wisely. While moral arguments can be used to justify oppressive interferences with individual liberties, it is also true that the refusal to judge preferences and interests can also lead to oppression if satisfying those preferences enables some to exercize illegitimate power over others. Oppression is as much a danger either way. Morality and justice-based arguments are therefore both unavoidable and necessary to shape the contours of the legal framework of a free and democratic society. We have various resources for thinking through and justifying rule choices based on their fairness, morality, and justice and bringing these methods to light can help both law professors and law students recognize what these methods are and allow us to develop better ways of analyzing and justifying the values underlying the rule of law.

\section{\$4.1 Orientation}

\section{\$ 4.1.1 Background understandings}

The first step in normative argument is to orient ourselves in a moral universe. Most of this orientation occurs unconsciously and is reflected in assumptions of which we may not even be aware. In debate about the right way to deal with a dispute, we often find competing orientations, including different assumptions about human nature, the good society, social relationships, the right way to think about justice, as well as the right way to view the facts. Charles Taylor has called these fundamental assumptions 
"social imaginaries"109 or "background pictures" that inform and frame our conceptions of social life and human relationships. ${ }^{110}$ Importantly for law, background understanding shape our conceptions of the legal framework of a free and democratic society. ${ }^{111}$ Taylor has also argued that it may sometimes can help to "articulate" our "background assumptions" so that we can be more reflective about their validity or defensibility. ${ }^{112}$ Similarly, Henry Richardson argues that "[w] hen people differ radically over what they take to be axiomatic, it is likely that they also arrived at these beliefs through strikingly different tacit exemplars." ${ }^{113}$ He further explains: "Tacit exemplars resist rational deliberation because it is difficult to become fully aware of them. Their influence in giving life to the terms we use and the views we hold is so pervasive that it is very difficult to bring them all to consciousness, let alone to obtain a critical perspective on them."114

Consider the well-known case of State $v$. Shack. ${ }^{115}$ A doctor and a lawyer enter a farm to provide government-funded medical and legal services to migrant farmworkers who were living and working there. The farm owner refuses to let them see the workers in the privacy of their barracks; instead, the farmer offers to have the meetings conducted in his offices while he watches and listens. The service providers refuse to agree to these conditions and the farmer orders them to leave his land. They refuse and are arrested for criminal trespass. They then move to dismiss the charges on the ground that they had a right to enter the land to provide government-funded services to the farmworkers who wanted to receive such services. How should the decision maker think about the case?

The farmer would argue that the case can be resolved by asking a simple question: who owns the land? The farmer will argue that he does and that owners have the right to exclude non-owners; the defendants' refusal to leave after he asked them to do so violates his property rights. Nor did the farmer

\footnotetext{
${ }^{109}$ Charles Taylor, Modern Social Imaginaries (2004).

110 TAYLOR, SOURCES OF THE SELF, supra note 7, at 3-4, 8.

111 See Singer, Things that We Would Like to Take for Granted, supra note 54.

112 TAYLOR, SOURCES OF THE SELF, supra note 7, at 8-11; see id. at 34 (arguing that "articulation" involves "try[ing] to increase our understanding of what is implicit in our moral and evaluative language"); see id. at 41 (discussing the need to "explore the background pictures which underlie our moral intuitions"). See also Charles Taylor, Leading a Life, in INCOMMENSURABILITY, INCOMPARABILITY, AND PRACTICAL REASON 170, (Ruth Chang, ed.)(1997).

${ }^{113}$ See RICHARDSON, supra note 5, at 271.

114 See RichaRDSON, supra note 5, at 292.

115277 A.2d 369 (N.J. 1971).
} 
waive his right to exclude in his employment contracts with his workers when he hired them; he did not give the workers a right to meet with outsiders on the farmer's land. The farmer's perspective, as I have presented it, rests on a set of background assumptions about the nature of property and contract, as well as conceptions of individual rights and liberties and what it means to live in a free and democratic society. We might call this framework a libertarian social vision.

The libertarian imaginary rests on powerful and perhaps even unconscious assumptions about the nature of both property rights and state power. It assumes, for example, that land can (and should) be owned by individuals; that each parcel of land has a single identifiable "owner"; that owners have absolute powers to control their land, including the right to exclude others; they they may exclude others for any reason, including a bad reason; that ownership rights protect individual interests in autonomy, privacy, and security and thus cannot be limited by law except in extraordinary circumstances; that owners can waive the right to exclude by allowing others to enter their property; that entry can be conditioned on terms chosen by the land owner; that business property is no different from residential property; and that government workers have no greater claim (and perhaps a lesser one) than private individuals to enter private property against the will of the owner. The libertarian framework also assumes that existing property rights have a just origin so that the exclusionary claims of existing owners are legitimate. Or it assumes that any unjust origins are so far in the past as to be irrelevant from a moral point of view as applied to current ownership claims. ${ }^{116}$ This set of assumptions is easily understood by members of our culture in the United States and they are associated with a particular conception of property that understands the "owner" as the sovereign of a castle with absolute power inside clear boundaries. ${ }^{117}$

Recognizing that the farmer's argument is based on a particular set of assumptions about social relationships, the meaning of property and liberty, and the proper relationship between sovereign powers and individual rights allows us to begin to question those assumptions and subject them to critical analysis. For example, while it is true that owners generally have the right to exclude non-owners from their land, this is only generally true. This, and all the other assumptions captured by the libertarian framework are either overstated or wrong. Owners do not have absolute rights; rather, property

\footnotetext{
116 See Joseph William Singer, Nine-Tenths of the Law: Title, Possession, and Sacred Obligations, 38 ConN. L. REv. 605 (2006).

117 Joseph William Singer, The Ownership Society: Regulatory Takings and Just Obligations, 30 HARV. ENVTL. L.J. 309 (2006).
} 
rights are limited to protect the personal and property rights of others. Nor are property owners perfectly free to place any conditions they like on those who enter their land. Neither are business owners subject to the same rules as are the owners of other kinds of property, such as homes. The farmer could not, for example, refuse to hire a worker because of his race even though you can choose your friends based on their race if you wish and deny entry to your home on a racial basis.

In addition, the farmer is too quick to assume that the ownership rights are all on his side here. Tenants have the right to receive visitors in their homes; landlords are not entitled to prevent their tenants from having friends over for dinner. This right is so well accepted that few precedents establish it. It is assumed that the transfer of possessory rights gives the tenant the ability to create a home and that it is a necessary part of that right to form human relationships with family, friends, and neighbors and to receive them as guests in your home. It is a contested question whether farmworkers in barracks have the status of tenants. If they do, then by inviting the workers to live on his land, the farmer has waived the right to exclude the defendants if the workers want to receive them in the barracks. In other words, it is the farmworkers - not the farmer - who own the right to determine whether these visitors are allowed in the barracks or not; by interfering with their right to receive visitors, it is the farmer who is interfering with the property rights of the workers, not the defendants who are interfering with the property rights of the farmer.

Even if the workers do not have the status of tenants, the libertarian conception wrongly assumes that property rights are never limited to protect the legitimate interests of non-owners. The doctrine of necessity allows individuals to enter the property of another to save a human life; thus, no trespasses occurred when New Orleans residents took refuge in their neighbors' homes during Hurricane Katrina to escape from the flood waters. Federal and state legislation provides assistance to migrant farmworkers because of their vulnerable status and their isolation from the broader community. The owner has rights but so do the farmworkers; by claiming a right to exclude here, the farmer seeks to exercise his property entitlements so as to deprive his workers of the ability to get benefits to which they are legally entitled. Rather than exercising his own property rights, the farmer is arguably abusing his rights to prevent others from taking advantage of what they are entitled to claim - in other words, of what they own. Indeed, the Supreme Court of New Jersey ruled that migrant farm workers housed in barracks have the same rights to receive visitors as do tenants in apartments - 
regardless of what the contract says. ${ }^{118}$ The farmer may be the owner of the land but by entering a contract that allowed his workers to live on his land, he parted with some of his ownership rights, and, according to the Supreme Court of New Jersey, it is the workers, not the farmer, who have the right to receive or turn away guests in their living quarters.

\section{\$4.1.2 Framing the question}

A second way lawyers orient themselves and decision makers is through framing the question presented. ${ }^{119}$ The farmer asks: who owns the land? The doctor and the lawyer will want to frame the issue rather differently. They will reverse the valence and put the onus on the farm owner to justify his actions. Instead of asking who owns the land, the defendants might ask, for example, "don't people have the right to receive visitors in their homes?" Just as the farmer's question suggests its own answer, this question also suggests its own answer, but this time in favor of the defendants. Alternatively, the defendants might ask whether the farmer is entitled to stop the government from providing services to needy people. Imagine, for example, how a judge would react if the farmer prevented an ambulance from entering his property to reach an injured worker who needed to be taken to the hospital. Could his right to exclude prevent the entry of the ambulance? Of course not.

Various methods can be used to reverse the burden of persuasion - to put the onus on the other side to justify the ways in which their actions impinge on the legitimate interests of the other side. The libertarian framework assumes, for example, that oppression comes when government officials restrict liberty or interfere with property rights. Conversely, if a person is exercising his rights (especially property rights), he cannot, by definition, be oppressing someone else. This worldview assumes that the ownership of property and the exercise of property rights (including the right to exclude) are self-regarding acts. ${ }^{120}$ Others have no legitimate interest in telling you what to do on your own land. If this is true, exclusion of nonowners from one's own land does not harm others because the owner is entitled to exclude non-owners; that is what it means to be an owner. The farmer is doing nothing more than exercising his rights. Since non-owners have no legitimate claim to trespass on land they do not own, trespassers are

\footnotetext{
118 cite

119 See Richardson, supra note 5, at 4 ("There is no uniquely canonical way to phrase a practical question"). For an excellent example of how framing matters, see Robert W. Gordon, Unfreezing Legal Reality: Critical Approaches to Law, 15 FLA. ST. U. L. REV. 195 (1987).

${ }^{120}$ See Singer, Externalities of Ownership, supra note 45.
} 
engaged in harmful, other-regarding conduct. The farmer will suggest that he is causing no harm to anyone while the defendants are invading his castle.

The defendants will frame the question differently. They will take advantage of the legal realist conception that rights protect legitimate interests. This means that the scope of a legal right is determined by the interests it is designed to protect, and those interests, in turn, are defined to exclude illegitimate interests in harming or controlling others or otherwise denying equal liberties to others. The case therefore presents normative questions about the legitimacy and relative strength of the parties' interests in this particular context. This framework makes it obvious that the exercise of a property right is not necessarily a self-regarding act; rather, such an exercise may harm the legitimate interests of others. An owner who uses his property so as to create air pollution is exercising his property rights but doing so in a way that creates externalities on neighboring owners and the community as a whole. An exercise of a property right is not necessarily a self-regarding act. If this is true, then it is not just government officials who can act in an oppressive manner by exercising illegitimate power over others; private property owners may themselves engage in oppressive behavior. Reversing the polarity, the defendants might ask (in the words of the opinion written by the Supreme Court of New Jersey): does an employer have the "right to isolate" his workers and deprive them of "associations customary among our citizens?"121

This way of framing the question reminds us that a free society is not one devoid of the rule of law. We are not perfectly free to do whatever we want. In our political and legal system, some contractual demands are out of line because they fail to treat others with equal concern and respect. ${ }^{122} \mathrm{By}$ preventing his workers from receiving visitors, the farmer is not associating with them on mutually advantageous terms; rather he is seeking undue control over their lives. He is acting like a master and treating them like servants. Far from a Jeffersonian yeoman farmer, he seems more like a feudal lord or a plantation owner who is treating his workers like indentured servants rather than equal citizens. Because we live in a free and democratic society, autonomy is protected by allowing actors to determine the terms of their agreements with others but only so long as they do not violate minimum standards regulations which define what Jedediah Purdy calls legitimate "terms of recruitment" for market relations. ${ }^{123}$

121 These quotations are from the court's decision. See 277 A.2d at 374.

${ }^{122}$ Singer, Things that We Would Like to Take for Granted, supra note 54.

${ }^{123}$ Jedediah Purdy, People as Resources: Recruitment and Reciprocity in the Freedom-Promoting Approach to Property, 56 DUKE L. J. 1047; Singer, Things that We Would Like to Take for 


\section{\$4.1.3 Narrative}

A third way lawyers engage in orientation is through narrative. Every case starts with the facts and the way in which we describe the narrative of what happened can be a powerful tool in helping us figure out the moral of the story. We often come to learn what we think by finding out what happened, by seeing the facts in a certain way. ${ }^{124}$ Lawyers present alternative versions of the facts. We teach students to create a core theory of what is at stake in the dispute, and constructing a story about what happened is a crucial part of this task. Coming to see the case one way or the other is part of how lawyers, judges, and jurors come to decide what the case means. Narrative techniques are not merely matters of strategy; nor are they merely matters of rhetoric. Rather, they are part of the way we reason about moral questions. They help us come to see what matters. Construction of appropriate narratives is a necessary supplement to the generally more abstract methods of moral and political philosophy. Indeed, some philosophers, especially Margaret Urban Walker, have argued that narrative analysis, combined with consideration of responsibilities implicit in particular social roles and relationships, is the best way to reach moral understanding of the situation. ${ }^{125}$

The farmer is likely to start the story by noting that he owns his farm and chose to start a business by recruiting employees to work for him. He was entitled to start a business and run it as he wished. The workers were not forced to work for him and they voluntarily agreed to his terms. Moreover, their freedom to refuse to work for him meant that he had to shape the terms of the contract in a manner that attended to their legitimate interests. The story is a freely negotiated contract between A and B. If the law comes in now with its heavy hand and rewrites the contract, it is only acting

Granted, supra note 54. See also ANDERSON, VAlUe In ETHICS AND ECONOMICS, supra note 3, at 163 ("[L]ibertarians argue that any constraints on people's freedom to alienate their property in themselves are paternalistic violations of liberty... But in democratically prohibiting the market alienation of certain goods embodied in the person, people exercise collective autonomy over the background conditions of their interaction."); Elizabeth A. Anderson, What is the Point of Equality? 109 ETHICs 287 (1999).

${ }^{124}$ See also WESTEN, supra note 15. Trial lawyers are intensely aware of the ways in which both jurors and judges understand cases by constructing the story. See ERIC OlIVER, FACTS CAN'T SPEAK FOR THEMSELVES: REVEAL THE STORIES THAT GIVE FACTS THEIR MEANING 6 (2005) ("It is not the facts, but the stories the decision makers build from and around those facts that create the personal meanings that lead to judgments for and against those listener created stories.").

${ }^{125}$ WALKER, supra note 83. 
paternalistically by interfering in a voluntary and mutually beneficial arrangement.

The doctor and lawyer (and the Supreme Court of New Jersey) told the story differently. Here is part of what the Court said:

Here we are concerned with a highly disadvantaged segment of our society. We are told that every year farmworkers and their families numbering more than one million leave their home areas to fill the seasonal demand for farm labor in the United States.... The migrant farmworkers come to New Jersey in substantial numbers....

The migrant farmworkers are a community within but apart from the local scene. They are rootless and isolated. Although the need for their labors is evident, they are unorganized and without economic or political power. It is their plight alone that summoned government to their aid. ${ }^{\mathbf{1 2 6}}$

Rather than a legitimate agreement among equal citizens who mutually benefit from their deal, the court describes a group that is disempowered and disadvantaged but which serves crucial social and economic functions in the market economy. Indeed, others are wholly dependent on the services that migrant farmworkers provide; we could not live without them. Yet it is not clear that we recognize our dependence on them or what we owe them. Barbara Ehrenreich argues that we should feel

shame at our own dependency; in this case, on the underpaid labor of others. When someone works for less pay than she can live on - when, for example, she goes hungry so that you can eat more cheaply and conveniently - then she has made a great sacrifice for you, she has made you a gift of some part of her abilities, her health, and her life. The "working poor," as they are approvingly termed, are in fact the major phlanthropists of our society. They neglect their own children so that the children of others will be cared for; they live in substandard housing so that other homes will be shiny and perfect; they endure privation so that inflation will below and stock prices high. To be a member of the working poor is to be an anonymous donor, a nameless benefactor, to everyone else. ${ }^{127}$

Rather than asking to left alone on his land, the farmer is asking for the right to isolate the workers, to deprive them of government services intended for their benefit, and to deny their "opportunity to live with dignity." ${ }^{28}$ Quoting

\footnotetext{
126277 A.2d at 372.

127 See Barbara Ehrenreich, Nickel and Dimed: On (Not) GetTing By in America 221 (2001).

${ }^{128} 277$ A.2d at 374.
} 
from a government report, the court notes that "'no trespass' signs represent the last dying remnants of paternalistic behavior." ${ }^{129}$ By denying the workers access to government services, the court suggests that the farmer was acting like a feudal lord or plantation owner, treating the workers like servants when all they ask is to be treated with equal concern and respect. This is not a story of a property owner asking to be left alone on his own land or an individual seeking protection from invasion of his property by the government. Rather, it is a story of a heartless employer who denies his employees basic services that he himself enjoys and takes for granted, subjecting them to harsh conditions and social isolation.

\section{$\$ 4.2$ Evaluative assertion}

\section{S4.2.1 The argument from humanity (dignity)}

Whether we are presented with alternative orientations or a question of what to do within an agreed orientation, we then face the task of justifying one orientation or outcome over another. Normative argument both within and between orientations depends on what Mark Timmons calls evaluative assertions - statements about the right way to act which contain built-in moral judgments. ${ }^{130}$ Timmons argues that moral claims are "assertions" in the sense that they can be right or wrong, true or false. Moral realists argue that such claims are based on "moral facts" that can be discovered by the use of introspection or reason or observation. Moral irrealists, like Timmons, argue that truth or falsity of moral claims does not rest on correspondence with moral facts out there in the world; rather than being descriptions of external facts in their world, moral assertions are evaluative judgments designed to guide conduct. Value judgments are not descriptions of some ultimate reality. Rather, they are claims we make on each other. Our inability to rest those claims on incontrovertible foundations outside human will does not deprive them of their value for human life; if we accept them, they can be used as contextually basic foundations for normative argument. ${ }^{131}$ Thus

\footnotetext{
129277 A. 2 d at 373.

130 Timmons, Morality without Foundations, supra note 58, at 6. See also Anderson, Pragmatism, science, and moral inquiry, supra note 36, at 21-22 ("the question of what is good and right is largely answered by articulating the field of thick evaluative concepts in terms of which we ought to describe, discriminate, and experience ourselves and the world").

131 See Timmons, Morality without Foundations, supra note 58 passim. See also RICHARDSON, supra note 5, at 203 ("Any end that stands firm on reflection can be accepted as a ground of justification"); Terry Horgan \& Mark Timmons, Morality Without Moral Facts, in
} 
Timmons argues that "[ $\mathrm{t}]$ he content of 'Apartheid is wrong' is apartheid is wrong." 132 The assertion that conduct "is wrong" is based, not on divine will or natural law but on a human judgment about defensible human conduct and the appropriate contours of social relationships.

How does normative argument begin? It arguably begins when we feel a need to justify ourselves to others; this usually occurs when we engage in action or make a claim that affects others. According to one legend, morality began when God asked Cain: "What have you done?" מה אשתה (ma asitah) The call to justify yourself may come from outside or inside; the pull may be external (a literal question from others) or internal (a felt need to justify ourselves). The Cain story rested on the idea that one had an obligation to defend oneself to God - a pretty heavy duty. The secular version of the story is the idea that one must be attentive to other human beings, simply because they are human. ${ }^{133}$

This felt obligation comes from a fundamental premise or assumption: human beings are entitled to be treated with dignity and respect. This normative impulse is different from the teleological argument offered by Hobbes; he suggested that it is in our self-interest to create a government that limits our freedom of action, enabling us to obtain security and avoid the violent death that may come from anarchy. ${ }^{134}$ The normative impulse I am describing is based, not on self-interest, but on the sense that human beings matter, that they are of enormous importance, that each person is unique and irreplaceable, that, as Kant put it, they are entitled to be treated as "ends in themselves" and not "merely" as means to satisfaction of the desires of others. ${ }^{135}$ The normative impulse comes from a felt obligation to treat others with equal concern and respect.

The Kantian idea that people are ends-in-themselves entitled to dignity is a secular equivalent of the religious understanding that human beings are

\footnotetext{
CONTEMPORARy Debates IN MORAL TheOry, supra note 59, at 220-238.

132 Timmons, Morality without Foundations, supra note 58, at 147.

${ }^{133}$ See KyMliCKA, supra note 19, at 43 ("human beings matter and matter equally").

134 Thomas Hobbes, Leviathan 227 (C.B. MacPherson ed.)(Penguin Books, 1976)(1651)(government is instituted "to defend them ... from the injuries of one another ... and to secure them in such sort, as that by their owne industrie, and by the fruites of the Earth, they may nourish themselves and lived contentedly ...."). See also id. at 254 ("preservation of life being the end, for which one man becomes subject to another"); id. at 188 ("The Passions that encline men to Peace, are Feare of Death; Desire of such things as are necessary to commodious living; and a Hope by their industry to obtain them.").

${ }^{135}$ KANT, supra note - at 41. For a discussion of Kant's philosophy see generally KORSGAARD, supra note 62; SCANLON, supra note - at 4.
} 
created in the image of God and are therefore of enormous importance and deserve to be treated with dignity. ${ }^{136}$ The liberal corollary to this view is that each person is of equal importance and entitled to equal concern and respect. This insight leads to some version of the Golden Rule, perhaps the central moral principle governing the acceptability of public reasons; the equal moral worth of persons means that one cannot claim something for oneself while denying it to others. It also means that one cannot demand something of others unless one can give reasons that we think they should be able to accept. This in turn is the source of something like Kant's categorical imperative, that an action cannot be justified unless it can be described by a principle that could be accepted as a universal law.

If other people are entitled to be treated as human beings - in other words, humanely - we then should feel an obligation to explain ourselves to others when we make claims or demands on them. It is more controversial to claim that we must account to others when we fail to help them; one area of debate between feminist theorists and others is the extent to which obligations of care are as fundamental to humanity as are obligations of respect (or autonomy). ${ }^{137}$ For now, however, I want to focus on a central impulse, which is a felt obligation to give reasons to others who seek to hold you to account for your actions (or your inactions). Those reasons, in turn, express values. They announce what is important; they say what really matters in human relationships.

But what is the foundation of those values? Philosophers may debate whether these core values have a foundation - in God (Saint Augustine, Thomas Acquinas), in human rationality (Kant), in communicative action (Habermas), in nature (Hobbes, Locke) - or not (Protagoras, Nietzsche, Sartre, Dewey, Wittgenstein all argue in various ways that human values originate in human assertion). Although these philosophical debates are of some use to lawyers, they also may be partially set aside. Whether or not we can say that human values have a firm foundation in something other than human will, we can start with a premise that seems fundamental to our current sense of ourselves: human beings matter.

Certainly lawyers start from this premise. They take for granted that

\footnotetext{
${ }^{136}$ Joseph William Singer, After the Flood: Equality and Humanity in Property Regimes, 52 LoY. L. REV. 243, 307-313 (2006).

${ }^{137}$ Martha Albertson Fineman, The Autonomy Myth: A Theory of Dependency (2005); Carol Gilligan, In a Different Voice: Psychological Theory and Women's Development (1993): Martha Minow, Making All the Difference: InClusion, EXClusion, AND AMERICAN LaW (1991); Nell Noddings, Caring: A Feminine Approach to Ethics and Moral EDUCATION (2d ed. 2003).
} 
human beings are important, that they are of intrinsic and immeasurable value, that they are imbued with dignity and entitled to respect. As someone once said, we hold these truths to be self-evident. Moreover, our current and evolving social norms view every person as entitled to equal concern and respect. This fundamental assumption seems obvious today but it has not always been universally accepted or respected. One need only think about our history of conquest of Indian nations, the slave system, and the historic oppression of women, to understand that it is not a small matter to contend, to believe, and to act on the premise that all human beings are created equal, and that they are entitled to be treated as if their worth had no price.

We can call this the argument from humanity. It both rests on the fundamental worth and importance of each person and the idea that people are entitled to be treated with humanity. Whether it is a universal principle or simply a fundamental assumption of our society is less important than the fact that, at least for us, it is a fundamental assumption. As Charles Taylor explains, we tend to want to give "an account" to explain why we have the intuition that human beings are entitled to "life and integrity."

The account seems to articulate the intuition. It tells us, for instance, that human beings are creatures of God and made in his image, or that they are immortal souls, or that they are all emanations of divine fire, or that they are all rational agents and thus have a dignity which transcends any other being, or some other such characterization; and that therefore we owe them respect. $^{138}$

Whether or not we can agree on a reason for respecting the humanity of individuals, it is a fundamental assumption of our social and legal culture that individuals have an innate dignity that must be respected by others. This belief obviously does not solve normative questions or make them go away. But it does furnish a foundational orientation to thinking about normative questions. It also rules many things out; the argument from humanity works partly by excluding laws that fail to treat persons as human beings. ${ }^{139}$ Indeed, it may well be that this argument excludes a great deal. As Alan Dershowitz and Barrington Moore, Jr. both have argued, there is more agreement about

\footnotetext{
138 TAYLOR, SOURCES OF THE SELF, supra note 7, at 5.

139 TAYlOR, SOURCES OF THE SELF, supra note 7, at 4 ("Perhaps the most urgent and powerful cluster of demands that we recognize as moral concern the respect for the life, integrity, and well-being, even flourishing, of others. These are the ones we infringe when we kill or maim others, steal their property, strike fear into them and rob them of peace, or even refrain from helping them when they are in distress. Virtually everyone feels these demands, and they have been and are acknowledge in all human societies.")
} 
what wrongs we should avoid than on what rights we should protect. ${ }^{140}$ Wrongs can be identified partly by asking what we cannot do to others given their status as human beings. Reminding ourselves that people are entitled to be treated with equal concern and respect itself generates the impulse to give reasons they could be expected to accept. And this, in turn, has substantial constraining effects on what legal rules we can publicly defend.

It does not, however, make the normative question go away. Rather, it may encapsulate the core issue raised by normative dilemmas. For example, in State v. Shack, the Supreme Court of New Jersey found that the entry of the doctor and lawyer onto the farm did not constitute a trespass. The court argued that the workers were entitled to "associations customary among our citizens" and that the farmer had no "right to isolate" the workers by refusing to allow them to receive visitors in their homes. ${ }^{141}$ This argument is premised on the notion that the workers have a right to "live with dignity." ${ }^{142}$ They do not and cannot be made to occupy a subordinate status; they are people, not work horses; they are free, not serfs or slaves. As human beings, they are entitled to certain fundamental rights which others have a duty to respect. "Indeed," the court explained, "the needs of the occupants may be so imperative and their strength so weak, that the law will deny the occupants the power to contract away what is deemed essential to their health, welfare, or dignity." 143

The farmer could answer this normative claim by arguing that he did not force the workers to work for him. They chose to do so and it would deny the farmer dignity if the court tried to control the terms on which he chooses to employ others on his own property. It would also treat the workers as incompetent children to deny them the freedom to contract with the farmers on terms chosen by them. Protecting the owner's free control of his own land and the freedom of all the parties to contract on mutually beneficial terms is the way to treat each person with equal concern and respect, while governmental regulation of property and contract fails to treat individuals as self-governing persons in charge of their own fates.

Both of these sets of arguments depend on the fundamental assumption

\footnotetext{
140 Alan Dershowitz, Rights from Wrongs: A Secular Theory of the Origins of Rights (2004); Barrington Moore, Jr., Reflections on the Causes of Human Misery and upon Certain Proposals to Eliminate Them (1970).

143277 A.2d at 372. On the role of needs in moral theory, see Soran Reader \& Gillian Brock, Needs, Moral Demands, and Moral Theory 16 Utilitas 251 (2004) (explaining the concept of a "morally important need").
} 
that human beings have a special status. They are entitled to be treated with dignity; they are entitled to autonomy (control over their own lives and the freedom to shape their destinies in relations with others). The debate is over the meaning of dignity - not whether human beings should be entitled to be treated with dignity. Human dignity is a foundational assumption upon which all normative argument rests. And reminding ourselves about this fundamental premise may persuade us that one resolution of a case is more just than another.

\section{$\$$ 4.2.2 Asserting values (ought statements)}

If human dignity is at the core of normative argument, how do lawyers operationalize that core value in hard cases? They do so by asking what respect for humanity requires of us. Respect for human beings entails making claims on individuals about proper rules of conduct in their relationships with others. Derived from the fundamental assumption of humanity, these claims amount to moral demands. As Charles Taylor explains, "The whole way in which we think, reason, argue, and question ourselves about morality supposes that our moral reactions have these two sides: that they are not only 'gut' feelings but also implicit acknowledgments of claims concerning their objects." ${ }^{44}$ Value statements begin by identifying human interests, wants, needs, and preferences and then characterizing what is valuable about them. Not all preferences are qualitatively equal. Some are mere tastes while others rise to the level of human values. Values are assertions about right and wrong; they embody judgments about the legitimacy of human interests and they support or undermine claims that people make on each other.

Particular evaluative assertions are specifications, in some sense, of the fundamental argument from humanity. ${ }^{145}$ Many of them will be uncontroversial, although their application in particular cases may well be contested and contentious. These assertions generally are claims at a lower level of specificity that either take the form of statements of "rights" - ways in which we are entitled to be treated by others or ways in which we are entitled to act - or statements of "obligations" - duties we have to others to respect them as human beings. Some of these judgments can be powerful either because reflection on our deepest values generates specific inferences or because those judgments rule certain things out.

The farmer will argue first that he has a right to control access to his own land. As owner of the property, he has no duty to allow strangers onto his

144 TAYLOR, SOURCES OF THE SELF, supra note 7 , at 7.

${ }^{145}$ On specification of general norms and concepts, see RICHARDSON, supra note 5, at 69-79. 
land. Indeed, they have an obligation to respect his autonomy by keeping off the land rather than invading it against his will. In addition, he will argue that he should be free to enter into contracts with his workers on whatever terms he likes as long as he can get them to agree. Individual liberty entails the freedom enter cooperative relationships with others on terms that are mutually beneficial to the parties. The employment contract does not give the workers the right to receive visitors in the barracks; if they wanted such a right they should have bargained for it. As Alan Schwartz has argued, "Individuals have the right to "do the best they can for themselves, given their circumstances." 146 It is a fundamental assault on human dignity to dictate the course of someone's life or to impose the terms of one's associations with others by regulating contracts, thereby depriving individuals of the power to make their own choices, suffer from their own mistakes, and chart the course of their own destiny. If the farmer has too much power in the bargaining process because of his relative wealth, this can be remedied by a "tax-andtransfer" program that increases the workers' bargaining power, leaving the parties' arrangement to a free contract system that best respects individual autonomy and enlarges individual choice.

Ruling that the farmer could not exclude the defendants from his land, the Supreme Court of New Jersey rested its opinion on a different set of evaluative assertions. Chief Justice Joseph Weintraub wrote in the Court's opinion:

$[\mathrm{W}] \mathrm{e}$ find it unthinkable that the farmer-employer can assert a right to isolate the worker in any respect significant for the worker's well-being. The farmer, of course, is entitled to pursue his farming activities without interference.... So, too, the migrant worker must be allowed to receive visitors there of his own choice,... and members of the press may not be denied reasonable access to workers who do not object to seeing them....

$[\mathrm{T}]$ he employer may not deny the worker his privacy or interfere with his opportunity to live with dignity and to enjoy associations customary among our citizens. These rights are too fundamental to be denied on the basis of an interest in real property and too fragile to be left to the unequal bargaining strength of the parties. ${ }^{147}$

These paragraphs contain a remarkable set of evaluative assertions, including (a) it is "unthinkable" that the farmer could "assert a right to isolate the

\footnotetext{
146 Alan Schwartz, Justice and the Law of Contracts: A Case for the Traditional Approach, 9 HaRv. J. L. \& Pub. Pol'y Rev. 110, 114-115 (1986).

147277 A.2d at $374-375$.
} 
worker," although (b) he is "entitled to pursue his farming activities without interference." (c) Nor may the employer "deny the worker his privacy or interfere with his opportunity to live with dignity" or (d) "to enjoy associations customary among our citizens." (e) The workers "must be allowed to receive visitors." These assertions both express and assert values; they describe the shape of a social world that is appropriate to human life; they make claims that can be defended because they describe interests that are entitled to respect by all persons and which therefore constitute appropriate demands on others.

Evaluative assertions often contain words like "should" or "ought." This is because moral claims are demands we feel entitled to make of others and those demands shape allowable conduct. Lawyers need not be ashamed to make arguments that include the word "ought" - as in, tenants ought to be able to receive visitors in their homes. But why? we might ask. Why do tenants have the right to receive visitors? Why not leave this issue to free contract? Why should the law interfere with the marketplace? It is important to remember that these questions frame the issue from a libertarian orientation. We could as easily flip the orientation and frame the question very differently, in a manner that highlights the values that support a ruling for the defendants, i.e., what gives the farmer the right to isolate his workers and deprive them of needed services?

The skeptical stance toward values is what leads law and economics theorists to the idea of deferring to individual preferences, whatever they happen to be, and then using economic analysis to figure out the consequences of alternative rules of law in order to identify the rules that maximize satisfaction of individual preferences. As I explained earlier, the fundamental problem with this normative framework is that it wrongly assumes that all preferences should be satisfied and that all preferences are of equal status. The libertarian assumes that preferences have a prima facie claim to be satisfied. But this is not true; reflection reveals that a free and democratic society is defined by minimum standards for market and social relationships. ${ }^{148}$ Some preferences are out of bounds; some contractual

${ }^{148}$ See Singer, Things that We Would Like to Take for Granted, supra note 54. As Elizabeth Anderson argues:

[D]emocratic institutions are needed to enable people to express certain kinds of valuations that can be expressed only in non-market social relations. Some of the concerns people have as citizens cannot in principle be expressed in their roles as consumers, but must be expressed through their political relations with other citizens. Consumers act individually, taking the background social relations of their interactions 
arrangements are indefensible; some uses of property are incompatible with the legal framework of a democracy and a free people. The assertion of a preference is not a self-regarding act when it involves creating arrangements that affect the legitimate interests of others, especially when those arrangements deny liberty and dignity to others.

But how do we ground the values we identify and assert? One ground is golden rule: would you want to be in a position where you could not receive visitors? The argument from consistency suggests that if you value this, humanity requires you to respect it for others as well. The pragmatic argument suggests that we take for granted the things that no one seriously questions. If we agree that unnecessary cruelty is a bad thing or that children should not be punished for the sins of their parents, or that people are entitled to form attachments with others, we can begin to build moral and legal principles that can serve as the basis for helping us think through harder questions. Evaluative assertions can provide an answer to the "because clause" (expressing and explaining why certain values should be protected) by appealing to the things we in fact already believe. ${ }^{149}$ In Charles Taylor's words, they articulate or bring to consciousness both our background understandings and our strong evaluations. They make us conscious of the underpinnings of our moral lives.

Of course, evaluative assertions do not necessarily decide cases, especially

for granted and generally assuming an instrumental attitude toward these relations. In their roles as consumers, they have little power over the social relations and norms governing their interactions, and hence little scope for expressing intrinsic concerns about their relations in market interactions. Citizens act collectively, taking their social relations as an immediate, intrinsic object of concern. Because these relations are constituted by shared legal, ethical, and social norms, people can reform them only through collective action. People care about the meanings embodied in the social relations in which risks are imposed and controlled, not just about the raw magnitudes and financial benefits of these risks. They also care about the character of their social life... Since people rationally express different valuations in different social contexts, costbenefit analysis deprives them of opportunities to express distinctively non-economic concerns in taking consumer preferences as normative for democratic politics.

Anderson, VAlue in Ethics AND ECONOMics, supra note 3, at 211-212. See also RAWLs, JUSTICE AS FAIRNESS, supra note 11, at 44 ("A free market system must be set within a framework of political and legal institutions that adjust the long-run trend of economic forces so as to prevent excessive concentrations of property and wealth, especially those likely to lead to political domination.").

149 See Richardson, supra note 5, at 300 (the "holistic approach...builds from something that [we] do, in fact, accept"). 
hard cases that involve legitimate interests on both sides. For example, in State $v$. Shack, it can be argued that we have plausible autonomy claims on both sides. At the same time, a decision maker may be able to choose the appropriate characterization of the interests asserted by the parties. Is the farmer, for example, asking for the freedom to manage his own business and enter mutually advantageous contracts or, on the contrary, is he asking for a "right to isolate" his workers and deny them "associations customary among our citizens?" Is he being stalwart in defense of his rights or obtuse in his denial of theirs? The decision maker needs to come to a conclusion about the plausibility of alternative characterizations of the interests asserted in the particular case and assess the legitimacy of the asserted interests as human values appropriate to the situation.

\section{$\$$ 4.2.3 Responsibilities in human relationships}

While normative argument starts with the recognition or belief in human dignity and then moves to more specific evaluative assertions associated with that fundamental value, the elaboration of the meaning of these values for legal relations among persons generally gets its normative shape from conceptualizing the responsibilties arising out of human relationships. Dignity and value claims are often used to assert "rights" but those rights only translate into legitimate claims against others if we can conclude not only that the right-holder has an interest that is prima facie worth protecting through legal control of the behavior of others but that those others are under no conflicting obligations. To come to this conclusion, we have to understand and shape the relationship between the parties. The nature of the relationship will help determine whether one of the parties has a responsibility to act (or refrain from acting) in a certain manner in regard to the right-holder. In the case of Hohfeldian "rights," the question is whether the other party is under a duty to act or not to act, while Hohfeldian "privileges" or liberties impose a vulnerability on the other party to suffer the effects of the exercise of those privileges. ${ }^{150}$ In either case, the legitimacy of the claimed legal entitlement cannot be persuasively asserted unless an argument can be made that the "victim" of the right has a responsibility to respect the claim of the right-holder to freedom of action (privilege or liberty) or security (Hohfeldian "right"). This relational perspective is most prominently associated with feminist moral and legal theory and is usefully

${ }^{150}$ Wesley Hohfeld, Some Fundamental Legal Conceptions as Applied in Judicial Reasoning, 23 YALE L. J. 26 (1913); Joseph William Singer, The Legal Rights Debate in Analytical Jurisprudence from Bentham to Hohfeld, 1982 WIS. L. REV. 975, 986-987. 
elaborated by philosopher Margaret Urban Walker and political and legal theorist Jennifer Nedelsky. ${ }^{151}$

In State v. Shack, the farmer argued that the relationship between the parties involved a free contract containing mutually beneficial arrangements that was entered into under circumstances that involved no coercion or fraud. The workers are not tenants; they do not have leases or the exclusive control of particular parcels of land or individual apartments. They are living on the employer's property and legitimately subject to his rules. This is what parents say to children: if you are living in my house, you must follow my rules. Nor do the defendants have legitimate claims to enter the employer's property against his will. If I let someone sleep in the back bedroom in my house, I am entitled to determine whether they receive visitors or not and the relationship between the parties here is no different. Neither the workers nor the defendants have claims that override the employer/owner's interest in controlling access to his land. The employer-employee relationship is a freely negotiated one and the employees have agreed to enter the employer's land. The relationship thus has a dual character as a contractual relationship and a property relationship. The contractual relationship is the freely negotiated employment/housing agreement and the property relationship is the legitimate claim of the owner has to control of his own land. The employer/owner relationship with the defendants is a relation of owner to non-owner who seeks access to his land and because the owner has not opened his property to the general public (as would be the case, for example, with a public accommodation), the defendants cannot claim a legitimate entitlement to intrude on his privacy or his property.

The defendants would argue that the relationship between the parties is of an entirely different character. The employer has created a relationship between himself and his employees that goes beyond an employment contract; it also involves housing arrangements, and whether or not the employees have "leasehold" interests, they are living apart from the employer and can exercise rights to receive visitors without intruding on the employer's privacy or his ability to run his business profitably. The defendants also have claims on the employer/owner which give him the responsibility to let them onto his land. As the court states, the employer has

${ }^{151}$ WALKer, supra note 83. See also JOSEPH William Singer, ENTITLEMENT (2000); Jennifer Nedelsky, Law, Boundaries, and the Bounded Self, 30 RePRENTATIONs 162 (1990); Jennifer Nedelsky, Reconceiving Rights as Relationships, 1 REv. CONST. STUDIES/REVUE D'ÉTUdES Constitutionelles 1 (1993). See also Martha Minow, Making All the Difference: InClusion, ExClusion, ANd American LaW (1990); Elizabeth V. Spelman, Inessential Woman: Problems of Exclusion in Feminist Thought (1988). 
no right to isolate the workers or deny them "associations customary among our citizens" when the property use in question is distinguishable from the guest in the back bedroom. In effect, the property use is legitimately understood as more on the "public" than the "private" side of the ledger; this is not a case of an owner controlling who accesses his living quarters, but is similar to the landlord who refuses to let his tenants receive visitors. That is deemed an oppressive relationship because the landlord is acting like a feudal lord who claims the legitimate right to control the tenant's personal life in a manner that deprives the tenant of autonomy and companionship. ${ }^{152}$ The owner has a responsibility in the relationship to act in a manner consistent with the dignity of the workers and this necessitates relinquishing the right to exclude individuals who are providing needed services to his employees in a manner that does not interfere with his legitimate business interests when the owner has opened his property to individuals in living arrangements like those in this case. ${ }^{153}$

\section{$\$ 4.3$ Contextualization}

When values conflict in a particular case, we try to avoid (or solve) the conflict by reinterpreting the values so that they fit with each other in a manner that does not result in outright contradiction. We do this by asking how values fit the circumstances, thereby seeking to determine whether one asserted value is appropriate to the situation while the seemingly conflicting value is not similarly appropriate. This may result in a reinterpretation of the interests asserted by the parties that may lead to the conclusion that one of the asserted values is not actually implicated in the situation; alternatively, it may result in the view the conflicting values are both operative but that one value should be subordinated to the other in the context of the case. Three contextualization methods used by lawyers are (a) situation sense; (c) restrained interpretation of values; and (c) social and historical accommodation.

\section{$\$$ 4.3.1 Situation sense (distinguishing cases and making analogies)}

The first way lawyers contextualize is by focusing on the social setting within

${ }^{152}$ See KyMLICKA, supra note 19, at 104-127 (noting how initial property allocations can give owners power over non-owners).

153 See KymlicKA, supra note 19, at 90 (arguing that it is important to "ensure that the advantaged to not have the power to define relationships of dominance and servility in the workplace."). 
which the issue is being addressed. The social context in which the right is being asserted matters because we find claims legitimate in one area of social life to be illegitimate when made in a different context. For example, you are legally free to choose your friends on the basis of race if you wish (even if this may be morally problematic) but you are not legally free to choose your customers by race if you are operating a restaurant. Thus, the lawyer argues that we are not talking about freedom of contract generally, but a specific contract term in a specific social setting. We are not talking about property rights generally, but a specific property claim in a specific social relationship. Contextual elaboration of the normative meaning of principles is closely associated with the lawyerly technique of distinguishing cases. It also involves what Karl Llewellyn called situation sense - a Gestalt judgment about how to understand the morally relevant features of a situation. ${ }^{154}$

State $v$. Shack posed a conflict between the right to control your own land and the right to receive visitors in your own home. Doctrinally, it required a judgment about whether this case fit within a legitimate exception to the owner's ordinary right to exclude non-owners from the property. Could the presumption in favor of the "owner" be overcome? Alternatively, it involved a conflict of property rights; if the farm workers were similarly situated to tenants, then they are imbued with the power to receive visitors in their homes or to deny access to others. If the workers own something like a leasehold, then they have the right to exclude or admit and it is the landlord/farmer who would have to overcome that presumption.

To answer this value conflict, the Supreme Court of New Jersey started with three assumptions: first, that owners have the right to exclude nonowners but that there are exceptions to this principle; second, tenants have a right to receive visitors in their homes (either because this is one of the exceptions to the first principle or because tenants are themselves conceptualized as owners of the "leasehold" who have the power to exclude); and third, that visitors do not themselves have the power to enter property without the consent of the property owner and, once admitted, visitors do not themselves have the power to invite others inside. While tenants have the right to receive visitors, dinner guests do not have the right to bring others to the dinner table without consent. Nor do overnight guests in your home have the right to invite anyone they want into your hourse; in that case, you legitimately have much greater control over what they do in your house than you would if they rented a separate apartment from you.

154 Llewellyn, The Common Law Tradition, supra note 108, at 121-157. See also Todd Rakoff, The Implied Terms of Contracts: Of "Default Rules" and "Situation-Sense" in GooD Faith AND FAUlt in CONTRACT LaW (Jack Beatson \& Daniel Friedmann eds., (1995). 
The migrant farmworkers were housed in barracks and one of the issues was whether this social context was closer to that of the overnight guest (with no right to receive visitors) or to the tenant living in an apartment (with a right to receive visitors). Answering this question requires a judgment about how to understand the situation. If it is true that a guest in one's home does not have the right to invite in visitors while a tenant does have such a right, the question is whether this case is closer to the first situation or the second. Answering this question requires the use of analogy. This involves identifying factual similarities and differences and generating reasons to treat those facts as relevant from a moral and legal point of view. ${ }^{155}$ In turn, this requires consideration of whether the interests asserted by the parties are legitimate in this social context. The court found that the farmer had legitimate interests in managing his business and excluding meddlesome outsiders but that he did not have a legitimate interest in isolating his workers, denying them "associations customary among our citizens" or preventing them from receiving government-funded services in the privacy of their living quarters. If this is true, then in the context presented in this case, the workers had legitimate interests in receiving visitors and government benefits while the employer had no legitimate interest in excluding the doctor and lawyer from his land. What appeared to be a conflict of values was actually a false conflict.

The farmer, of course, asserted that his interests were legitimate in this context. He had not forced the workers to work for him or accept his terms; if they did not like the arrangement, they could go elsewhere to live and work. According to the farmer the situation here is simply a part of the free market working its magic; there is no basis for the court to substitute its judgment for that of the parties on what contractual arrangements are mutually beneficial. Nor does this contravene the rule that allows tenants to receive visitors. Workers living at their workplace in barracks are differently situated than tenants and the farmer's needs to control the operation of his business are stronger than those of a residential landlord; conversely, the workers' interests are correspondingly weaker when they have not been granted exclusive control over a segment of the property as occurs in the case of a leasehold because giving them the power to invite others onto the property could disrupt the business in ways that would not occur in the case of tenants receiving visitors in their apartments.

\section{\$4.3.2 Restrained interpretation of values}

155 There is a rich debate about the normative status and appropriate use of analogy. Scott Brewer, Exemplary Reasoning: Semantics, Pragmatics, and the Rational Force of Legal Argument y Analogy, 109 Harv. L. ReV. 923 (1996); Lloyd Weinreb, Legal REASON (2005). 
Situation sense is explicitly or implicitly tied to re-interpretation of the conflicting values at stake in the case. Lawyers reevaluate the legitimacy of the asserted interests or the cognizability of the claimed harms in the particular context at issue. This is an example of the more general method of restrained interpretation. ${ }^{156}$ When each party asserts the right to have or exercise a property right, each owner experiences the exercise of the rights of the other as imposition of an externality. However, if we engage in restrained interpretation of the rights associated with "ownership," we may convince ourselves that the bundle of rights associated with ownership never included the particular entitlement in question. If one never owned the right to begin with - if it never was part of the package of property rights an owner could legitimately claim - then a rule limiting the right will not be experienced as the imposition of an externality. In that case, one person is exercising her property rights and the other (the victim of the externality) has no legitimate claim. If we see the case this way, we may convince ourselves that exercise of the entitlement can be legitimately viewed as self-regarding in nature.

For example, the farmer may concede that tenants have the right to receive visitors in their homes but argue that they also have the right to waive

156 This concept comes from conflict of laws. Brainerd Currie, the inventor of interest analysis, argued that conflicts of law between two different states could be resolved by determining whether both states had a legitimate interest in applying their law to the case at hand. If they did, he suggested taking a second look at the state interests to see if it is possible to engage in a restrained interpretation of state interests to conclude that one of the state has no real interest in applying its law to the parties or the transaction or occurrence, either because the parties relationship is centered in another state or because the state has an affirmative interest in comity by allowing another state to regulate the events or relationships in the case. Brainerd Currie, The Disinterested Third State, 38 L. \& Contemp. Probs. 754, 757 (1963); see William M. Richman \& William L. ReYnolds, Undestanding Conflict of LAWs $\$ 79[a]$, at 247 (3d ed. 2002). See also ANDERSON, VALUe In ETHICS AND ECONOMICS, supra note - at 62-63 ("The application of intuitive principles requires an interpretation of their underlying expressive point in light of the relations the agent has to the people for whose sake she acts. If different principles appear to generate conflicting recommendations, the task for a rational agent is not to weight and aggregate their consequences, but to seek more refined interpretations of their demands so that all of them can be satisfied. This is the traditional task of casuistry, reasoning by analogy, and the other commonsense modes of practical reasoning familiar to ordinary life."); RICHARDSON, supra note - at 127 ("The alternative...is to find some way to restrict the scope of application of these [conflicting] principles so that they are kept out of each other's way"); id. at 170 (arguing that specifying the meaning of a norm requires careful attention to its appropriate range of application, resulting in modification of the original norm so that it coheres with other norms). 
that entitlement in exchange for compensation or employment or lower rent from the landlord/employer. Alternatively, the farmer may argue that the value of free association is not appropriate for employees at work; business cannot operate if employees are free to invite others onto the premises. Although the workers are housed in barracks, their work/home boundary is less clear than in the usual case and their rights of free association correspondingly legitimately limited in this context. More on point, however, the farmer would argue that the defendants have no right of access to private property against the will of the owner. In this case, the workers are relevantly distinguishable from tenants and the owner who has the right to exclude or admit is the farmer, not his employees. He therefore has legitimate interests in controlling access to his land, and they are making claims that illegitimately interfere with his liberty and property rights.

Conversely, the workers will argue that when they are not working, they are similarly situated to tenants and their rights of free association are relevant and important. Moreover, while the farmer has an acknowledge right to run his business, that right can be fully protected without denying the workers the right to receive visitors. As the Court explained, the owner has "no legitimate interest" in preventing his employees from receiving visitors in their living quarters or enjoying "associations customary among our citizens." Either way, the normative technique is to narrow the scope of application of the value in question so that it does not conflict with the legitimate interests asserted by the other side.

\section{$\$$ 4.3.3 Social and historical accommodation}

A third form of contextualization is to fit the case into current social practice, historical tradition, and emerging values and principles. The development of the common law represents a series of compromises between fit and justice. ${ }^{157}$ The rules must be made to fit with each other in a coherent way if possible; they must also be made to fit both our considered judgments and our settled social values and current social conditions. At the same time, our normative claims may give us reason to criticize existing practices or conclude that certain rules of law are inconsistent with other rules of law, emerging or settled notions of justice, or competing values that are appropriately relevant in this context.

The farmer may argue that we have moved from a customary regime

157 Ronald DWORKIN, LAW's EMPIRE 239 (1986) (“The judge's decision-his postinterpretive conclusions-must be drawn from an interpretation that both fits and justifies what has gone before, so far as that is possible."). 
based on status and tradition to a dynamic market economy that rests on free contract and individual autonomy. Promoting the "free market" will both promote social wealth and individual freedom while keeping the state away from unjust interferences with autonomy and self-government. Opportunities abound for individuals and the operation of the free market will discipline employers who are harsh in their treatment of their workers.

The doctor and lawyer (and the court) argued instead that we have moved from historical customs of feudalism and plantation slavery, as well as unequal status of persons, to a free and democratic society that treats each person with equal concern and respect. This means that there are certain minimum standards for market relationships which must be respected in order to comply with the appropriate legal framework for a free and democratic society. Isolating workers from visitors, insisting that the farmeremployer observe discussions between his workers and their lawyers and the medical care granted them, is inconsistent with the form of social life we have developed that is based on human dignity and equality. The farmer's claimed interests are not legitimate, at least in the context of this case.

\section{\$ 4.4 Prioritization}

If we cannot reconcile conflicting values in a particular case by careful designation of the scope of the values through contextualizing techniques, we must then seek some kind of impartial procedure or standpoint from which we can evaluate which of the conflicting normative claims should be vindicated, given their relevance in the context of the case. In a free and democratic society, we begin with the assumption that individuals, in general, are entitled to choose their own path, their own sense of the good life, and their own values. But of course, individuals do not live alone; we are engaged in normative argument because of conflicts among human interests and because we cannot avoid choosing an applicable law to govern the relationship between the parties. Autonomy must be conceptualized in a manner that is consistent with coexistence with others; this means that limits on freedom of action are essential for responsible human relationships. Further, because legitimate government is based on treating each person with dignity (equal concern and respect), and thus on the consent of the governed, we must justify public policy and law by reasons that could or should be accepted by every person subject to those laws. The three most important normative methods used by lawyers to analyze persistent conflicting legitimate interests are balancing interests, contractualism (golden rule or role reversibility), and reflective equilibrium (coherence). 


\section{$\$$ 4.4.1 Balancing interests}

One primary prioritization method is the legal realist technique of balancing interests. This method is as useful to discussions of fairness and justice as it is to economic analysis. But normative argument based on notions of justice and fairness starts from the assumption that not all preferences are entitled to respect by the legal system, that not all interests can be weighted equally or counted as relevant in determinations of what the law should be and that there are qualitative differences among interests that make it impossible to reduce them to a common metric without distortion. ${ }^{158}$ These normative balancing discussions identify human interests, determine when they are legitimate, and then seek to weigh (or assess) their relative strength, importance, or relevance in particular social and legal contexts. Normative analysis that focuses on concerns of fairness, justice, and morality generally eschews converting interests to a common metric (like dollars); comparisons of interests can be made even if the values on both sides are incommensurable (not reducible to a "common currency"). When we do this, we may talk about the "strength" or "weight" of the interests in context; we may also talk about which interest should "give way" or which party is obligated to defer to the interests of the other given the interests and values we have identified. We may say that certain interests are not "appropriate" or "relevant" in a particular context when the competing interests are of a certain character or kind; in such cases, one interest may "outweigh" the other. We may talk in terms of the "needs" of the parties, or again consider whether the "needs" are "legitimate" given the impact their assertion will have on others with competing needs, interests, wants, or claims.

For example, while the farm owner in State $v$. Shack may have privacy interests, it is not clear that those interests should be recognized as strong or even relevant when the question is whether he is entitled to deny those same interests to workers housed on his land. Similarly, the farmer-employer may have associational interests in choosing whom to allow onto his land but it is

${ }^{158}$ See ANDERSON, VALUe In ETHICS AND ECONOMICS, supra note 3 (describing the importance of different ways of valuing different human interests); KYMLICKA, supra note 19, at 144 (arguing that "when we think about the value of different liberties in relation to peo0ple's interests, we see that some liberties are more important than others, and indeed some liberties are without value entirely..."); April Flakne, Through Thick and Thin: Validity and Reflective Judgment 20 HYPATIA 115, 115-116 (2005) ("any attempt to apply an ethical term with an intuitive context within an existing vocabulary to a new or different context itself involves an act of judgment"). 
not clear that those interests are relevant (whether he is entitled to assert those interests) when he has opened his property to others and their own associational interests are at stake.

The New Jersey Supreme Court found it "unthinkable" that the farmerowner could "assert a right to isolate" the workers or "deny the worker his privacy or interfere with his opportunity to live with dignity and to enjoy associations customary among our citizens." This language assesses the farmer's interests and characterizes them in a manner that denies their relevance, legitimacy or strength in this social context. In a sense, this is an argument that the owner's interests do not count at all in the balance. The workers have strong interests in receiving visitors and government services and living in dignity and the farmer-employer has "no legitimate need" to deny them these rights. This makes the "balance" one that is assessed, not by market measures or strength of preference, but by appropriateness to the situation. Alternatively, the court could have found the owner's interests in freedom of contract, control of his business and property, to be legitimate ones but overridden by the interests of the workers.

The farmer could counter these arguments by suggesting that alternative means exist to protect the workers' legitimate interests and that the court was wrong to assume that his assertion of control over his own land in any way prevented the workers from obtaining legal and medical services. Or he could argue that the workers voluntarily waived these rights by entering their contract with him and that the right to earn a living by obtaining a job outweighs any interests regulating the terms of the employment contract. Part of this kind of argument may also rely on consequentialist concerns of the sort that suggest that regulation of the agreement may wind up hurting the very people it was intended to protect by decreasing their wages or limiting job opportunities. These adverse consequences of regulation could overwhelm any benefits sought to be derived by imposing minimum standards on the contractual relationship, thereby reversing the balance of interests.

\section{\$4.4.2 Contractualism (golden rule or role reversibility)}

How do we choose between two competing accounts of how to balance the conflicting interests in the case? If both seem plausible and equally convincing, we may turn to another prioritization method which rests on the idea of the social contract which itself is a derivation of the Golden Rule. We begin with the observation that treating other people with dignity requires us

to try to see the world from their point of view as well as our own; we should 
consider how we would want to be treated if we were in their shoes. Christine Korsgaard and Tim Scanlon have both argued that morality is based on the idea that we must justify our actions by reasons that others could accept (or that they could not reasonably reject). ${ }^{159}$ Rawls extends this insight to liberal political theory by assuming that we live in a society with persistent diversity on the meaning of the good life. If we respect each person's dignity, we must consider what choices reasonable persons would make about the basic structure of society if they could not be sure that they would be the ones in charge of the government. ${ }^{160}$ What rules of the game would we favor if we did not know in advance what role we would play in society? What things do we hope to take for granted? What moral norms governing social interaction could be accepted by others and defended by those of us who want to impose them on others? ${ }^{161}$ The method of reversing roles, of defending an outcome to the losing side, of recognizing the costs as well as the benefits of any rule, is a staple of normative argument used by lawyers.

The farmer may ask whether you would like it if the government told you that you must open your property to strangers or told you how to manage your own business. The opposing side asks what the contract would have said if the contracting parties did not know on which side of the bargaining table they would be sitting. This Rawlsian question suggests that the farmer himself would not want to be deprived of the right to receive visitors as well as needed legal services and medical care if he were in the position of his workers. Different interpretations of these arguments are possible. John Rawls suggested we consider what rules would be adopted by persons who did not know which social roles they would be occupying. These rules could be justified to anyone, including those who appear to be the losers in the situation. Robert Nozick and Charles Fried suggest maximizing the scope of individual freedom, interpreted in a libertarian manner; Jedediah Purdy (and my own work) suggest a very different conception of what freedom entails. ${ }^{162}$

Fundamentally, the object of a judicial opinion is to recite reasons for the result that could justify the result to the losing party. The idea is that anyone who thought about the matter clearly, with appropriate information and motivation, could accept this outcome as the most just way to resolve an

\footnotetext{
${ }^{159}$ KORSGAARD, supra note 62; SCANLON, supra note 62.

${ }^{160}$ RAWLS, JUSTICE AS FAIRNESS, supra note 11.

${ }^{161}$ See Samuel Freeman, Moral Contractarianism as a Foundation for Interpersonal Morality, in CONTEMPORARy Debates IN MORAL THeORY, supra note 59, at 57-76.

${ }^{162}$ Jedidiah Purdy, A Freedom-Promoting Approach to Property: A Renewed Tradition for New Debates, 72 U. CHI. L. REv. 1237 (2005); Singer, After the Flood, supra note 135; Joseph William Singer, Things that We Would Like to Take for Granted, supra note 54.
} 
intractable conflict involving competing values.

\section{\$4.4.3 Reflective equilibrium (coherence)}

The most quintessentially lawyerly prioritization method is a version of Rawls's method of reflective equilibrium. ${ }^{163}$ In some ways, this is the most prototypically "legal" way of analyzing normative questions. We reason from general principles down to specific cases, but we also use the system of precedent to establish fixed points that are at least temporarily if not permanently closed to revision. In moral theory, we do the same thing by starting with strong intuitions about how certain moral quandaries should be resolved and we relate those fixed cases to our general principles. When we consider a hard case, we reason back and forth between the cases and the principles with the goal of developing a coherent story of how they all fit together. ${ }^{164}$ This cannot be done by applying an algorithm or a disembodied decision procedure. Nor does it result in anything like an equilibrium. Indeed, we lawyers were experts at deconstruction before deconstruction was invented. We know how to challenge claims, to unsettle certainties, to find the incoherencies lurking behind coherent stories. Yet at some point, the judge writing the opinion or the lawyer writing the brief or making the oral argument is satisfied that she has created a story that fits available normative and legal resources together in a manner that does the best job possible, given the context in which we are acting. The lack of a determinate, noncontroversial decision procedure is beside the point; when multiple normative arguments are relevant, competing and contested institutional roles are present, and values are conflicting but powerful, we simply have to do the best we can.

Reflective equilibrium does not operate wholly deductively or inductively and it does not follow a decision procedure. Nor does it resolve all value conflicts by an algorithmic metatheory. Analysis can begin from the top down by applying principles to particular cases. Or it can begin from the bottom up by characterizing the legal rules as applied in the past. The system of precedent allows lawyers to tentatively identify a few fixed points. We know in this situation, the plaintiff wins for these reasons and that in this different situation, the defendant wins for these other reasons. The case we are addressing is hard because it arguably fits within both categories. We use

${ }^{163}$ RAWLS, JUSTICE AS FAIRNESS, supra note 11, at 26-29. See also RICHARDSON, supra note 5, at 178 (discussing Rawls's method of reflective equilirium.

164 KYMLICKA, supra note 19, at 67 (describing reflective equilibrium as "work[ing] from both ends"). 
a combination of argument from analogy and policy arguments to help divide up the cases that are appropriately governed by one rule or another. We may wind up overruling a case, or narrowing its scope of application; alternatively, we may broaden its holding to this new situation. We use factual similarities among cases but combine those factual discussions with attention to principle and policy that can legitimately distinguish the cases where a rule applies and where it does not apply. The result may not be a set of principles that can be applied deductively; this is because attention to social context, and historical settlement of issues, as well as considerations of judicial role, all matter enormously.

This method of reflective equilibrium also illustrates all the elements of working within a tradition (as Alasdair MacIntyre expresses it) ${ }^{\mathbf{1 6 5}}$ and undertaking a craft that involves expertise (as Karl Llewellyn expresses it). ${ }^{\mathbf{1 6 6}}$ It also is shaped by practical reason rather than deductive logic and requires the exercise of considered judgment. ${ }^{167}$

In State v. Shack, the court determined that it was not important to decide whether the migrant farm workers were or were not in the status of "tenants." Either way, their situation was close enough to that of tenants (living apart from the owner but on the owner's land) that the same values which lead us to protect the right of tenants to receive visitors applied here to the farmworkers. This resolution protected the farmer's legitimate interests while simultaneously protecting the workers' legitimate interests and fit the situation into established normative patterns and moral relationships. The farmer had argued in contrast that the workers were not similarly situated to tenants and that the owner had legitimate interests in controlling access to his land, which was used for business purposes and not merely housing, that did not exist in the situation of the ordinary residential tenant. He could have argued that tenants should be entitled to give up the right to receive visitors in return for lower rent or other favorable concessions by the landlord and that the same reasons for expanding the realm of free contract would apply in this case. He might have argued that the poorest persons are even more in need of free contract than richer persons because their choices are more limited to begin with. ${ }^{168}$ These normative arguments could be tied to cases that preserve the employer's power to manage his business by controlling the

\footnotetext{
165 Alasdair Macintyre, Three Rival Versions of Moral Enquiry: Encyclopaedia, Genealogy and Tradition (1990).

${ }^{166}$ LLEWELlyn, COMMON LAW TRADiTION, supra note 108, at 213-235.

167 See RICHARDSON, supra note 5, at 4, passim (discussing the nature of "practical deliberation").

${ }^{168}$ Schwartz, supra note 146.
} 
conduct of his workers while analogizing the workers to live-in housekeepers who give up some of their freedom to live in the employer's home.

In the end, the case was decided in the favor of the workers because, all things considered, the court found the story presented by the defendants to be a more compelling story. It better matched the court's judgment about the appropriate balance of interests by identifying the employer's asserted interests as illegitimate in the situation at hand and the workers' interests as both legitimate and consistent with the contours of a private property regime in a free and democratic society.

\section{$\S 5.0$ RESPONSIBILITY AND HUMAN JUDGMENT}

[I]t seems clear to me that many of the systems of rules we follow are in fact inconsistent, and beyond this, it seems inevitable that, in some cases at least, we have no course other than to learn how to live with this inconsistency. ${ }^{169}$

Robert Fogelin

Some contradictions are manifestly better to live with than others... ${ }^{170}$

Elizabeth Anderson

The notion of responding to a responsibility confronts us with a paradox. It clearly involves an element of choice and a complete absence of choice. Responding to a responsibility to which one is called upon to respond is not the act of a subject. But neither is it simply a matter of being "subject to" a responsibility. To be responsible is a mode of existence that cannot be reduced to either the passive or the active voice. ${ }^{171}$

Johan van der Walt

At the end of the day, normative arguments come from us and we cannot expect a human invention to save us from ourselves. "Where could I go," Saint Augustine lamented, "yet leave myself behind?" 172 But it is also true that

\footnotetext{
${ }^{169}$ FogELIN, supra note 1, at 45.

${ }^{170}$ ANDERSON, VALUe IN ETHICS AND ECONOMICS, supra note 3, at 136.

171 Johan W. G. VAN der Walt, The Twilight of Legal Subjectivity: Towards a Deconstructive Republican Theory of Law 431 (Doctor of Laws Thesis, Rand Afrikaans University, 1995)(on file at Langdell Library, Harvard Law School).

172 St. Augustine, Confessions 78 (R. Pine-Coffin trans. 1961). See Leff, supra note 58 at 1249 ("All I can say is this: it looks as if we are all we have.").
} 
if anyone is going to save us, it is going to be ourselves. We create our normative world but we also live by it. We are free in one sense to live as we please, to create the kind of society we want to create; at the same time, our need to live with others - to cooperate with them - requires us to give reasons for the claims we make on others, to justify ourselves by defending the world we seek to create in ways that others could also find attractive. We seek to satisfy our desires but we also subject those desires to critical thought, both learning and teaching ourselves about the desires we should suppress or fail to satisfy in order to live with others in a free and democratic society. We distinguish between base and higher desires; we limit our initial instincts by creating a moral space, a normative world. We see the conflicts among our own values and seek to articulate them in the context of creating and imposing law. We also criticize our own normative constructions and listen to critiques posed by others that we had not thought of; this is not a process that can come to a definitive end. As Charles Taylor explains, "Because our language gives expression to qualitative distinctions, by which we have a sense of higher goals, and hence have an emotional experience with strong evaluation, we open an issue which can never be definitively closed." ${ }^{173}$ At the same time, despite our disagreements with each other, our internal conflicts among competing values we cherish, and our lack of a definitive decision procedure, "there is a lot we can still say to each other." ${ }^{174}$

We are the creators of our world (and our legal system) but we are also eternally in the position of Cain, hearing the question, "What have you done?" and feeling compelled to have an answer - an answer that would be acceptable to those to whom we are accountable. Some may believe this is God but in the political/legal realm our audience is other people, as well as ourselves. In the end, we are the ones to whom we must account; this means we must be true to ourselves (including the depth and complexity of our values) and we must be true to other people to whom we bear responsibility. We hope that our reasons we give for our moral and legal choices are good ones and that they promote justice. Yet we must always be on the lookout for the danger of legitimation; it is pathetically easy to act on the basis of selfinterest and exercise illegitimate power over others while justifying it to

\footnotetext{
173 TAYlOR, Human AgENCY AND LANGUAGE, supra note 44, at 57.

${ }^{174}$ Id. at 121 . See Flakne, supra note 158 at 116 ("My goal is to show that application of thick ethical concepts is best understood as a process of reflective rather than deductive judgment; that this reflective process means that thick ethical concepts facilitate rather than halt ethical understanding and transformation; and that such reflective processes, though interpretive, produce their own kind of validity without recourse to thin, purportedly neutral, universal or context-independent ethical terms.").
} 
ourselves as the height of virtue. Oppression can be committed with impunity when the perpetrators are convinced that justice is on their side. It is horribly tempting to dismiss a claim of injustice by calling an argument "unsound," retreating to the idea that it is incompatible with other settled practices, and then refusing to answer the claim by reasons that speak to the claim being made, either explaining why those practices are justified or why this case is different from them. It is also pathetically easy to forget to see the case from someone else's point of view; it is even easier to think one knows what their point of view is, even if they are not available (or sufficiently empowered) to explain it to you.

We must therefore develop justificatory strategies that keep competing claims in mind, that prompt us to investigate how people actually experience moral claims and human relationships, and remember to remain open to the possibility that we may find out that we were wrong. We must seek reasons that could be persuasive to people who have very different comprehensive conceptions of the good; yet we must also be aware that this sort of impartiality does not and cannot be completely divorced from controversial judgments and that some forms of the good will be suppressed no matter how neutral we try to be. ${ }^{175}$ Indeed, if our goal is to create a free and democratic society, we must acknowledge that we begin with certain fundamental normative commitments - things we used to call "inalienable rights" or "government of the people, by the people, and for the people."

We are inhabitants of some form of what has been called the "postmodern condition." 176 But this experience is not so new as one might suppose. One of the most famous Jewish jokes of all time (so well-known that it appears in an early scene in Fiddler on the Roof) involves two disputants who approach the rabbi to ask him to resolve their conflict. The first one speaks, gives his arguments, and the rabbi is convinced. "You're right," the rabbi says. Then the second man speaks, makes opposite arguments, and is equally convincing. "You're right, too." the rabbi says. The rabbi's wife, having heard all this, says to the rabbi, "You said he was right and now you say this one is right. But they contradict each other; they can't both be right." The rabbi responds, "You know, "You're right too!"

175 See RICHARDSON, supra note 5, at 298 (arguing that "the mere multiplicity of incommensurable conceptions does not mean that Dionysian revelry is all that one is left with: A more objective approach, extending to collective rationality if not indeed to objective truth, is possible.").

${ }^{176}$ Jean-Francois Lyotard, The Postmodern Condition: A Report on Knowledge (1984). For an argument that postmodern insights are not incompatible with ethics, see BAUMAN, supra note 18. 
It always hurts to analyze a joke, but this one is too close to the argument I want to make to let it go. What is the moral of the joke? One reading is that it is typical self-deprecating Jewish humor that is making fun of the rabbi, who is supposed to be learned and know the answer to all questions but clearly has no clue how to solve a hard problem. Does the rabbi have the answer or not? We tend to assume the law gives an answer and the rabbi is the expert in the law and since the law comes from God, we should be able to find out an answer either from the Torah itself, or the commentary of the rabbis elaborating on the meaning of the given rules. But the rabbi seems stumped; he sees the arguments on both sides and has no way to choose between them. There must be an answer; they can't both be right, but the rabbi has no way to find this answer. This either means he's not a very good rabbi (that's the self-deprecatory message - that he is not learned enough to see who is right) or it means that we were wrong to expect the rabbi to know better than the rest of us how to come up with a just answer for a hard case. Maybe there are no experts better than ourselves, or no answers out there to help us in cases of genuine doubt.

But another, more provocative reading of the joke is that the wife is wrong when she says: "they can't both be right." Perhaps the human condition requires us often to confront the simultaneous truth of two seemingly contradictory insights. ${ }^{177} \mathrm{We}$ are often faced with hard cases that have no easy resolution. When this happens, we often have well-developed, strongly supported normative arguments on both sides; we may feel torn between competing goods or values or unsure how to balance competing legitimate interests. We may not know where to draw the line between incommensurable goods or we may not know how to divide social life into appropriate spheres for the exercise of different, competing entitlements. There is no easy answer and we have no ready way to choose between them. That is why the rabbi tells both men that they are right. This is not a mistake; the rabbi is not a bad rabbi, but a learned one who recognizes that the truth of the matter - the truth of our normative world - is that both are right even though they contradict each other. We have competing values and we are unsure how to draw the line.

But in one sense, the rabbi's wife must be right: when the case calls for a resolution, we must act. The law is not a theoretical system but a practical enterprise, requiring an answer. It is not a debating society which can continue talking forever. We have a case and one of the parties must win and

177 On this point see Martha Nussbaum, The Fragility of Goodness: LuCK AND ETHICS IN Greek Tragedy and Philosophy (1986). 
the other lose right now, or some compromise must be reached. A rabbi who says they are both right is not doing his (or her) job if he or she is sitting as a rabbinical court empowered to decide the case. A law review author can take this position and say "it's very hard," and refuse to give a clear answer. But a judge cannot do this. Moreover, the rabbi's wife insists that the resolution must be "right"; it must be a just resolution and it must be accomplished even though both of the disputants are right and no voice from heaven will save the decision maker from the need to decide the case. A choice must be made and reasons must be given - even though we know and accept the reasons on the other side and even though those reasons are ones we cannot repudiate. The Talmud deals with this problem by religiously (pun intended) preserving minority opinions and by sometimes not even stating which opinion prevailed in the rabbinic courts.

"You're right, too" means that we have a duty to do the right thing even when we have no simple answer as to what this means and even though there are arguments on both sides that we accept, care about, and believe. Decision makers need to act and need to give reasons, but they need also to acknowledge counter-arguments and competing reasons. They need to recognize the injustice they commit as they go about the job of doing justice. ${ }^{178}$ The absence of a metatheory that generates a determinate decision procedure to solve such cases does not mean that there is nothing to think through and nothing to say. Indeed, it is precisely in such cases where speech matters the most. The rabbi's wife insists on a resolution, not an endless debate, and she insists that morality is possible even in the face of strong, competing moral claims which are not easily resolved. She insists on the persistence of justice in the absence of a noncontradictory metatheory that resolves competing arguments. She insists on creating a normative world where justifications matter even if they are not decisive. She insists that reasons must be given for the choices we make. ${ }^{179}$

Normative methods provide a foundation for law not because they provide answers to hard cases but because they help structure appropriate conversation by law makers about what really matters. They force lawmakers to speak to law-takers. Charles Taylor explains:

All structures need to be limited, if not suspended. Yet we can't do without structure altogether. We need to tack back and forth between codes and

\footnotetext{
178 See generally JOHAN VAN DER WALt, LAW AND SACRIFICE: TOWARDS A POST-Apartheid THEORY OF LAW (2006).

${ }^{179}$ See RICHARDSON, supra note 5, at 302 ("it is important to be able to legitimate social actions and institutions by justifying them on the basis of principles that all can accept").
} 
their limitation, seeking the better society, without ever falling into the illusion that we might leap out of this tension of opposites into pure antistructure, which could reign alone, a purified non-code, forever. ${ }^{\mathbf{1 8 0}}$

Normative methods structure human judgment but they also are constructed by human beings, who are fallible, who have a partial perspective on the world, who easily misunderstand, but who (hopefully) are also eager to do the right thing. Our best practices combine plural considerations and multiple methods; in particular, they combine impartial procedures with fundamental values, narrative elaboration, and situational contextualization. Our best practices in making normative arguments to resolve hard cases make assertions that express evaluative judgments about why certain values outweigh other values in particular contexts in light of the appropriate way to understand the meaning of the situation, the events that led up to it, the relations among the parties, and the contours of our way of life. The goal is to show respect for all persons affected by the dispute. Although there may not be a unique, mechanically derivable "right answer," the decision maker is still obligated to come up with her best formulation of the right answer. ${ }^{181}$ At some point, the decision maker actually has to decide, and then has to justify the decision by the best reasons the decision maker can offer which show respect to the loser and which affirm the attempt to treat the loser with equal concern and respect. ${ }^{182}$

${ }^{180}$ Charles Taylor, A SeCular Age 54 (2007).

181 See TAYlor, Philosophy AND the Human SCIEnCES, supra note 10, at 53 (explaining that reasoning may be "unformalizable" but nonetheless productive of "insight"); TIMMONS, MORAL THEORY, supra note 20, at 96-97 ("in cases of conflict we simply must appeal to the details of the case at hand and use good moral judgment to decide which rule, in that particular case, should be followed... The key idea here is that in cases of conflict, there is no supreme moral principle or superrule that determines what we are to do; rather, in such cases, moral judgment must take over.').

182 See RAWLS, Justice AS FAIRNESS, supra note 11, at 31 ("The most reasonable political conception for us is the one that best fits all our considered convictions on reflection and organizes them into a coherent view. At any given time, we cannot do better than that."); RICHARDSON, supra note 5, at 189 ("Since [my view] puts forward no further standards by which the agent is to determine what is acceptable upon reflection, there is necessarily a nondiscursive layer to this view. Practical justification will not turn out to be discursive 'all the way down.' Since the justificational view is holistic and bidirectional, however, it is always open to the agent to keep pursuing the question why, if doing so proves fruitful. The existence of this ineliminable element of intuition in the account of justification does not imply that it traces justification back to self-certifying intuitions... Instead, the rational support... that derives from providing an improvement in mutual support among the norms found 
All this seems very humanistic rather than logical, artistic rather than deductive, pragmatic rather than systematic. But, we should not lament the absence of a mechanical decision procedure for justice; such a procedure was never available to us in the first place, and if it were, we would not be the human beings we are or seek to be. The construction of a just world is a human task. ${ }^{183}$ It is a job for grown-ups, not computers. It is not a task that can be completed, but it is also a not a task we can avoid. And it helps to remind ourselves that we have some notion of how to do this.

Normative method is meaningless without some substantive vision both of human beings and the just society. At base, the fundamental premise of all normative method is humanity ${ }^{184}$ Human dignity is where we start and defensible human relationships are our goal. What kind of society best embodies "our" most fundamental values - the ones we can defend to each other, despite our differences about the nature of both justice and the good? Although our goal can be phrased in different ways, a good candidate is the creation of a free and democratic society that treats each person with equal concern and respect. At least, I have so argued. ${ }^{185}$ Through all the negotiations, procedures, briefs, arguments, trials, rulings, decisions, appeals,

acceptable upon reflection may always be viewed as rebuttable by further considerations."); TAYlor, Human AgENCY and Language, supra note 44, at 62 ("Now our direct, intuitive experience of import is through feeling. And thus feeling is our mode of access to this entire domain of subject-referring imports, of what matters to us qua subjects, or of what it is to be human. We may come to feel the force of some imports through having explained to us their relations to others, but these we must experience directly, through feeling. The chain of explanations must be anchored somewhere in our intuitive grasp of what is at stake.").

${ }^{183}$ See RICHARDSON, supra note 5, at 182 ("All arguments must come to an end somewhere, Wittgenstein remarked. One way to put my present point, however, is that on the model I propose there is never any one particular place at which deliberative argument - or discursive practical reasoning - must come to an end. It is the sovereign deliberator who declares closure, as it were, not some ultimate principle."). See also David Cole, "How to Skip the Constitution" - An Exchange, N.Y. Rev. of Books, Jan. 11, 2007, at 63 (letter to the editor)(" It is true that text, precedent, tradition, and reason do not determine results in some mechanistic way. That is why we ask judges, not machines, to decide constitutional cases. But these sources are nonetheless critically important constraints on and guides to constitutional decision making. They are what identify those principles that have been deemed fundamental - and therefore constitutional - over our collective history. That there are differences over principle in no way excludes the need for reasoned argument about them.").

184 TaYlor, Human Agency And LANGUAge, supra note 44, at 60 (discussing the "reflexive sense of what matters to us as subjects, as being distinctively human [or] a sense of what it is to be human"); Singer, After the Flood, supra note 135, at 338-343.

${ }^{185}$ Singer, Things that We Would Like to Take for Granted, supra note 54. 
and scholarship, it behooves us to keep this goal in mind. 